Florida International University FIU Digital Commons

\title{
Health changes in Hispanic older adults in a Spanish arthritis self management education program
}

Helen Z. Cornely

Florida International University

DOI: $10.25148 /$ etd.FI14061517

Follow this and additional works at: https://digitalcommons.fiu.edu/etd

Part of the Education Commons

\section{Recommended Citation}

Cornely, Helen Z., "Health changes in Hispanic older adults in a Spanish arthritis self management education program" (2003). FIU Electronic Theses and Dissertations. 2640.

https://digitalcommons.fiu.edu/etd/2640 
FLORIDA INTERNATIONAL UNIVERSITY

Miami, Florida

HEALTH CHANGES IN HISPANIC OLDER ADULTS IN A SPANISH ARTHRITIS SELF MANAGEMENT EDUCATION PROGRAM

A dissertation submitted in partial fulfillment of the

requirements for the degree of

DOCTOR OF EDUCATION

in

ADULT EDUCATION AND HUMAN RESOURCE DEVELOPMENT

by

Helen Z. Cornely

2003 
To: Dean Linda Blanton

College of Arts and Sciences

This dissertation, written by Helen Z. Cornely, and entitled Health Changes in Hispanic Older Adults in a Spanish Arthritis Self Management Education Program, having been approved in respect to style and intellectual content, is referred to you for judgment.

We have read this dissertation and recommend that it be approved.

Barry Greenberg

Awilda R. Haskins

Douglas H. Smith, Major Professor

Date of Defense: November 25, 2003

The dissertation of Helen Z. Cornely is approved.

Dean Linda Blanton College of Arts and Sciences

Dean Douglas Wartzok University Graduate School

Florida International University, 2003 
(c) Copyright 2003 by Helen Z. Cornely All rights reserved. 


\section{DEDICATION}

I dedicate this dissertation to my parents who instilled in me the unquestionable value of education and to my Dad who's quiet questions about how it was going were motivation to continue.

I dedicate this dissertation to my kids as a challenge for them and proof that commitment to achievement and learning is life long.

Lastly, I dedicate this dissertation to my husband, who is my balance, total life support, and my dream maker. Without his encouragement, help, and patience, this dissertation would never have been completed. Thank you for once again helping to make my life dreams come true.

My family is truly the "soul" author for this work and I thank them all. 


\section{ACKNOWLEDGMENTS}

I wish to thank the South Florida Arthritis Foundation for having the courage to evaluate and review their education programs and entrusting me with the challenge of the analysis. I want to specifically thank Teresita Gonzalez, for her help in data collection and implementation of the Spanish Arthritis Self Management Education Program.

I wish to thank Florida International University Physical Therapy graduate students, Miguel Garcia, Jorge Gonzalez, and Gabriel Fidalgo for their assistance in the year post data collection. Their enthusiasm for the research process was an inspiration and reminder of the excitement of research endeavors.

I wish to thank Dr. Barry Greenberg for his collegial support, total trust, and input throughout my doctoral education and dissertation process. He was always an encouraging and positive force.

I wish to thank Dr. Awilda Haskins, mentor extraordinaire, who has guided me not only through this doctoral dissertation but through my entire academic and professional career. Her belief in my abilities to succeed was far greater than my own. She has been the driving force of my professional success and the depth of my gratitude is enormous.

I wish to thank my major professor, Dr. Douglas Smith. It was Dr. Smith who introduced me to the field of adult education, a field I have come to embrace with passion and enthusiasm. His adept guidance, endless patience, cheerful humor, superb editing, and consistent support have helped me stay the course of this dissertation journey and to perform with distinction. Thank you. 


\title{
ABSTRACT OF THE DISSERTATION
}

\section{HEALTH CHANGES IN HISPANIC OLDER ADULTS IN A SPANISH \\ ARTHRITIS SELF MANAGEMENT EDUCATION PROGRAM}

by

\author{
Helen Z. Cornely
}

Florida International University, 2003

Miami, Florida

\section{Professor Douglas H. Smith, Major Professor}

Arthritis is the most common chronic condition affecting older people and is a major cause of limited activity. Arthritis education programs in English have demonstrated a positive impact on health but these programs have not reached the Hispanic communities where arthritis is the leading cause of disability. Minorities, such as Hispanics, have traditionally been reluctant to pursue self-help programs, and have been identified as an under-served population in terms of medical care. This study examined the effectiveness of one community health adult education program targeting Hispanic older adults with arthritis, the Spanish Arthritis Self Management Education Program (SASMEP), by evaluating changes in the participants' general health, pain, disability, self-efficacy, health perceptions, frequency of physician visits, and exercise. A pre and post control group experimental design and analyses of covariance were used to determine the pre and post differences in health status and health behaviors for a group participating in the SASMEP and a group who did not using gender and age as covariates. A repeated measures design was also used, and repeated measures analyses of variance and post hoc tests were done on health status and health 
behavior data collected pre, post and one-year post education to determine long-term differences.

Results indicated the participants' health status significantly improved in general health, significantly decreased in pain, and significantly decreased in arthritic disability immediately following the education. Self-efficacy and health perceptions increased for both groups but not significantly. The participants' health behaviors showed significantly fewer physician visits and significantly increased time spent performing stretching and strengthening exercise and time spent performing aerobic exercise. No group differences were found in the frequency of arthritis physician visits.

The improvements seen immediately after the SASMEP participation were not reflected in the post one-year scores. No significant differences were found for the participants' health status or health behaviors one year following the education. Health status and health behaviors did not return below baseline scores after one year suggesting the participants' health, although not improved, did not deteriorate. Therefore, the SASMEP education provided short-term health benefits for older Hispanic adults with arthritis, but not long-term health benefits. 


\section{TABLE OF CONTENTS}

CHAPTER

I. INTRODUCTION........................................................ 1

Background of the Problem................................................ 1

Purpose of the Study.......................................................... 7

Problem Statement.......................................................... 7

Research Questions ..................................................... 8

Significance of the Study ................................................. 11

Assumptions........................................................... 13

Limitations of the Study ............................................... 14

II. REVIEW OF THE LITERATURE...................................... 17

Health Promotion Education, Adult Health Education,

and Minority Health Education.......................................... 17

Health Promotion Education Research...................................... 21

Arthritis Overview..................................................... 25

III. METHODOLOGY OF THE STUDY $\ldots \ldots \ldots \ldots \ldots \ldots \ldots \ldots \ldots \ldots \ldots \ldots \ldots \ldots, \quad 35$

Methodological Rationale............................................... 35

Population and Sample................................................... 42

Methodological Procedure................................................ 44

Treatment of the Data...................................................... 53

IV. RESULTS.............................................................. 58

Sample Characteristics............................................... 58

Differences in Health Status and Health Behaviors-

The Analysis of Data for Specific Research Questions 1 and 2............. 66

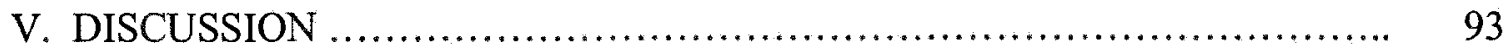

Overview of the Study ................................................ 93

Results and Discussion of the Research Questions.......................... 97

Significance and Impact of the Spanish Arthritis Self Management

Education Program.................................................... 112

Recommendations...................................................... 115

REFERENCES........................................................... 119

APPENDICES ........................................................... 125

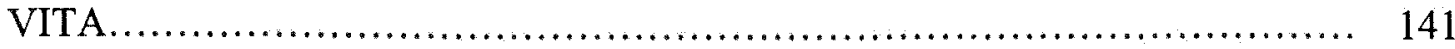




\section{LIST OF TABLES}

TABLE

PAGE

1. Experimental Design- Pre Post Questionnaire.............................37

2. Experimental Design - Repeated Measures...............................38

3. Health Status Data Collection Instruments.................................48

4. Health Behavior Data Collection Instruments............................52

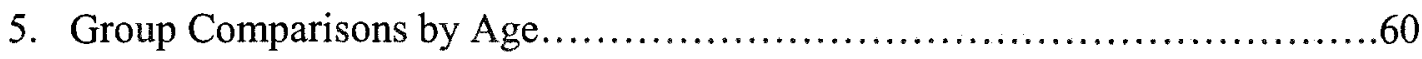

6. Group Comparisons by Gender.....................................61

7. Type of Arthritis by Group..........................................62

8. Pre Education Questionnaire (Baseline) Health Status by Group...............64

9. Pre Education Questionnaire (Baseline) Health Behaviors by Group............65

10. ANCOVA of General Health by Group and Time..............................69

11. General Health Means Pre and Post Adjusted for Age and Gender..............69

12. Pain Means Pre and Post Adjusted for Age and Gender........................ 70

13. ANCOVA of Disability by Group and Time.............................. 71

14. Disability Means Pre and Post Adjusted for Age and Gender...................72

15. ANCOVA of Health Perceptions by Group and Time........................73

16. Health Perception Means Pre and Post Adjusted for Age and Gender............74

17. ANCOVA of Physician Visits (Medical) by Group by Time.....................76

18. ANCOVA of Stretching/Strengthening by Group by Time .....................77

19. Stretching/Strengthening Means Pre and Post Adjusted for Age and Gender.....78

20. ANCOVA Aerobic Exercise by Group by Time..............................79

21. Aerobic Exercise Means Pre and Post Adjusted for Age and Gender............80 
22. Health Status Pre, Post, One-Year for the Experimental Education Group.......83

23. Health Behavior Pre, Post, and One-Year for the Experimental Education Group........................................85

24. Changes in Health Status and Health Behavior from Pre to Post Test of the Control and Experimental Groups. 


\section{CHAPTER I}

\section{INTRODUCTION}

An underlying premise of community health adult education programs is that a well-planned initiative can produce desired social and health results. This study examined the effectiveness of one community health adult education program, the Spanish Arthritis Self Management Education Program, to produce desired health results. The Spanish Arthritis Self Management Education Program is a six-week arthritis self-management education program targeting Hispanic older adults with arthritis. The program effectiveness in producing desired health results was evaluated at the conclusion of the education program and again after one year using self reporting surveys collecting data on general health, pain, disability, self-efficacy, health perceptions, number of physician visits, and amount of exercise.

In this chapter, an explanation of the problems with arthritis, health disparities within the Hispanic community, management of arthritis, and health models framing selfmanagement community education programs are presented. A statement of the problem to be researched with the specific research questions and hypotheses to be addressed, and the purpose and significance of this study follow. An overview of the methodology of the study, definitions of terms used in this study, and assumptions as well as limitations of this study are then identified.

\section{Background of the Problem}

The background of the problem of this study is centered on the concerns with arthritis as a chronic disease, the crisis of disparities in health care for Hispanics, and the need for critical evaluation of community adult health education programs. 
Arthritis Facts

Although not a leading cause of death, arthritis is the most common chronic condition affecting older people and is a major cause of limited activity (CDC, Arthritis Fact Sheet, 2000). The term arthritis refers to the more than 100 diseases that cause pain, swelling, and limited range of motion in joints and connective tissue throughout the body. The disease affects one out of every six Americans, approximately 43 million people (CDC, Arthritis Fact Sheet, 2000). This number is expected to increase to 60 million by 2020. In fact, all persons over the age of 60 have been estimated to have some physical evidence of arthritis, with over 70 percent having some musculoskeletal complaint (National Center for Health Care Statistics, 1995). In Florida alone, arthritis affects over three million people. This translates into approximately 20 percent of all Floridians being affected by arthritis. According to 2000 Florida Behavioral Risk Factor Surveillance Systems Data, the prevalence rate for Hispanics with arthritis is estimated at 25 percent.

Because arthritis is so common and the symptoms of joint pain, swelling, decreased strength and decreased mobility are so closely associated with the normal aging process, older people may erroneously accept arthritis as an inevitable part of aging. Because of this erroneous belief, many fail to seek treatment for arthritis symptoms or to learn self-management strategies to reduce arthritic pain that leads to decreases in activity and in independent functioning. While arthritis is a chronic disease with no known cure, the management of the symptoms with exercise, medications, stress control, diet, modalities, and education are used to control progressive arthritis disablement. 
There are many health disparities in the United States related to inequalities in income, education, ethnicity, age, language, and transportation. Healthy People 2010 is a comprehensive set of disease prevention and health promotion objectives for the nation to achieve over the next decade (Healthy People 2010 Fact Sheet, 2002). Healthy People 2010's two central goals serve as a framework for improving the health status of all Americans. The country is challenged to " 1 ) increase the quality and years of healthy life and 2) eliminate health disparities" (Healthy People 2010, 2001, pp. 3-7). Minorities such as Hispanics have traditionally been reluctant to pursue self-help programs, and have been identified as an under-served population in terms of medical care and allocation of resources (Fiscella, Williams, \& Moss, 1997). Although during the past 15 years, arthritis self-management programs in English have demonstrated positive impact on health behaviors, health status, and health care utilization (Hirano, Laurent, \& Lorig, 1994), these programs have not reached the Spanish communities where arthritis is the leading cause of disability (Morbidity and Mortality Weekly Report: Prevalence and impact of arthritis by race and ethnicity- United States, 1989-1991, 1996).

Health Models

Having discussed the problem of arthritic disease and minority health disparities, an understanding of the shift from the medical model of treatment of symptoms to the disablement model of prevention and management of symptomology helps to clarify the importance of community adult health education in the management of disease. 


\section{Disease Medical Model}

Community education and health promotion education is growing as the shift from a disease medical model to a disease prevention health promotion model, or the disablement model, occurs. In a disease medical model, health is defined as the absence of disease with the assumption that disease and injury can be treated and cured (Minaire, 1992). Symptoms are treated as they appear. No attempt at prevention or health promotion is apparent. This model focuses on physical aspects of health without consideration of how the totality of patient quality of life is affected by the illness. As people are living longer with health care advances, the inadequacy of the disease medical model for dealing with the problems of aging, chronic disease, and disability that do not fall within the medical model rubric of treat and cure is apparent.

\section{Disablement Model}

In the disablement model, a framework for looking at a broader context of health is provided. It expands the medical disease model to emphasize functional consequences and social roles focusing on the multidirectional relationships among pathology, impairments, and functional limitations (Nagi, 1991; Verbrugg \& Jette, 1994). Health is not merely an absence of disease, but an interplay of psychological, spiritual, physical, sociological and environmental well-being. The disablement model focuses on health promotion and disease prevention and not merely treatment of current symptomology. It is for these reasons, this study is based on the disablement model.

\section{Community Health Education Programs}

Community health programs based on the disablement model, look at working to improve functional outcomes based on sociological, physical, environmental and behav- 
ioral risk factors that can be modified to improve the overall health and quality of life of individuals. However, it is vitally important that community health education programs be critically evaluated on their actual impact on the health of persons. Often health promotion programs are instituted, but have no formal research strategies to evaluate their effectiveness (Jette, 1995).

Because health care promotion interventions generally focus on individual change, their relevance has been questioned for low income and ethnic minorities (Hirano, Laurent, \& Lorig, 1994). Few health promotion efforts have been effectively implemented with low-income populations or ethnic groups. Preoccupied with meeting their basic needs, minorities may view exercise or healthy eating as luxuries and not necessities.

Hispanic older adults in particular have poor access to and underutilize the health care systems in large part due to language barriers, low education, distrust of medical systems and professionals, limited health insurance benefits, illegal status and reliance on folk remedies (Hooyman \& Kiyak, 1999). Therefore, it is imperative to evaluate the outcomes of the health promotion education programs aimed at this population who have been identified at greater health risk. The purpose of this study was to examine the impact of one such health promotion education program, the Spanish Arthritis Self Management Education Program, in improving the health status and health behaviors of Hispanic older adults with arthritis in Miami-Dade County, Florida.

Spanish Arthritis Self Management Education Program

This study is based on the Spanish Arthritis Self Management Education Program (SASMEP) which is a community health education program developed at Stanford Uni- 
versity Arthritis Center. It is composed of six weekly, two-hour education sessions on the self-management of arthritis symptoms (California Arthritis Partnership Program, 2000). The intent of this program is to help Hispanic older adults with arthritis to better self manage and problem solve, to empower them to deal with their current symptoms, and to prevent a lifetime of disability and dependence. Topics include basic disease information, relaxation techniques for pain, stress management, how to exercise, how to stretch, pain management, self-massage, medication instruction, alternative therapies, safety, and when to access the doctor. The Arthritis Association provides educational materials, marketing, and promotion. There is no fee to take the course.

Lay individuals, who have been trained in a two-day workshop to lead the series, conduct the sessions in Spanish at local community centers. Lay individuals are the instructors as opposed to medical personnel because it is believed that Hispanics are more apt to follow instructions from their peers, and are cautious of and intimidated by medical authority (Stanford \& Schoenrock, 1992). Modeling principles of self-efficacy theory states people learn more and try harder when they are motivated by people they perceive to be like themselves (Bandura, 1997).

The program is taught using techniques to enhance self-efficacy such as modeling, mastery, and persuasion. Bandura's self-efficacy theory states the greater the belief in your own capabilities to achieve and control a desired outcome, the greater the probability of actually achieving such a behavior (Bandura, 1997). It was theorized that stronger self-efficacy may predict stronger changes in health related behaviors and better health status. 
The purpose of the Spanish Arthritis Self Management Education Program was to reach the underserved Hispanic population to determine if they will accept and use the education information and demonstrate improvement in health status as measured by changes of physical abilities, activities of daily living, pain, and frequency of doctor visits. The program attempted to empower the Hispanic older adult with arthritis to learn to self manage and be in control of their disease symptoms. It was hoped the education program would reduce the impairment and activity limitation due to arthritis.

\section{Purpose of the Study}

The purpose of this research was to determine the effectiveness of a community health promotion education program, the Spanish Arthritis Self Management Education Program in Miami-Dade, Florida. The effectiveness was determined by evaluating changes in the health status and health behaviors of Hispanic older adults with arthritic symptoms. Health status was measured using carefully selected survey instruments that collected data on self reported general health, pain, disability, self-efficacy, and health perceptions. Health behaviors were measured by amount of exercise and frequency of physician visits.

\section{Problem Statement}

Arthritis is a chronic disabling disease that deleteriously affects the function and quality of life of those afflicted. There is no known cure for arthritis, but arthritis selfmanagement education programs in English have demonstrated a positive impact on health behaviors, health status, and health care utilization (Hirano, Laurent, \& Lorig, 1994). However, these programs have not reached or been evaluated within the Spanish communities where arthritis is the leading cause of disability (Morbidity and Mortality 
Weekly Report: Prevalence and impact of arthritis by race and ethnicity - United States, 1989 -1991 Atlanta Georgia, CDC, 1996).

This study attempted to determine if a community health education program, the Spanish Arthritis Self Management Education Program, would prove successful in reducing the arthritis health problems and improve the health status and health behaviors of Hispanic older adults.

\section{Research Questions}

This study was guided by the following basic research question and. From the basic research question, two specific research questions were developed. Basic Research Question

Does the health status and the health behaviors of Hispanic older adults with arthritis improve following the participation in the Spanish Arthritis Self Management Education Program?

Basic hypothesis $\left(H_{b}\right)$. The health status and health behavior of Hispanic older adults with arthritis will improve upon completion of the Spanish Arthritis Self Management Education Program compared to adults who do not take the program. Specific Research Questions

Question 1. Were there any changes in health status and in health behaviors in the experimental group as compared to a control group based on gender and age before and immediately following completion of the Spanish Arthritis Self Management Program?

Hypothesis 1. The experimental group as compared to a control group and controlling for gender and age before and immediately following completion of the Spanish 
Arthritis Self Management Program will exhibit significant positive changes in health status and in health behaviors.

Research question 2. Were there any changes in health status and health behaviors of the experimental group at the conclusion of the program and one year following completion of the Spanish Arthritis Self Management Program?

Hypothesis 2. There were significant improvements in the participants' health status and health behaviors immediately following completion of the program and one year following completion of the Spanish Arthritis Self Management Program.

\section{Overview of the Method}

What follows is an overview of the method of the study describing the population, design; instruments, and analysis. A complete description of the methodology of the study is given in Chapter 3 .

\section{Subjects}

The population researched was Hispanic older adults diagnosed with arthritis. The target sample was Hispanic older adults with diagnosed arthritis residing in MiamiDade, Florida. The subjects for this study were participants from the Spanish Arthritis Self-Management Education Program. Hispanic older adults were defined as males or females 65 years of age or older with self-reported Hispanic heritage. With eight educational sessions for 10-12 participants, the total sample was 80 subjects in the experimental group and 100 in the control group.

Design

A pre and post control group experimental design was used to assess the differences pre and post participation in the Spanish Arthritis Self Management Education Pro- 
gram. Subjects were randomly placed in an experimental group to start the Spanish Arthritis Self Management Education program immediately or were placed on a waiting list for the next offering of the program. The experimental group completed a pre education program questionnaire the first week of class and a post education program questionnaire six weeks later at the end of the class. The subjects on the wait list formed the control group. The control group was given the same pre questionnaire as the intervention group and was surveyed again six weeks later when they were taken off the wait list and put into an education program. This allowed for parallel testing on all assessment measures for both groups. Demographic data (gender, age, and type of arthritis) were collected for all participants.

To determine long-term effects of participation in the Spanish Arthritis Self Management Education Program a repeated measures design was used. Data on health status and health behavior were collected for the experimental group pre, post, and one year following completion of the program.

The research methodology of the study is applied outcomes research as defined by Merriam and Simpson (1995) as it focuses on solving an immediate practical problem of determining the effectiveness of the Spanish Arthritis Self Management Education Program in improving the health status and health behaviors of older Hispanic adults in Miami-Dade, Florida.

\section{Instruments}

Seven instruments were used to assess the participant's changes in general health, pain status, disability, self-efficacy, health perceptions, amount of exercise, and physician visits. The seven instruments were the following: Medical Outcomes Study Self-Rated 
Health Item (Ware, Nelson, Sherbourne, \& Stewart 1992), Visual Analogue Pain Scale (Sherbourne, 1992), Health Assessment Questionnaire (HAQ) Disability Scale (Fries, Spitz, Krammes, \& Holman, 1980), Arthritis Self-Efficacy Scale (Lorig, Shoors, \& Holman, 1989), Health Feelings Scale (Gonzalez, Stewart, Ritter, \& Lorig, 1995), Physical Activities Scale (Gonzalez, Stewart, et al., 1995), and self reported physician visits. The Spanish versions of these instruments have met acceptable levels of reliability and validity (Gonzalez, Stewart, Ritter, \& Lorig, 1995) and will be described in Chaptẹr 3. These scales are widely used in arthritis and health services research to measure changes in physical function, health, and pain levels. Analysis of the Data

Analyses of covariance (ANCOVA) were used to determine the pre and post differences in health status and health behaviors for the experimental and control group using gender and age as covariates. Repeated measures analyses of variance (ANOVA) and post hoc tests, alpha $=.05$, were done to determine differences in the pre, post, and one year outcomes on the questionnaire measures (Merriam \& Simpson, 1995).

Significance of the Study

The need for health promotion education intervention specifically targeting Hispanic minorities is evident due to the many health disparities in the United States related to inequalities in income, education, ethnicity, age, language, and transportation in this population. Healthy People 2010's two central goals serve as a framework for improving the health status of all Americans. The country is challenged to "1) increase the quality and years of healthy life and 2) eliminate health disparities." (Healthy People 2010, 2000, pp. 7-3). Minorities, such as Hispanics, are a traditionally underserved population and are 
in need of access and information to eliminate health disparities and improve their health status and quality of life (Fiscella, Williams, \& Moss, 1997). This study determined if health promotion education for arthritis was effective in the Hispanic population. It is important that the programs be critically evaluated as to their impact on the health status of persons especially those minorities who have been identified at greater health risk due to overall lower socioeconomic and education levels, language and transportation and access barriers. One key to reducing minority health disparities is to critically evaluate the health education programs being offered.

Effectiveness of Community Adult Health Education Programs

There is a proliferation of health education programs offered in the field of adult education, however, few of these programs analyze participant outcomes in terms of actual measurable health outcomes (Community Partnerships for Adult Learning, 2003). Too often in adult education, programs if evaluated at all, are evaluated from participant satisfaction data and participation data leaving the true concept of whether the education program has impacted the individual's behavior and health, undiscovered (Brownson, Baker, \& Novick, 1999). Adult based health education programs are increasingly being offered especially in the health education field without any defined research strategy to determine the effectiveness or outcomes of the education programs (Fries, 1997). With thorough evaluation of adult education programs offered, the impact of the education can be quantified and the impact on the field of adult education strengthened.

Medicine is evidence based. No intervention should be rendered to any patient or client unless there is a documented and researched basis for that intervention. In the same vein, no adult education program should be administered without critical inquiry as to its 
effectiveness with the targeted population. This research attempted to demonstrate the impact of community adult education programs by evaluating the effectiveness of one such program.

\section{Definition of Relevant Terms}

The following terms are defined as used in this study.

Health behaviors. The term health behaviors is used throughout this study and refers to measures of health outcomes of frequency of physician visits, and amount of exercise.

Health status. The term health status is used throughout this study refers to measures of health outcomes of self-reported general health, pain, disability, self-efficacy, and health perceptions.

Hispanic. In this study, ethnicity is self-declared. The term Hispanic is often synonymous with the term Latino. The term Hispanic is used commonly to pertain to Spain and its culture, language and people (Merriam Webster, 2002).

\section{Assumptions of the Study}

To conduct this study, four assumptions had to be made. First, it was assumed that the participants in this study answered the questions truthfully. Second, it was assumed the self reported data reflected the actual physical health status of each participant. Third, it was assumed the lay instructors were adequately trained, followed the course content and delivery outline, and the participants' education experience was equivalent for all sessions. The fourth assumption, as stated in Chapter 3, Methodology, is that the dependent variable is normally distributed for each of the populations, the variances of the de- 
pendent variable are the same for all populations, and the cases represent random samples from the population (Green \& Salkind, 2002).

\section{Limitations of the Study}

Two limitations of this study, the self-reporting of the data and the selection of the subjects, need to be clarified.

\section{Self Reports}

In this study, the subjects were asked to provide a self-report on their general health, pain, physical abilities, amount of exercise and number of physician visits. Relying solely on self reported measure could be misleading, since the respondents may intentionally or inadvertently provide information that is not accurate. Some individuals, even under the conditions of anonymity, may feel pressured to "say the right thing", and report more positive or negative health status than is actually present.

Recall of information might also be imprecise, especially when very specific data such as "number of minutes exercised per week" and "number of physician appointments over last four months" is requested from the individual. In the case of health measurements, perceptions about one's health status may be overly optimistic or pessimistic, and lead to inaccurate self reports. Psychological impairments could also impact the reliability of self-reported measures.

Although these concerns are reflected in the literature, it is also true that this type of self reported survey instrument has been widely and successfully utilized in health care research with proven reliability and validity (Chandola \& Jenkinson, 2000). Furthermore, some constructs such as general health, health perceptions, and self-efficacy have both physical and mental components. This intrinsic mental element can only be analyzed ap- 
propriately taking into account the subjects' perception of their own health. In the area of culture and conceptualization of health, Chandola and Jenkins (2000), studied self rated health in different ethnic groups to determine if they completed health self-reports in a systematically different way, and found that there was no evidence of significant differences between the groups. In this research study, self-report was the optimal measure for general health status and health behaviors.

\section{Selection of Subjects}

The limitations for subject selection in terms of geographic context, health education context, and the context of diversity as relate to this study need to be discussed.

Geographic context. Subject selection from one geographic area provides homogeneity to the sample in terms of access to health care and relative socioeconomic status, all of which are variables that may influence health status across populations. However, with that homogeneity come possible problems with generalization to the entire minority population studied.

Health education context. The fact that the subjects were recruited in the context of interest in participating in health education could indicate that this cohort is more proactive, more health conscious, better able to manage their own health, and more apt to search out information on arthritis disease management than the population at large. If this were true, the generalizability of the findings of this study in this more proactive group of research participants may have limited generalizability.

Diversity of Hispanic population. "Hispanic" is a label that encompasses many cultural subgroups, and in some cases the differences between these groups may outweigh the similarities. The fact of sharing a common language and history does not nec- 
essarily imply that health beliefs and behaviors are homogeneous across different national origins.

\section{Summary}

This research attempted to determine the effectiveness of the Spanish Arthritis Self Management Education Program for Hispanic older individuals with arthritis. If the education intervention improves the participants' health as measured by changes in self reported general health, pain, disability, self-efficacy, health perceptions, frequency of physician visits, and exercise, and if changes in the participant's health status and health behaviors were maintained for one year post education intervention, the long term effectiveness of a community health education program can be demonstrated through the improved health of its participants. The improved health of the participants will serve to help reach the goals and objectives of Healthy People 2010 of increasing the quality and years of healthy life and eliminating health disparities among minority populations (Healthy People 2010,2002). The improved health would demonstrate the importance of adult education programs in health promotion and disease management. 


\section{CHAPTER II}

\section{REVIEW OF THE LITERATURE}

This study examined the effectiveness of the Spanish Arthritis Self Management Education Program for Hispanic older adults in Miami-Dade County, Florida to produce desired health changes. The effectiveness of the Spanish Arthritis Self Management Education Program was determined using questionnaires to collect data on changes in health status and health behaviors as defined by self reported general health, pain, disability, self-efficacy, health perceptions, number of physician visits, and amount of exercise. The health status and health behavior changes at the conclusion of and one year following the education program were evaluated to determine if the program had long term effectiveness in changing health status and behaviors for the older Hispanic adults with arthritis.

In this chapter, the theoretical background of health promotion adult education and its impact on changing health behaviors is discussed. The rationale and the importance of studying the Hispanic population follow. An overview of arthritis pathology and disease management, the importance of adult education in the selfmanagement of arthritis, and the current status of arthritis adult education programs provides an overarching framework on which the research questions for this study are based.

Health Promotion Education, Adult Health Education, and Minority Health Education

This review of the literature summarizes papers and studies of health promotion education, adult health education, and minority health education. 
The importance of health promotion was introduced in Chapter 1. The relationship between health promotion, adult education and minority education are discussed. This discussion starts with a review of Healthy People 2010, the US government's report on health goals and priorities for the Nation.

Healthy People 2010. A summative report by the US Health and Human Services (2001), Healthy People 2010, supports health promotion education activities that will reduce the incidence of disabling chronic diseases and enhance the older person's functional independence and overall quality of life. The report presented two overarching goals, increasing the quality and years of healthy life, and eliminating health disparities, as the guide for developing objectives that will actually measure progress (National Center for Health Statistics; Healthy People 2010, 2001). The report presented 467 national disease prevention and health promotion objectives to be achieved in the first decade of the 21 st century. The objectives are designed to serve as a road map for improving the health of all people in the United States, and are based on similar initiatives pursued over the past two decades. Healthy People 2010 's goal of eliminating health disparities among minorities forms the foundation of the importance of health promotion education in the minority Hispanic population and is the driving focus of this dissertation study.

Health promotion education financial allocation. The nationwide agenda of Healthy People 2010 is focused on the education of the public behaviors that can change health. Health promotion education is recognition that chronic diseases cannot be cured, but can be prevented from causing disability. Although the Surgeon General's Report on 
Health Promotion and Aging (1988), reported health promotion education would decrease health care expenditures, this awareness is not reflected in the actual allocation of health care dollars. Only $3 \%$ is of the national health care dollar is spent on health promotion (Brown, 1994) and of this $3 \%, 2.5 \%$ is for disease prevention such as medical screenings and vaccinations, and health protection in the physical environment such as toxic agent and radiation. This leaves only $.5 \%$ for health promotion education.

Health promotion is an ignored priority. Health professionals have given only lip service to health promotion education because they have not been reimbursed for it. Health promotion and education is a recognized community and national need, but in order to secure the funding for empowerment, the effectiveness of education programs in changing health status must be proven.

\section{Adult Health Education}

Health education has advanced beyond the idea that knowledge alone inspires change (Haber, 1999). Given the overabundance of information that pours out of the media, bookstores, libraries, Internet, and even word of mouth, it is often difficult for individuals to sort out accurate, up to date information that is pertinent to their particular health needs. Older adults learn best in andragogical situations in which new ideas are presented in collaborative, small relationships and in small, participative groups where they have control of the situation. Andragogy is the art and science of teaching adults (Knowles, 1980). It is based on a set of assumptions about learning developed by Knowles and is different from traditional pedagogy. For example, adults learn best with active involvement and peer interaction (Brookfield, 1990). This is the basis of the health education program used in this study. The Spanish Arthritis Self Management Education 
program is based on andragogical concepts of small participatory groups (eight to ten persons), peer led, community based, and self-management or control driven.

\section{Minority Health Education}

Health promotion interventions and their relevance has been questioned for low income and ethnic minorities. Health promotion and education is a low priority for minority and disadvantaged populations, who, preoccupied with meeting basic needs, may view exercise or healthy eating as luxuries not necessities (Fiscella, Williams, \& Moss, 1997). Few health promotion efforts have been effectively implemented with low income or ethnic groups adding to the disparities in health status for minorities. Programs that have tried to offer health promotion programs to minority populations have had problems with recruitment and retention (Yee \& Weaver, 1994). Hispanic older adults in particular, have poor access to and underutilize the health care systems in large part due to language barriers, low education, transportation difficulties, distrust of the medical systems and professionals, limited insurance health benefits, illegal status and reliance on folk remedies (Hooyman \& Kiyak, 1999).

Leading health indicators such as physical activity, access to health care, obesity, injury and violence, and responsible sexual behavior have remained level or declined over the past decade in Hispanics while indicators in the general population have improved. A renewed commitment to eliminating these health disparities through focused education and interventions is essential (Aday, 1994). Hispanic health is not equivalent to their non-minority counterparts. The driving purpose of this study was to determine if an arthritis education program would indeed help to eliminate some of the disparities in the health of Hispanics older adults with arthritis. 
An underlying premise of health promotion education is that one can indeed promote positive health changes. Without sufficient evaluation, however the effectiveness of a community health education initiative to produce positive health changes cannot be assured. Other reasons for evaluation include requirements by funding agencies for programs to be accountable, information on what programs work and how, and ethical considerations that health education programs are of benefit to participants and are cost effective (Israel, 1995; Green \& Lewis, 1986; Windsor, 1994).

As community health education programs are complex in nature and involve many variables, they are difficult to research in the traditional experimental model for conclusive cause and effect based on randomized control trial. Often the constructs studied are difficult to measure, such as happiness or quality of life. Often the results may take many years to produce measurable health changes. Because of the intricate nature of community education initiatives, multiple data collection research requirements, and analysis extended over long periods of time, researchers are challenged to develop adequate sampling, measurement, design, and implementation strategies. It is because of these complexities of evaluation requirements, that many community health education programs are not adequately evaluated. Many are just implemented and continue without ongoing evaluation (Jette,1995).

Successful Health Promotion Education Studies: The Lorig Studies

Despite the difficulties in evaluating community health education programs, several studies provide us with useful information on the effectiveness of education programs in changing health status and health behaviors. Kate Lorig has been a 
prominent developer of community health education programs and researcher of the effectiveness of adult education programs in changing health behaviors. Four of Lorig's studies are discussed in this section and provide the research framework for which this dissertation is based.

Chronic disease self-management education program. In a study by Lorig and Sobel, et al. (1999), the researchers posed the question of whether or not a chronic disease self-management education program could improve health status and decrease hospitalization. This six-month randomized, controlled trial included 952 patients who were 40 years of age or older and were diagnosed with heart disease, lung disease, stroke or arthritis. Health behaviors, health status and health service utilization were measured using questionnaires. The topics covered in the chronic disease self-management program included exercise, use of cognitive symptom management techniques, nutrition, fatigue and sleep management, use of community resources, use of medications, dealing with emotions, and communication with health professionals.

The results of this study by Lorig and Sobel, et al. (1999) study, showed that treatment subjects, when compared with control subjects, demonstrated improvement at six months in weekly minutes of exercise, frequency of cognitive symptom management, communication with physicians, self-reported health, health distress, fatigue, disability and social/role activities limitations. Results also showed fewer hospitalizations and days of hospitalization. No differences were found in pain, physical discomfort, shortness of breath, or psychological well-being. Despite the positive results of this study, the authors realized that because most chronic disease patient education programs have not been formally evaluated, it was difficult to determine whether or not a heterogeneous program 
is more effective than a homogeneous one (Lorig, 1999). Furthermore, Lorig's study was based on several chronic diseases clumped together and not just arthritis.

This study gives credence to the fact that health behaviors can improve in individuals with diverse pathology with community adult education programs, however the study is based on multiple chronic pathologies and on English speaking populations. Studies to date have not included minority populations in their subject selections.

Arthritis self management program twelve-year review-English. Another study by Lorig and Holman (1993) examines the twelve-year history of the arthritis selfmanagement studies for the English speaking population. The original purpose of the study was to determine if an Arthritis Self Management Program (ASMP) could change behaviors and health status. The article reviews the four studies conducted with the ASMP in the past twelve years. The authors also provide medical information on arthritis, as well as its health care cost. A brief description of the theory of self-efficacy is provided by the authors. They also explained how self-efficacy is highly predictive of future behavior and easily manageable.

After reviewing the studies, the authors reached several conclusions. First, using randomized trials, they demonstrated improved behaviors, self-efficacy and aspects of health status with the health education program, ASMP. The effects of the ASMP lasted for as long as 4 years without formal reinforcement. Improvement gains by the participants have importance both clinically and in terms of cost savings. ASMP health status effects appear to be more closely linked to changes in self-efficacy than to changes in behaviors. Finally, the ASMP is an intervention that can be and has been disseminated widely. 
compared with medications. In a study by Lorig and Ward (1996), the researchers compared the effects of education interventions and the use of non-steroid anti inflammatory drugs (NSAID) medication treatment on pain and functional disability in patients with osteoarthritis and rheumatoid arthritis. Based on the meta analysis performed by the authors, patient education interventions provide additional benefits that are $20 \%-30 \%$ as great as the effects of NSAID treatment for pain relief in osteoarthritis and rheumatoid arthritis, $40 \%$ as great as NSAID treatment for improvement in functional ability in rheumatoid arthritis and $60 \%-80 \%$ as great as NSAID treatment in reduction in tender joint counts in rheumatoid arthritis. In this study by Lorig and Ward (1996) adult education interventions for pain control and functional disability in patients with arthritis was more effective than prescribed medications.

Arthritis education program for Spanish participants. The purpose of this study conducted by Lorig and Gonzalez (1998) was to determine the effects of a community based arthritis self-management education program for Spanish speaking participants. To date, there have been no randomized studies of the effectiveness of arthritis education in this population. The Spanish Self-Management Program was a 12-hour community based program given in two-hour lessons over six weeks in California (Lorig \& Gonzalez, 1998). This program was taught in churches and neighborhood centers. Spanish-speaking subjects completed the questionnaires either by self-administration, by mail or by telephone. Post data were collected via mailed questionnaires or with telephone follow up. Subjects demonstrated improvements in exercise, general health, disability, pain, selfefficacy and depression. 
The Lorig and Gonzalez (1998) study specifically focused on older adult Hispanic populations. However, it is critical to note that the Hispanic populations of California and Florida are distinctly different populations. The California Hispanics come from a predominantly Mexican background. Florida Hispanics, especially in Miami-Dade are predominantly from Cuba, the Caribbean, and Central America. The mere coincidence of sharing a similar language does not indicate similar cultures. Britain, USA, and Australia all have a common language but have marked cultural differences.

The Arthritis Foundation in Florida has stated one of their major objectives is, "To increase self-management behaviors among persons with arthritis" (Break the Grip of Arthritis, 2002). The Spanish Arthritis Self Management Education Program is designed to empower individuals with arthritis with knowledge on how to control arthritic symptomology. The model, although initiated in the California, needs to be tested in Florida in the hopes of providing data of significant improvement in the health of the participants to provide specific rationale and data to support offering the program. This is the driving focus of this research, that is, to determine the effectiveness of the Spanish Arthritis Self Management Education program in helping to improve the health status and health behaviors of the participants.

In the following section, the rationale for studying arthritis health promotion education among Hispanic minorities will be explained as well as give an overview of the pathology and management of arthritis.

\section{Arthritis Overview}

Arthritis is one of the most common diseases in the United States with over 70 million Americans being affected by over 100 conditions that attack the joints and create 
limitations in the activities of daily living of those affected by the disease. Arthritis is the leading chronic ailment of older adults (Bottomely \& Lewis, 2003). Arthritis is a chronic disease that affects the joints through degeneration. According to the Arthritis

Foundation, the most common type of arthritis is osteoarthritis. Almost every person over the age of 60 shows some signs of osteoarthritis (Arthritis Foundation, March 2003). Osteoarthritis is characterized by the breakdown of cartilage and usually manifests itself as a form of joint pain, stiffness, enlargement or swelling, limited range of motion, muscle wasting, and/or deformity. Osteoarthritis usually attacks the hands and weight bearing joints such as the lower back, hips, knees, ankles and feet. Some sort of limitation in movement activities is reported by $89 \%$ of persons with arthritis (Arthritis Foundation, March 2003). Arthritis is a debilitating, progressive, disabling, and chronic disease.

\section{Demographics of Arthritis}

As discussed previously, over 70 million Americans suffer from arthritis symptomology (Arthritis Foundation, March 2003). Arthritis is the leading chronic ailment of older adults (Bottomely \& Lewis, 2003). According to the Arthritis Foundation, $19.17 \%$ of Floridians have arthritis, which equals 2.48 million people (Arthritis Foundation, March 2003). This makes up 3.5\% of all Americans who suffer from the disease. South Florida is an excellent location for those who suffer from arthritis because weather can play an integral role in the symptoms that persons with arthritis suffer from. Arthritis is characterized by inflammation of the joints and this can be exacerbated by cold weather. Migration of older adults from colder climates, therefore, increases the incidence and the prevalence of persons with arthritis is South Florida (Break the Grip of Arthritis, 2002). With an increasing incidence and prevalence comes a 
need for health education and medical intervention in the management of arthritic disease.

\section{Treatment of Arthritis}

Treatment of arthritis focuses on managing or controlling the symptoms because arthritis is a degenerative debilitating disease for which there is no known cure. Several methods are used to try to treat the degenerative changes that occur to the joints and muscles to prevent joint immobility and deformity, pain, weakness and disability. These methods include medications, modalities, exercise, stress control, nutrition, weight reduction, surgery, and education (Manek \& Lane, 2000).

Medications. Many medications are used to try to treat the disease including antiinflammatories, which include corticosteroids and non-steroidal anti-inflammatories. Aspirin has long been used to treat the pain and inflammation of arthritis. These are used to try to combat the swelling that result secondary to the disease which bring on the symptoms of joint tightness and pain (Manek \& Lane, 2000).

Modalities. Heat, cold, and massage are long standing interventions to treat the pain and joint stiffness of arthritis. The soothing relaxation and increased local blood flow with the application of superficial heat help ease pain, decrease swelling and inflammation and allow the individual to more freely move joints and limbs and to become more mobile (Falvo, 1999). Cold also has an analgesic effect. This analgesic effect comes from numbing the nerve endings and in essence anesthetizing the area of application. This numbing effect reduces pain and localized swelling and allows for increased movement of joints and limbs and increased mobility for functional daily 
activities. Gently massaging muscles can also minimize aches and pains of arthritis (Manek \& Lane, 2000).

Exercise. A normal response to pain is rest. However, with arthritis pain and immobility, resting can lead to progressive muscle weakness and joint deformity furthering the deleterious effects of the arthritic disease. Exercise is critical in the management of arthritis (Arthritis Foundation, 2003). Strengthening exercises build muscle that surround and support the joints and forces lubricating fluid into the cartilage to keep it healthy and nourished (Falvo,1999). Rall (1996) found even persons with severe arthritis could safely increase strength almost $60 \%$ in a 12 -week progressive resistive exercise program.

Exercise needs to be a life long commitment in order to assuage the recurring and progressive symptoms of arthritis. In his study on exercise and exercise maintenance of individuals with arthritis, Minor (1993) discussed the importance of supervised exercise in a community group setting for maintenance of the exercise frequency. In the study, Minor (1993) examined the relationships between factors of a supervised exercise experience and maintenance of exercise by persons with arthritis. The purpose of the study was to identify what factors associated with the initial exercise experience, including changes experienced and perceived by subjects during initial exercise class, contributed to the explanation of maintenance of exercise in self-directed settings over time.

One hundred and twenty subjects with arthritis were used for this study. The ages of the participants ranged between twenty-one and eighty-three. All the participants had symptomatic weight-bearing joints. The sample was $82 \%$ female, $95 \%$ white, and $30 \%$ of 
the participants were employed. Furthermore, the participants were stratified by diagnosis into one out of three groups, which included, low to moderate in intensity aerobics aquatics, aerobic walking, or a usual treatment control group of range of motion and relaxation exercises with no aerobic stimulus. All the groups met at similar facilities with the same instructors for exactly twelve weeks. Each session lasted a period of sixty minutes, three times a week.

The data collection process took place immediately following the exercise intervention, at three and at nine months. Assessments of these times included objective measurements of exercise, tolerance, flexibility, and disease activity. The second stage of data collection included questionnaires mailed 18 months after the completion of the original study. The information collected from the questionnaire included subject report of support for exercise by family or friends, the impact of illness on exercise activity, and weekly exercise activity.

At three months, five variables that best explained exercise behavior included depression, anxiety, aerobic capacity, changes in depression and social activity that occurred during the exercise class. At 18 months after participation in the exercise class, all the participants reported improvements in pain following the initial exercise program.

The results of this study indicated that health practitioners could favorably influence exercise maintenance in the context of an initial supervised exercise experience. This study discovered the importance of providing comfortable social experience in which participants can enjoy physical activity and that depression and anxiety are associated with dropping out exercise. This study provides the basic premise of the adult education class including exercise and stress reduction as components as well as 
providing the education in the context of a community peer led event. The study also draws attention to the difficulty of maintaining healthy behaviors long term.

Surgery. As a last resort in the management of arthritic pain and deformity, often joint surgery is performed. Joint replacements can alleviate pain and actually replace worn joints. Hip replacement surgery is most common followed by shoulder and knee replacements (Falvo, 1999).

Education. Because arthritis has no known cure and is a chronic progressive disease, education of individuals with arthritis on how to self manage their arthritic symptomology have become common in the past decade and they have shown positive results. Individuals must be knowledgeable on how to balance and utilize the varied treatment interventions such as medications, modalities, exercise, nutrition, and physician visits available to help them with managing their arthritic symptomology (Hirano, Laurent, \& Lorig, 1994).

Incidence of Arthritis in Hispanics

According to data collected from the 1989-1991 National Health Interview Survey (National Center for Health Care Statistics, 2003), 11.3\% of the approximately 22 million Hispanics in the United States reported having arthritis. The prevalence of arthritis in the total population is estimated to increase by $57 \%$ over the next two decades (Helmick, et al., 1995; US Department of Health and Human Services Arthritis Prevalence, 1994). This increase in arthritis prevalence is expected in all groups, including Hispanics especially considering the rapid growth in the number of Hispanics over age 65 and the changes in immigration patterns (Bassford, 1995). 
In Florida alone, arthritis affects over three million people (Break the Grip of Arthritis, 2003). As one of the states with the fastest growing Hispanic populations in the country, arthritis represents a major public health and social problem for Floridians. According to the Florida Behavioral Risk Factor Surveillance Systems Data (2000), the prevalence rate for Hispanics with arthritis is estimated at 25 percent. The importance of a self-management program in South Florida targeting the Hispanic population can be demonstrated by the enormous influx of Hispanics in the past ten years, 1990-2000. South Florida witnessed its first huge influx of Hispanic immigrants in the early 1960s when Fidel Castro took power of Cuba and thousands of Cubans searched for exile in the United States, especially South Florida. The Cuban population has now increased to over 650,000 in Miami Dade County according to the 2000 United States Census Bureau and accounts for more than half (52\%) of all Cubans living in the United States (Driscoll, 2001; Grosman, 1997).

Besides the large Cuban population in South Florida, the most recent census demonstrates that almost all Hispanic groups have increased in size over the past ten years. Some of the groups that have shown the largest increase were the Dominican and Mexican populations, which increased by $55 \%$ and $65 \%$ respectively (Arthritis Foundation, March 2003). Combining all Hispanic population groups, it is estimated there are at present close, to one million Hispanics living in Miami-Dade County. With South Florida poised as the gateway between the United States and South and Central America, the influx of Hispanic populations will most probably continue. 


\section{Summary}

Health promotion education is a focus of current medicine. Self-management of disease symptoms through adult education is vital to current medical practice. People are living longer and have more chronicity of disease. Chronic disease cannot be cured and treated in the disease medical model of looking merely at treating the symptoms as they appear. Adult education is the critical piece to bridge the gap of the medical disease model to the disablement model. Individuals cannot self manage disease symptomology with out being given the knowledge of how to do so. Hence, community health adult education programs are of vital importance to help keep older adults free from the disabling sequela of chronic disease.

Adult education programs in the community need to be evaluated with research paradigms for their effectiveness in impacting the participants. Adult education programs are difficult to evaluate and many are being offered without critical research as to their effectiveness.

Adult education is truly only effective if the education affects long-term behaviors, i.e. one-year post education intervention. If the impact holds long term, then the education program unquestionably changed behaviors and affected participants health and can be deemed successful or effective.

Arthritis is a chronic disease with huge risk of disability and pain if not managed well. Hispanics are a large portion of the population with arthritis. Minorities are at increased health risk due to health disparities. Education programs for English speaking individuals to manage arthritic symptomology are in existence and have been proven 
successful. However, there exists minimal research as to effectiveness and impact of adult education programs for arthritis self management in minorities such as Hispanics.

Therefore, this study looked to discover the impact or effectiveness of a community health promotion education program in improving the health behaviors and status of an underserved and under researched Hispanic minority population to demonstrate the importance of adult education in health promotion.

\section{Research Questions}

This study determined if one health promotion education program for Hispanic older adults with arthritis was effective in changing health behaviors and health status of its participants. In essence, was the health education program successful? Based on the review of the literature presented in this chapter the following research questions have evolved to prove the program's success or failure.

\section{Basic Research Question}

Does the health status and the health behaviors of Hispanic older adults with arthritis improve following the participation in the Spanish Arthritis Self Management Education Program?

Basic hypothesis $\left(H_{b}\right)$. The health status and health behavior of Hispanic older adults with arthritis will improve upon completion of the Spanish Arthritis Self Management Education Program compared to adults who do not take the program.

\section{Specific Research Questions}

Question 1. Were there any changes in health status and in health behaviors in the experimental group as compared to a control group based on gender and age before and immediately following completion of the Spanish Arthritis Self Management Program? 
Hypothesis 1. The experimental group as compared to a control group and controlling for gender and age before and immediately following completion of the Spanish Arthritis Self Management Program will exhibit significant positive changes in health status and in health behaviors.

Research question 2 . Were there any changes in health status and health behaviors of the experimental group at the conclusion of the program and one year following completion of the Spanish Arthritis Self Management Program?

Hypothesis 2. There were significant improvements in the participants' health status and health behaviors immediately following completion of the program and one year following completion of the Spanish Arthritis Self Management Program.

With these research questions as the basis for inquiry, the methodology for determining the answers to these questions is required. In Chapter III, the research methodology is discussed including methodology rationale, the population studied, instrument selection, and treatment of the data. In the following chapter, research procedures are discussed in depth. 


\section{CHAPTER III}

\section{METHODOLOGY}

This study analyzed the effectiveness of the Spanish Arthritis Self Management Education Program in Miami-Dade County, Florida as measured by changes in the participants' health status and health behaviors. Health status was measured by the participants' changes in general health, disability, pain, self-efficacy, health perceptions, exercise, and frequency of physician visits. It was the intent of the Spanish Arthritis Self Management Education Program to educate older Hispanic adults regarding selfmanagement of their arthritic conditions and empowering them with the knowledge to improve their health status.

In this chapter, the methodological rationale, description of the general population and specific sample, procedures for conducting the study and description of instruments used to collect the data are discussed. The basic and specific research questions and strategy for analyzing and answering each is then presented.

\section{Methodological Rationale}

This study is considered applied research as it focuses on solving an immediate practical problem (Merriam \& Simpson, 2000). This study analyzes the effectiveness of the Spanish Arthritis Self Management Education Program in improving the health status and health behaviors of older Hispanic adults in Miami-Dade County, both short-term (six weeks) and long-term (one year). In this section, the experimental design and the rationale for selecting the design is described. The pre and post experimental design and the repeated measures time series design are now discussed. 
This study used two basic designs, experimental pre and post design and repeated measures time series design. Both designs used face-to-face interview and telephone interview data collection methods. The pre and post experimental design was selected because randomization of the participants into control and experimental groups was possible for the pre and post intervention. Post intervention data, while collected for both groups at six weeks, could not be collected one year following the program for the control group because it would be unethical to withhold education intervention for those on a waiting list for one year. Therefore, in order to determine one-year post outcomes, the repeated time series design was utilized. Both designs are now discussed in depth.

Pre and post experimental control group design. The pre and post experimental control group design is used to compare two or more groups that are formed by random assignment (Kane, 1997). One group receives an intervention and the other group does not receive the intervention. In this study, the intervention is the participation in the Spanish Arthritis Self Management Education Program. One group participated in the program and the other group did not.

A key to this experimental design is random group assignment. In this study, subjects were randomly assigned to take the course immediately, or placed in the control group and waited six weeks before participating in the education program. Because of the random assignment, the groups can be assumed to vary only because of what occurs in between measurements (Portney \& Watkins, 2000). 
This design is considered the scientific standard in clinical research for establishing cause and effect (Horowitz, 1987). The term randomized controlled trial $(\mathrm{RCT})$ is often used for this design. See Table 1 for study design.

The pre test measurements provide a basis for establishing initial equivalence of the groups. Selection bias is controlled by random assignment of groups. History, maturation, testing, and instrumentation effects should affect both groups equally in both pre and post questionnaire measurements. Attrition is the only threat to internal validity not controlled in the pre and post test experimental design (Portney \& Watkins, 2000).

In order to use this design, it is assumed that the dependent variable is normally distributed for each of the populations, the variances of the dependent variable are the same for all populations, the cases represent random samples from the population and the scores on the test variable are independent of each other (Green \& Salkind, 2002). This study follows all the assumptions for use of the pre and post experimental design. Table 1 Experimental Design - Pre and Post Intervention Questionnaire

$$
\text { Time of Testing }
$$

Group Pre Post

\begin{tabular}{lll}
\hline Experimental & Health Status & Health Status \\
& Health Behaviors & Health Behaviors \\
\cline { 2 - 3 } Control & Health Status & Health Status \\
& Health Behaviors & Health Behaviors
\end{tabular}


Repeated measures time series design. A repeated time series design was the second measure used to compare the differences in the experimental group assessing data collected pre, post and one year following education program intervention. See Table 2 for the repeated measures design. The repeated measures design was selected because one group was exposed to the treatment variable and their clinical performance could be assessed over time (Portney \& Watkins, 2000).

Table 2

Experimental Design - Repeated Measures Pre, Post, and Year Post Questionnaire

Time of Testing

\begin{tabular}{llll}
\cline { 2 - 4 } Group & Pre Education & Post Education & One Year Post \\
\hline Experimental & Health Status & Health Status & Health Status \\
& Health Behaviors & Health Behaviors & Health Behaviors \\
\hline Control & Health Status & Health Status & - \\
& Health Behaviors & Health Behaviors & -
\end{tabular}

In this design, the dependent variables were health status and health behaviors of the participants, and the independent variable was time. All participants received the intervention, their participation in the Spanish Arthritis Self Management Education Program. Each subject was evaluated at three time intervals; pre, post and year following the education program. The major advantage of the repeated measure design is the ability to control for the potential influence of individual differences. For example, it is assumed that important subject characteristics, such as age, gender, type of arthritis, motivation, and intelligence will remain relatively constant throughout the experimental time frame. 
The differences observed over time are more likely to reflect the intervention effects and not variability between subjects. In a sense, the subjects are being used as their own control which provides the most equivalent comparison group possible. However, the limitation to this design is that without a control group, internal validity poses a threat, as it cannot be totally assured the changes would not have occurred over time without the intervention (Portney \& Watkins, 2000).

\section{Sample Procedure}

A convenience sample of the persons volunteering to take the Spanish Arthritis Self Management Education Program was used. As subjects registered to participate in the Spanish Arthritis Self Management Education Program, they were randomly assigned to attend the program immediately or placed on a waiting list for the next available offering of the program. Thus, a control group was obtained from individuals who registered to take the arthritis education program but were placed on the waiting list. Both the experimental and control groups were given the pre test at the same time. The experimental group then participated in the program while the control group waited six weeks until the next program offering. The experimental group completed the post questionnaire at the end of the program and the control group completed the questionnaire again when they began the program allowing for parallel testing for both groups.

Experimental Data Analysis Rationale

An analysis of covariance (ANCOVA) was conducted for the pre and post outcomes data collected for the experimental and for the control group with one between subjects variable, group (experimental, control) and one within subjects variable, time 
(pre, post). The ANCOVA was conducted using the data on self reported general health, pain, disability, self-efficacy, health perceptions, exercise, and number of physician visits using age and gender as covariates. Age and gender were independent variables that seemingly could influence performance in the outcome measures and therefore were analyzed to determine their influence on the outcome measures. The variance in the group baseline demographics and data at the beginning of the study was analyzed using chi-square tests for demographic variables and independent $t$-tests for health behaviors and health status baseline outcomes.

A repeated measures analysis of variance (ANOVA) was conducted to determine differences in the pre, post, and one-year post outcomes on the questionnaire measures (Merriam \& Simpson, 2000). A repeated measures ANOVA was done with the data collected at three times: pre education intervention, post education intervention, and oneyear post education intervention on the experimental education group. The repeated measures ANOVA was conducted for the variables of self-reported general health, pain, disability, self-efficacy, health perceptions, exercise, and number of physician visits.

\section{Data Collection Rationale}

The data collection methodology of this study was a combination of face-to-face interview and telephone interview methods. All data collection instruments were in Spanish and done by Spanish speaking individuals. The methodology was chosen based on the research that follows.

A study by Lorig, Gonzalez, Ritter, and Nacif de Brey, (1997) compared the quality and quantity of data collected from Spanish speaking subjects using three different data collection techniques: face to face interview, telephone interview, and self 
administered mail survey. Approximately 150 Spanish-speaking adults were recruited in the San Francisco Bay area. Fifty subjects were randomized to complete a survey using one of three methods: face-to-face interview, telephone interview, or self-administration through the mail. The surveys used were five scales, all previously translated into Spanish and validated. The scales used were the Health Assessment Questionnaire (HAQ) Disability Scale, Center for Epidemiologic Studies Depression Scale (CES-D), the Visual Analog Pain Scale, the Arthritis Self-Efficacy Scale for Pain and Other Symptoms, and a Physical Activities Scale. The HAQ Disability Scale, the Visual Analog Pain Severity Scale, the Arthritis Self-Efficacy Scale and the Physical Activities Scale were all also used in this dissertation study. The CES-D was not used in this dissertation study because Gonzalez, et al. (1995) reported problems with translation and concepts with some items not culturally appropriate for Hispanics.

Researchers Lorig, Gonzalez, Ritter, and Nacif de Brey, (1997) found no significant difference in the quality or quantity of data collected by face-to-face interview or telephone interview but did find a significant decrease in quality of data with mail survey alone. However, the quality of data increased $100 \%$ when telephone follow up was used with the mail survey. Telephone follow up of mail survey required less than half the personnel time used in face to face interviews.

Therefore, based on this research information on the effectiveness of various data collection methodology in the Hispanic population, the data collection method selected for this study was a combination of face-to-face interview and telephone interview methods, with all data collection instruments in Spanish and interviews conducted by Spanish speaking individuals. 
In this section, the population of this study and the sample selection are discussed, concluding with the rationale for studying a Hispanic population.

\section{Population}

The population researched was male and female Hispanic older adults with diagnosed arthritis. Older adults were defined as individuals 65 years of age or older.

\section{Sample}

The target sample were all the participants from the South Florida Arthritis SelfManagement Education Program conducted between January 2002 and May 2003. Ethnicity was self-declared. All the participants in the Arthritis Self Management Education Program had their physicians fill out a medical form allowing them to participate in the program and verifying their arthritis diagnosis. Ten, six-week sessions with eight to ten participants were conducted, thus the experimental sample totaled 81 100. All subjects signed informed consent releases. This study was approved by Florida International University Institutional Review Board, \#062701-05 for consent to use human subjects. See Appendix Ifor IRB approval.

\section{Rationale for Studying a Hispanic Population}

Hispanics need to be included in research studies if health care policy is to have accurate information on which to base health care decisions (National Center on Minority Health and Health Disparities, 2003). The Hispanic population has been identified as an underserved population concerning health care (Fiscella, Williams \& Moss, 1997). They have been identified as not accessing the medical system due to mistrust, language 
confusion, lack of funds to pay for the services, and reliance on home remedies (Hooyman \& Kiyak, 1999).

Over the past 15 years, arthritis self management programs have demonstrated an impact on health behaviors, health status, and health care utilization (Hirano, Laurent, and Lorig, 1994), but these programs have not reached the Spanish communities where arthritis is the leading cause of disability (Morbidity and Mortality Weekly Report: Prevalence and Impact of Arthritis by Race and Ethnicity-United States, 1989-1991 1996).

Because arthritis is so common and the symptoms so closely associated with the normal aging process, older people may accept arthritis as an inevitable part of aging. Because of this belief, many fail to seek treatment or to learn self-management strategies to reduce pain and support independent functioning. Minorities such as Hispanics have traditionally been especially reluctant to pursue self-help programs and have been identified as a under-served population in terms of medical care and allocation of resources (Healthy People 2010, 2003).

The Arthritis Foundation, prior to implementing the Spanish Arthritis Self Management Education Program series on a statewide and national level, requires validation to determine the effectiveness of the program in helping Hispanic individuals to improve their quality of health status through self-management of arthritic symptoms. Similarly, in the field of adult education there is the continuous need to validate and verify the effectiveness of educational programs to continue to improve the field of adult education and particularly programs for diverse populations. Although a Spanish Arthritis Self Management Education Program has been delivered in California (Lorig, 2000), the 
generalizability of the research results is questioned as the demographics for that

Hispanic population differ greatly from the demographics of South Florida. The Hispanic population in Miami-Dade County is unique in its composition. The Hispanic population is composed of Cuban, Central American, South American and Caribbean immigrants. Hispanics in California are predominantly from Mexican heritage. Therefore, this study looked specifically at the Hispanic population in Miami-Dade to determine the effectiveness of an arthritis education program in improving the health status and health behaviors of the participants.

\section{Methodological Procedures of this Study}

To understand the procedures in this study, the Spanish Arthritis Self Management Education Program needs to be explained, its administration presented, and the questionnaire procedures and control group procedures discussed.

\section{Explanation of Intervention: Spanish Arthritis Self Management Education Program}

Developed at Stanford University Arthritis Center and adopted by the Arthritis Foundation in 1981, Spanish Arthritis Self Help Course Series is composed of six weekly, two-hour education sessions on the self-management of arthritis symptomology (California Arthritis Partnership Program, 2000). The content of the program is based on a needs assessment study of the concerns of people with arthritis that is, pain, depression, stress reduction, disability, and fear of deformity. The intent of the program is to help persons with arthritis better self manage and problem solve to empower them to deal with their current symptoms and prevent a lifetime of disability and dependence. Topics include for example, basic disease information, relaxation techniques for pain and stress management, how to exercise, how to stretch, pain management, self-massage, 
medication instruction, alternative therapies, safety, and when to call the doctor. The program targets Hispanic older adults as they have traditionally poor access to the health care systems, language barriers, and distrust of the medical systems and professionals. Lay individuals, who have been trained in a two-day workshop to lead the series, run the sessions in Spanish. The Arthritis Association provides educational materials. The Arthritis Foundation does promotion and marketing. The courses are held in local churches, community centers, retirement centers, residential centers, and hospitals. There is no fee to take the course (California Arthritis Partnership Program, 2000), Administration of the South Florida Spanish Arthritis Self Management Program

The South Florida Arthritis Foundation was responsible for promoting, scheduling, registering, and implementing the Spanish Arthritis Self Management Education Program. The Spanish Arthritis Self Management Education Program consisted of a twelve-hour community based program given in two-hour sessions over six weeks. It was taught in community settings and the education centers of medical offices. The programs were held at three locations selected for accessibility for the older Hispanic adults. Two locations were at meeting rooms at medical centers, and the third was at an adult education senior center in a high school. This departed from the more traditional medical education settings of hospitals and clinics and was viewed as more accessible to this population since many of the participants do not routinely access hospitals or even medical care.

All aspects of the program including recruitment, leader training, data collection and course activities were held in Spanish. Leaders were recruited by the Arthritis Foundation. To be eligible for the leader position, the individual had to be Hispanic, 
Spanish speaking, an older adult diagnosed with arthritis, and willing to commit to teach a minimum of two courses per year and to participate in educational training. No previous medical experience was required. Leaders were paid $\$ 10$ per session. To prepare for standardized content delivery, each leader went through an eighteen-hour educational training similar to the actual Spanish Artbritis Self Management Education Program. Program content included an overview of the anatomy and physiology of the various types of arthritis and the effects and uses of medications. Other topics included nutrition, patient/physician communications, and how to problem solve disease related problems. Additionally, participants were assisted to design individualized exercise and cognitive pain management programs (Lorig \& Holman, 1993; Lorig, Mazonson, \& Holman, 1993). See Appendix 2 for sample program agenda.

\section{Questionnaire Administration}

As stated previously in this chapter, a pre and post control group experimental design was used. The pre questionnaires were completed at the first session of the program and the post questionnaires at the last session. Data collection was done in parallel with the control group and experimental group pre and post data collected six weeks apart. Printed directions for every instructor to read in the administration of each questionnaire were required to standardize procedures of data collection. The year post questionnaires for the experimental group were collected by telephone interview one year following the completion of the program. The telephone data were collected by Spanish speaking graduate students from a state university in Southeast Florida. All instruments used were translated and validated in Spanish. See Appendix 3 for pre and post questionnaire data collection instruments. 
The control group for this study was comprised of individuals who registered for the program. When every Hispanic older adult called to register, they were randomly assigned to either the experimental group to start the course immediately or were placed on a waiting list and became part of the control group. The individuals assigned to the control group were contacted by telephone for data collection and told they would have to wait six weeks until a class became available to attend. Because it would be unethical to withhold education from these individuals for one year prior to their attending the program, only pre and six weeks post data were collected from the control group. The control group and treatment group were compared for homogeneity.

\section{Instruments}

Seven instruments were selected to assess the participants' changes in health status and health behaviors. The seven instruments were: Medical Outcomes Study SelfRated Health Item (Ware, Nelson, Sherbourne, \& Stewart 1992), Visual Analogue Pain Scale (Sherbourne, 1992), Health Assessment Questionnaire (HAQ) Disability Scale (Fries, Spitz, Krammes, \& Holman, 1980), Arthritis Self-Efficacy Scale (Lorig, Shoors, \& Holman, 1989), Health Feelings Scale (Gonzalez, Stewart, Ritter, \& Lorig, 1995), Physical Activities Scale (Gonzalez, Stewart, et al., 1995), and self reported physician visits.

Each instrument was completed pre and post for the control group and pre, post, and one-year post for the experimental group. Each data collection instrument is individually described in the following section, grouped under Health Status Instruments and Health Behavior Instruments. The pre and post assessment questionnaire is a 
compilation of the seven instruments and can be found in Appendix 3. Both the Spanish and English translation are presented.

\section{Health Status Instruments}

Health status, defined by the outcomes of general health, pain, disability, selfefficacy and health perceptions was measured using five instruments: Medical Outcomes Study (MOS) Self-Rated Health Item (Ware, Nelson, Sherbourne, \& Sewart 1992), Visual Analogue Pain Scale (Sherbourne, 1992), Health Assessment Questionnaire (HAQ) Disability Scale (Fries, Spitz, Krammes, \& Holman, 1980), Arthritis SelfEfficacy Scale (Lorig, Shoors, \& Holman, 1989), and Health Feelings Scale (Gonzalez, Stewart, Ritter, Lorig, 1995). See Table 3 for the five instruments used to collect data on health status. They are also presented in Appendix 3.

Table 3

Health Status Data Collection Instruments

\begin{tabular}{ll}
\hline Health Status & Data Collection Instrument \\
\hline General Health & MOS Self-Rated General Health Item \\
Pain & Visual Analog Pain Scale \\
Disability & HAQ Disability Scale \\
Self-Efficacy & Arthritis Self-Efficacy Scale \\
Health Perceptions & Health Feelings Scale \\
\hline
\end{tabular}

Self-rated general health item. The Medical Outcomes Study Self-Rated General Health Item was chosen because it assesses general health, an area important in arthritis clinical management (Decker, 1982). It consists of one question on how one perceives 
their general health, "Generally, Would you say your health is... ?". The answers range from excellent (0), very good (1), good (2), regular (3), and bad (4). A higher score reflects worse health. This item is included in many national health surveys (National Health Interview Survey, 2003) and is part of the Medical Outcome Study: Six Item General Health Survey (Ware, Nelson, Sherbourne, \& Sewart, 1992). This single item has strong correlation to an individual's actual health. The self-rated health item has a test - retest reliability of .87 (Gonzalez, Stewart, et al., 1995).

Modified visual analogue pain scale. This instrument was chosen because it assesses pain, an area important in arthritis clinical management (Decker, 1982). The Modified Visual Analogue Pain Scale (Sherbourne, 1992) uses a $10 \mathrm{~cm}$ vertical analog bar graph scale on which subjects are asked to rate the intensity of their arthritis pain during the last week. It has an extensive history of use and has been shown to be reliable (Downie, Leathman, Rhind, Wright, Brenco, \& Anderson, 1978). Internal consistency reliability was .87 (Gonzalez, et al, 1995). The ratings range from $0=$ no pain to $10=$ pain as bad as it could be. Lower scores reflect less pain (Dixon \& Bird, 1989).

Health assessment questionnaire disability scale. The Health Assessment Questionnaire (HAQ) Disability Scale developed by Fries, Spitz, Krammes, \& Holman (1980) assesses eight areas of individual function: dressing and grooming, arising, reaching, gripping, eating, hygiene, walking and errands/chores. This instrument was chosen because it assesses disability, an area important in arthritis clinical management (Decker, 1982). Test-retest reliability ranges from .87 to .96 and its validity has been supported in a number of studies (Ramey, Raynaud, \& Fries, 1992). Internal consistency reliability is high at .91 (Gonzalez, Stewart, Ritter, \& Lorig, 1995). The scale score is the 
mean of these eight categories' scores. Each category is scored by choosing the highest score for any of the questions within that category. Scores range from $0=$ without any difficulty, 1 = with some difficulty, 2 = with much difficulty, and $3=$ cannot perform activity. However, if any aids or devices and/or help from another person are checked, the score is adjusted upward to 2 . Furthermore, if the basic score is already a 2 or 3 , the score remains unchanged. A lower score means less disability (Fries, Spitz, Krammes, \& Holman, 1980.)

Arthritis self-efficacy scale for pain. Self-efficacy, or peoples' belief or confidence in accomplishing certain behaviors or action was assessed because this is the construct upon which the theoretical framework on which the Arthritis Self Management Education Program is built (Lorig, Chastain, Ung, Shoor, \& Holman, 1989). The Arthritis Self-Efficacy Scale for Pain was developed by Lorig, Shoors, and Holman (1989) to measure perceived self-efficacy in persons with arthritis. The reliability is high $(\alpha=.95)$, with a test-retest reliability of $\alpha=.92$, and item to scale correlations $(r)$ ranging From .65 - .83. All items met discriminate validity criteria (Gonzalez, Stewart, et al., 1995). Eight questions are asked on how well a person is in control of their arthritis disease symptom management to determine the confidence people have in performing specific arthritis self-management activities. For each question, the subject is asked to assess their confidence in being able to perform selected activities on a scale of 1-10, with $1=$ very uncertain to $10=$ very certain and to mark same on a visual analog line scale. The score is a mean of the eight items. Total scores range from 1- 8 . Higher scores reflect more confidence in self-management activities (Lorig, Shoor, \& Holman, 1989). 
Health perceptions. Four questions relating to one's perception of feelings about their health were asked of all participants. These questions provided an insight and measured the amount of control one has over one's health and one's preoccupation with one's health. It measures how much the arthritic symptomology are affecting one's feelings about their health (Gonzalez, Stewart, Ritter, \& Lorig, 1995). Scoring for each question, "How much time during the last week...?" is $0=$ Never, $1=$ very few times, 2 = sometimes, 3 = occasionally, $4=$ majority of the time, $5=$ all the time. The health perception score is the mean of four responses. A lower score is indicative of feeling more in control and less preoccupied with their arthritic disease symptoms. No reliability or internal consistency statistics are available for this scale.

\section{Health Behavior Instruments}

Health behavior in this study is defined by amount of time spent performing exercise, both stretching and strengthening and aerobics; and frequency of medical and arthritis physician visits. Health behavior was measured using the following two instruments: Physical Activities Scale (Gonzalez, Stewart, et al., 1995) and self reported physician visits. Refer to Table 4 for the health behavior data collection instruments. They are also presented in Appendix 3.

Physical activities scale. The Physical Activities Scale was used to assess changes in the amount of time spent doing different types of exercise. Exercise is another of the self-management behaviors emphasized in the Arthritis Self Management Education Program and is an integral part of arthritis self management. The Physical Activities Scale is used to assess changes in the amount of time in minutes spent doing different types of exercise. 
Table 4

Health Behavior Data Collection Instruments

Health Behavior Data Collection Instrument

Time Spent Performing Exercise

Stretching/Strengthening

Physical Activity Scale

Aerobics

Physical Activity Scale

Physician Visits

Medical

Frequency

Arthritis

Frequency

during the past week (Gonzalez, Stewart, et al., 1995). The Physical Activities Scale can be divided into two summary measures: total time spent performing stretching and strengthening exercise and total time spent doing aerobic exercise. The test-retest correlations for these two scores were .91 and .89 respectively (Gonzalez, Stewart, Ritter, \& Lorig, 1995). Subjects selected the appropriate amount of time from categories of none (score $=0$ minutes exercised), less than 30 minutes per week (score $=15$ minutes), $30-60$ minutes per week (score $=45$ minutes), $1-3$ hours per week $($ score $=120$ minutes), more than 3 hours per week (score $=180$ minutes). The score for each category is the median number of minutes. Time spent doing stretching and strengthening exercise is the median value for the single item. Time spent doing aerobic exercise is the sum of the median values for items $2-6$ in the instrument that relate to walking, swimming, bicycling, aerobic exercise equipment, and other aerobic exercise. 
Frequency of physician visits. Physician visit frequency was collected for it has been shown that individuals with rheumatic disease average eight physician visits per year, which is twice that of persons with other conditions, costing and estimated 72.3 billion dollars in medical care (Searle/Arthritis Foundation, 1999). Individuals were asked to recall the number of visits to physicians they had gone to in the last four months. They were also asked to recall the number of visits to physicians they had gone to specifically for arthritic complaints. This was numeric data and reported descriptively.

In summary, it was the intent of the Spanish Arthritis Self Management Education Program to educate older Hispanic adults regarding self-management of arthritic conditions and thereby improve the quality of health of participants. Health status and health behavior data were collected through the seven instruments described above and compiled together as the pre, post, and the one-year post questionnaire used in this study. See Appendix 3 for data collection questionnaire.

Treatment of Data

This study questions if the Spanish Arthritis Self Management Education Program for Hispanic older adults with arthritis significantly improved the participants' health status and health behaviors. To answer this question, data collected from the health status and health behavior instruments, described above, were used (see Table 3 for a summary of health status data collection instruments and Table 4 for a summary of health behaviors data collection instruments). In this section, the basic and specific research questions are given, followed with the data collected and how the data were analyzed for the two specific research questions. 
Outcome data from the Spanish Arthritis Self Management Education Program were analyzed using SPSS $\circledast 11.0$ version statistical software with Microsoft Excel® as an ancillary program. Figures and tables included were created with Microsoft Word®. Basic Research Question

Does the health status and the health behaviors of Hispanic older adults with arthritis improve following the participation in the Spanish Arthritis Self Management Education Program?

Basic hypothesis $\left(H_{b}\right)$. The health status and health behavior of Hispanic older adults with arthritis will improve upon completion of the Spanish Arthritis Self Management Education Program compared to adults who do not take the program. Specific Research Questions

Specific research questions 1 and 2 and hypotheses are listed next followed by the data collected and analysis of data used to answer each question.

Question 1. Were there any changes in health status and in health behaviors in the experimental group as compared to a control group based on gender and age before and immediately following completion of the Spanish Arthritis Self Management Program?

Hypothesis 1. The experimental group as compared to a control group and controlling for gender and age before and immediately following completion of the Spanish Arthritis Self Management Program will exhibit significant positive changes in health status and in health behaviors.

Data collected for research question 1. Health status data of self-reported general health, pain, disability, self-efficacy, health perceptions, and health behavior data of 
exercise, and number of physician visits were collected pre and post for the experimental and control group. Refer to Table 3 and Table 4 for specific instruments used.

Analysis of the data for research question 1. In order to compare the experimental and the control group at the start of the education program, independent $t$ - tests were run using the pre questionnaire data on age, self reported general health, pain, physical disability, self-efficacy, health perceptions, physician visits, stretching/strengthening exercise, and aerobic exercise. Cross tabulations and chi-square tests were ran to compare the experimental and control group on categorical variables of gender and type of arthritis.

An analysis of covariance (ANCOVA) using age and gender as covariates and post hoc tests were then run to test the effects of the education intervention pre and post in the control group and the experimental group to answer Specific Research Question 1. The ANCOVA was conducted using the health status data of self-reported general health, pain, disability, self-efficacy, health perceptions, and the health behavior data of exercise, and number of physician visits using age and gender as covariates. The differences pre and post between the control group and experimental group outcomes in general health, disability, pain, self efficacy, health perceptions, exercise, and physician visits were analyzed using $p<.05$ level of significance.

Research question 2 . Were there any changes in health status and health behaviors of the experimental group at the conclusion of the program and one year following completion of the Spanish Arthritis Self Management Program?

Data collected for research question 2. Health status data of self-reported general health, pain, disability, self-efficacy, health perceptions, and health behavior data of 
exercise, and number of physician visits were collected pre, post, and one year following completion of the Spanish Arthritis Self Management Education Program for the experimental group. See Table 3 and Table 4 for specific instruments used.

Analysis of the data for research question 2. A repeated measures ANOVA general linear model was used to determine the changes in health status data of general health, pain, disability, self-efficacy, health perceptions, and health behavior data of exercise, and physician visits for the experimental group pre, post and one year post. The differences between pre, post, and one year post outcomes in general health, disability, pain, self-efficacy, health perceptions, exercise, and physician visits pre were analyzed using $p<.05$ level of significance.

\section{Summary}

The need for health promotion education intervention for Hispanic minorities is evident, as many health disparities exist in the United States related to inequalities in income, education, ethnicity, age, language, and transportation (National Center on Minority Health and Health Disparities, 2003). Healthy People 2010's two central goals serve as a framework for improving the health status of all American. The country is challenged to " 1 ) increase the quality and years of healthy life and 2) eliminate health disparities." (Healthy People 2010, 2001, pp. 7 - 3). Minorities, such as Hispanics are a traditionally underserved population and are in need of access and information to eliminate health disparities and to improve their health status and quality of life. The Spanish Arthritis Self Management Education Program through education of older Hispanic adults regarding self-management of arthritic conditions attempts to improve 
the quality of health status of participants by empowering them with methods of selfmanagement of their arthritic symptoms.

This project was designed to determine if a community based lay led arthritis education program for Hispanic older adults improves the participants' health status and health behaviors as measured by changes in general health, pain, disability, self efficacy, health perception, exercise and frequency of physician visits, and if changes in the participant's health status and health behaviors were maintained for one year post education program. If the education proved successful in helping this underserved and at risk population, the program could be extended to other minority Hispanics to help to eliminate health disparities faced by Hispanic minorities. If the education intervention proved successful, it would help to satisfy the goals of Healthy People 2010 in reducing health care disparities for minorities and in improving the health status of Hispanic older adults with arthritis and help provide evidence on which to base the practice of health education programs with Hispanic adults. If the education intervention proved successful, it would validate the importance of adult education and self-management of arthritic symptomology for health promotion. 


\section{CHAPTER IV}

\section{RESULTS}

This study examined the effectiveness of the Spanish Arthritis Self Management Education Program for Hispanic older adults in Miami-Dade County, Florida to produce desired health changes. The Spanish Arthritis Self Management Education Program effectiveness was determined using questionnaires to collect data on changes in health status and health behaviors as defined by self-reported general health, pain, disability, self-efficacy, health perception, exercise, and physician visits. The health status and health behavior changes one year following the education program were evaluated to determine if the program had long term effectiveness in changing health status and behaviors for the older Hispanic adults with arthritis.

In this chapter, the sample characteristics of attrition and participation, number, age, gender, type of arthritis, health status, and health behaviors of the experimental and the control group using pre questionnaire data are presented, followed by a comparison of the pre and post experimental and control group health status and health behaviors. In addition, for the experimental group, health status and health behavior differences pre, post, and one-year post education program intervention are discussed. The results provide a framework to determine both the short-term and long-term effectiveness of the Spanish Arthritis Self Management Education Program in changing participants' health status and health behaviors.

\section{Sample Characteristics}

In this section, sample characteristics of participation and attrition, age, gender, and type of arthritis are discussed. This is followed by the comparisons of the 
experimental and control group on baseline or pre intervention data for health status and health behaviors. Independent $t$ - tests were run to compare the experimental and the control group at the start of the education program using the pre questionnaire data on age, self reported general health, pain, physical disability, self-efficacy, health perceptions, physician visits, stretching/strengthening exercise, and aerobic exercise. Cross tabulations and chi square tests were run to compare the experimental and control group on categorical variables of gender and type of arthritis.

\section{Participation and Attrition}

From the total sample of 200 individuals who registered for the Spanish Arthritis Self Management Education Program, 100 were randomly placed in the experimental group and 100 were assigned to the control group and wait listed to start the course in six weeks. Of the 100 individuals in the experimental group, 92 completed the Spanish Arthritis Self Management Education program. Regarding the eight individuals who did not complete the program, three individuals did not complete the education program due to illness, one due to transportation difficulties, one due to lack of continued interest, and three individuals could not be contacted to ask why they did not complete the research study. Of the 92 completing the course, 81 individuals completed both pre and six week post questionnaires and were used in the research study. Eleven individuals completed the pretest questionnaire but did not complete the posttest questionnaire, and therefore were not used in the research because of the incomplete data. The incomplete data for eleven subjects was due to one instructor's confusion over the need for both the pre and post questionnaire. 
Of the 101 individuals in the control group, all $101(100 \%)$ completed the pre and six-week post questionnaire and all were included in this study.

Of the 81 individuals in the experimental group who completed the pre and six week post questionnaire, 67 completed the one-year post questionnaire for an attrition rate of $12 \%$. Fourteen individuals did not complete the one-year post survey for the following reasons: telephone disconnected $(n=3)$, refused $(n=7)$, no answer $(n=3)$, and telephone number given was a fax line $(n=1)$. Due to the yearlong duration of the research, some attrition was expected. The $12 \%(n=14)$ attrition rate for this study is acceptable.

Age

The mean age of the control group was significantly older $(M=77.07)$ than the experimental group $(M=72.74), t(179)=3.81, p<.001$. See Table 5 for experimental and control group comparisons by age.

Table 5

Group Comparisons by Age

\begin{tabular}{lcccccc}
\hline & & \multicolumn{3}{c}{ Age } & & \\
\cline { 3 - 5 } Group & $n$ & $M$ & $S D$ & $t$ & $p$ \\
\hline Experimental & 80 & 72.74 & 6.93 & 3.81 & $<.001$ \\
Control & 101 & 77.07 & 8.09 & & \\
\hline
\end{tabular}


Gender

The control group and experimental group were predominantly female with the control group having a significantly lower percentage of females than the experimental group, as determined by a chi-square analysis and significant difference $\chi^{2}(1, N=181)=$ $5.56, p<.02$. The experimental group consisted of $88 \%$ females compared to $73 \%$ of the control group being female. See Table 6 for group comparisons by gender.

Table 6

Group Comparisons by Gender

\begin{tabular}{|c|c|c|c|c|c|c|}
\hline \multirow[b]{2}{*}{ Gender } & \multicolumn{2}{|c|}{ Experimental } & \multicolumn{2}{|c|}{ Control } & \multirow[b]{2}{*}{$\chi$} & \multirow[b]{2}{*}{$\mathrm{p}$} \\
\hline & $\mathrm{n}$ & $\%$ & $\mathrm{n}$ & $\%$ & & \\
\hline Male & 10 & 12.5 & 27 & 26.7 & 5.56 & .018 \\
\hline Female & 70 & 87.5 & 74 & 73.3 & & \\
\hline
\end{tabular}

The control group and experimental group were significantly different in age and gender. The control group was older. Both the control group and experimental group were predominantly female, but the control group had a significantly lower percentage of females than the experimental group.

Arthritis Diagnosis

Osteoarthritis was the most common type of arthritis diagnosis $21(27.3 \%)$ for the experimental group while rheumatoid arthritis is the most common arthritis diagnosis for the control group $31(30.7 \%)$. Of concern is the fact that a large number of persons in both groups did not know their arthritic diagnosis. In the control group, $50(49.5 \%)$ and in 
the experimental group $30(39.0 \%)$ were not aware of the type of arthritis they had been diagnosed with by their physician. There was a significant difference in arthritis diagnosis between the control and experimental group as determined by a chi-square analysis $\chi^{2}(3, N=172)=16.94, p=.001$. Note that arthritis diagnosis categories of gout, ankylosing spondlyosis, and lupus were not used for chi-square analysis because these cells had an expected count less than five. A chi-square analysis was conducted on the categories of osteoarthritis, osteoporosis, rheumatoid arthritis, and don't know what type of arthritis. See Table 7 for type of arthritis by group.

Table 7

Type of Arthritis by Group

\begin{tabular}{|c|c|c|c|c|c|c|}
\hline \multirow[b]{3}{*}{ Diagnosis } & \multirow{2}{*}{\multicolumn{2}{|c|}{$\frac{\text { Experimental }}{(n=77)}$}} & \multirow{2}{*}{\multicolumn{2}{|c|}{$\frac{\text { Control }}{(n=101)}$}} & \multirow{2}{*}{\multicolumn{2}{|c|}{$\begin{array}{l}\text { Total } \\
(n=178)\end{array}$}} \\
\hline & & & & & & \\
\hline & $f$ & $\%$ & $f$ & $\%$ & $f$ & $\%$ \\
\hline Osteoarthritis & 21 & 27.3 & 6 & 5.9 & 27 & 15.2 \\
\hline Gout & 1 & 1.3 & 1 & 1.0 & 2 & 1.1 \\
\hline Osteoporosis & 9 & 11.7 & 11 & 10.9 & 20 & 11.2 \\
\hline $\begin{array}{l}\text { Anklylosing } \\
\text { Spondlyosis }\end{array}$ & 0 & 0.0 & 1 & 1.0 & 1 & .6 \\
\hline Rheumatoid & 14 & 18.2 & 31 & 30.7 & 45 & 25.3 \\
\hline Lupus & 2 & 2.6 & 1 & 1.0 & 3 & 1.7 \\
\hline Don't Know & 30 & 39.0 & 50 & 49.5 & 80 & 44.9 \\
\hline
\end{tabular}


As described previously in this chapter, five instruments were used to assess the health status of the experimental and control groups. These five instruments are presented in Table 8. There was no significant difference found between the self-reported general health of the groups. The control group had a significantly higher average pre education program pain score $(M=6.32)$ as compared to the experimental group $(M=5.51)$ significant at $t(141)=2.41, p=.02$. The control group also had significantly higher average disability scores, $(M=1.41)$ as compared to the experimental group $(M=.66)$ $t(175)=6.8), p<.001$. The control group also had a lower mean efficacy score, $(M=5.11)$ versus the experimental group $(M=6.28), t(178)=4.5, p<.001$. This means the control group was less confident in their abilities than the experimental group. There was a significant difference $t(129)=2.70, p=.01$ between the health perceptions of the two groups. The mean of the control group $(M=2.63)$ was higher than the mean of the experimental group $(M=2.11)$, which means the control group was more bothered by health problems. See Table 8 for health status baseline comparisons.

Based on the pre education program questionnaire (baseline) data, the control group and the experimental group were significantly different on four of the five health status instruments, pain, physical disability, self-efficacy, and health perceptions. The groups were not different in self-reported general health. Overall, the control group reported more pain, were more disabled, had lower self-efficacy, and were more bothered by health problems than the control group. 
Pre Education Program Questionnaire (Baseline) Health Behaviors

As described previously in this chapter, two measures, physician visits and exercise were used to assess the health behaviors of the experimental and control group. The measures are subdivided into general physician visits and physician visits specifically for arthritis, and time spent performing stretching/strengthening exercise and time spent performing aerobic exercise. These measures are presented in Table 9. On the first measure, physician visits, the control group had a significantly higher

Table 8

Pre Questionnaire (Baseline) Health Status by Group

\begin{tabular}{llrrrrr}
\hline $\begin{array}{l}\text { Health Status } \\
\text { Characteristics }\end{array}$ & \multicolumn{1}{c}{ Group } & $n$ & $M$ & $S D$ & $t$ & $p$ \\
\hline General Health & Experimental & 80 & 3.48 & .83 & 1.54 & .13 \\
& Control & 101 & 3.65 & .70 & & \\
Pain & Experimental & 80 & 5.51 & 2.49 & 2.49 & .01 \\
& Control & 101 & 6.32 & 1.84 & & \\
Physical Disability & Experimental & 80 & .66 & .59 & 6.57 & $<.001$ \\
& Control & 101 & 1.41 & .87 & & \\
& Experimental & 79 & 6.28 & 1.92 & 4.52 & $<.001$ \\
Self-Efficacy & Control & 101 & 5.11 & 1.55 & & \\
& & & & & & \\
& Experimental & 79 & 2.11 & 1.48 & 2.83 & .01 \\
Health Perceptions & Control & 101 & 2.63 & .98 & & \\
\hline
\end{tabular}

average number of visits to the physician $(M=3.53)$ than the experimental group $(M=$ 2.03), $t(162)=6.06, p<.001$, although they did not differ in visits to the physician for 
arthritis. For the second measure, exercise, the control group had significantly lower mean stretching exercise time $(M=16.78)$ than the experimental group $(M=34.81)$ $t(122)=2.46, p=.01$, but the two groups did not differ on time spent on aerobic exercise activity. Table 9 summarizes health behavior pre questionnaire baseline comparisons.

Table 9

Pre Education Questionnaire (Baseline) Health Behavior by Group

\begin{tabular}{llrrrrr}
\hline $\begin{array}{l}\text { Health Status } \\
\text { Characteristic }\end{array}$ & Group & $n$ & $M$ & $S D$ & $t$ & $p$ \\
\hline Physician Visits & Experimental & 63 & 2.03 & 1.20 & 6.06 & $<.001$ \\
& Control & 101 & 3.53 & 1.72 & & \\
& Experimental & 59 & 1.19 & 1.15 & 0.59 & 0.55 \\
$\begin{array}{l}\text { Arthritis } \\
\text { Physician Visits }\end{array}$ & Control & 101 & 1.33 & 1.59 & & \\
& & & & & & \\
Stretching & Experimental & 78 & 34.81 & 56.67 & 2.61 & 0.01 \\
Minutes/Week & Control & 101 & 16.78 & 35.45 & & \\
& & & & & & \\
& Experimental & 76 & 25.46 & 49.17 & 0.20 & 0.84 \\
$\begin{array}{l}\text { Aerobics } \\
\text { Minutes/Week }\end{array}$ & Control & 101 & 26.88 & 43.75 & & \\
& & & & & & \\
\hline
\end{tabular}

In summary, based on the pre education questionnaire (baseline) data, the control group was significantly older than the experimental group. They also had significantly more pain, significantly more disability or lower functional abilities, significantly less self-efficacy, and were significantly more bothered by health problems. The control group also had significantly higher frequency of physician visits and performed less 
stretching/strengthening exercise. The two groups self reported general health was equivalent, and the arthritis physician visits, and time spent performing aerobic exercises were not significantly different. Thus, it is apparent from the baseline data analysis that the control and experimental groups were significantly different on some key health characteristics. This baseline group difference is important to note and will be included throughout this chapter and further discussed in Chapter 5.

Differences in Health Status and Health Behaviors -

The Analysis of the Data for Specific Research Questions 1 and 2

To further analyze the data of this study, it is necessary to examine the data in the context of the specific research questions 1 and 2. Both research questions need to be discussed prior to the data being presented.

In order to answer the specific research question 1, whether the Spanish Arthritis Self Management Education Program for Hispanic older adults with arthritis significantly improved the participant's health status and health behaviors as compared to a control group not receiving the education, an ANCOVA was run on each health behavior and health status outcome variables. Before the ANCOVA, homogeneity of slopes was tested for each variable used. Age and gender were used as covariates.

In order to answer if the specific research question 2 , if changes in health status and health behaviors were maintained for one-year following the Spanish Arthritis Self Management Education Program, the pre, post and one year post questionnaire data for the experimental group were analyzed using a repeated measures ANOVA. Health status was measured by self-reported general health, pain, physical disability, self-efficacy and 
health perceptions. Health behavior change was measured using the physical activities scale and frequency of physician visits.

In this section, to answer specific research question 1, of whether the Spanish Arthritis Self Management Education Program for Hispanic older adults with arthritis significantly improved the participant's health status and health behaviors as compared to a control group not receiving the education, the results for pre and post experimental and group differences in health status then health behaviors are discussed for each individual outcome variable.

The results for the pre, post, and one year post questionnaire data differences in health status and health behaviors for the experimental group are presented and discussed to answer specific research question 2 , if changes in health status and health behaviors were maintained for one-year following the Spanish Arthritis Self Management Education Program.

\section{Experimental and Control Group Differences in Health Status}

In order to determine if the education program intervention had a significant effect on health status between the experimental and control group, an ANCOVA was run on the health status data for general health, pain, disability, self-efficacy, and perceived health using age and gender as covariates. Before the ANCOVA was conducted, homogeneity of slopes was tested for each variable. For significant $F$ tests, Bonferroni post hoc tests were carried out on the appropriate means to test for pair wise differences using $p<.05$. In this section, results of each health status outcome variable, general health, pain, disability, self-efficacy, and health perceptions are discussed. 
General health. The main effect of group on general health showed a significant difference between the experimental and control groups on the adjusted means for general health summed over pre and post, $F(1,176)=5.25, p<.023$. The adjusted mean on general health for the experimental group was significantly better (adj $M=3.40$ ) than for the control group ( $\operatorname{adj} M=3.66$ ) where $1=$ excellent health. The interactions between group and time on general health was a significant, $F(1,176)=5.62, p<.019$. See Table 10 for group differences on general health.

Table 10

ANCOVA of General Health by Group and Time

\begin{tabular}{llllll}
\hline Source & $d f$ & $F$ & $p$ & $\eta^{2}$ & power
\end{tabular}

Covariates

$\begin{array}{llllll}\text { Age } & 1 & 1.35 & .25 & .01 & .21\end{array}$

$\begin{array}{llllll}\text { Gender } & 1 & 3.99 & .05 & .02 & .51\end{array}$

$\begin{array}{llllll}\text { Group } & 1 & 5.25 & .02 & .03 & .63\end{array}$

$\mathrm{MSE}_{\mathrm{b}} \quad 176 \quad 1.06$

$\begin{array}{llllll}\text { Time } & 1 & .10 & .75 & .001 & .06\end{array}$

$\begin{array}{llllll}\text { Time X Age } & 1 & .34 & .56 & .002 & .09\end{array}$

$\begin{array}{llllll}\text { Time X Gender } & 1 & .16 & .69 & .001 & .07\end{array}$

$\begin{array}{llllll}\text { Time X Group } & 1 & 5.62 & .02 & .031 & .65\end{array}$

$\begin{array}{lll}\text { MSE }_{\mathrm{w}} & 176 & .12\end{array}$

Post hoc tests revealed that at pre education questionnaire, the experimental group and control group were not significantly different $[\operatorname{adj} M(\exp )=3.48$, adj $M$ (control) $=$ 
3.65], but at post education questionnaire there was a significant difference between the two groups, with the experimental group having a significantly better adjusted mean health score ( $\operatorname{adj} M=3.22$ ) compared to the control group (adj $M=3.68$ ). The experimental group significantly improved from pre to post on general health but the control group remained constant showing no significant improvement. Table 11 shows these adjusted means comparisons for general health.

Table 11

General Health Means Pre and Post Adjusted for Age and Gender

\begin{tabular}{lccc}
\hline \multicolumn{1}{c}{ Group } & $n$ & Pre & Post \\
\hline Experimental & 80 & $3.48_{\mathrm{a}}$ & $3.32_{\mathrm{b}}$ \\
Control & 100 & $3.65_{\mathrm{a}}$ & $3.68_{\mathrm{a}}$ \\
\hline $\begin{array}{l}\text { Note: Column (row) with same subscripts do not differ significantly, Bonferroni test, } \\
p<.05 .\end{array}$
\end{tabular}

Pain. There was a significant interaction of age by group on the pain difference from pre to post, $F(1,174)=5.47, p=.02$. For the experimental group, the older participants showed larger decreases in pain from pre to post, $r=.25, p<.03$, whereas for the control group, no relationship was found, $r=-.05, p=.63$. This violates the homogeneity of slopes in ANCOVA so additional ANCOVAs were conducted with gender but not age as a covariate. Results were similar so the results from the analysis using age and gender are reported.

There was a significant main effect of group on pain $F(1,177)=32.62$, $p=<.001$. There was a significant interaction effect of group by time on pain, 
$F(1,177)=36.20, p<.001$. The experimental adjusted mean over pre and post was 4.87 while the control group adjusted mean was 6.62 . See Table 12 for pre and post differences in pain means adjusted for age and gender.

Table 12

Pain Means Pre and Post Adjusted for Age and Gender

\begin{tabular}{lccc}
\hline \multicolumn{1}{c}{ Group } & $n$ & Pre & Post \\
\hline Experimental & 80 & $5.38_{\mathrm{a}}$ & $4.36_{\mathrm{b}}$ \\
Control & 100 & $6.42_{\mathrm{c}}$ & $6.81_{\mathrm{d}}$
\end{tabular}

Note: Column (row) with same subscripts do not differ significantly, Bonferroni Test, $p<.05$.

At pre education questionnaire, the experimental group reported significantly less pain than control group. At post questionnaire, the experimental group reported significantly less pain than control group. For the experimental group pre education questionnaire pain was significantly greater than post questionnaire pain. For the control group, pre education questionnaire pain was significantly less than post six weeks.

\section{Disability}

There was a main effect of group on disability as seen in the significant difference between the experimental and control groups on the adjusted means for disability summed over pre and post, $F(1,176)=57.03, p<.001$. The adjusted mean of disability for the experimental group was significantly lower $(M=.60)$ than the control group $(M=1.39)$, where the maximum score was 3 . The interaction effect of group and time on disability was significant, $F(1,176)=7.19, p<.008$. See Table 13 . 
Table 13

ANCOVA of Disability by Group by Time

\begin{tabular}{|c|c|c|c|c|c|}
\hline Source & $d f$ & $F$ & $p$ & $\eta^{2}$ & power \\
\hline \multicolumn{6}{|l|}{ Covariates } \\
\hline Age & 1 & 14.72 & $<.001$ & .08 & .97 \\
\hline Gender & 1 & 26.62 & $<.001$ & .13 & 1.0 \\
\hline Group & 1 & 57.03 & $<.001$ & .25 & 1.0 \\
\hline $\mathrm{MSE}_{\mathrm{b}}$ & 176 & .86 & & & \\
\hline Time & 1 & 1.40 & .24 & .008 & .22 \\
\hline Time X Age & 1 & .75 & .39 & .004 & .14 \\
\hline Time X Gender & 1 & .60 & .44 & .003 & .12 \\
\hline Time X Group & 1 & 7.19 & .01 & .039 & .76 \\
\hline $\mathrm{MSE}_{\mathrm{w}}$ & 176 & .03 & & & \\
\hline
\end{tabular}

Poc hoc tests revealed that mean disability score of the experimental group at pre (adj $M=.67$ ) decreased significantly to post ( $\operatorname{adj} M=.53$ ) whereas there mean disability score for the control group at pre ( $\operatorname{adj} M=1.41$ ) showed no significant change at post (adj $M=1.34$ ). There was a significant difference between the experimental and control groups with regard to disability score pre and post with the control group showing more disability at both times. Refer to Table 14 for group differences in disability. 
Table 14

Disability Means Pre and Post Adjusted for Age and Gender

\begin{tabular}{llll}
\hline \multicolumn{1}{c}{ Group } & $n$ & Pre & Post \\
\hline Experimental & 79 & $.67_{\mathrm{a}}$ & $.53_{\mathrm{b}}$ \\
Control & 100 & $1.45_{\mathrm{c}}$ & $1.37_{\mathrm{c}}$
\end{tabular}

Note: Column (row) with same subscripts do not differ significantly, Bonferroni test, $p<.05$.

Self-efficacy. There was a significant difference between the experimental and control groups on the adjusted means for self-efficacy summed over pre and post, $F(1,175)=26.11, p=<.001$ with the experimental group reporting more self efficacy (adj $M=6.52$ ) than the control group (adj $M=5.26)$.

Health perceptions. There was a main effect of group on health perceptions as seen in the significant difference between the experimental and control groups on the adjusted means for health perceptions summed over pre and post, $F(1,173)=14.75$, $p<.001$. The adjusted mean of health perceptions for the experimental group was significantly better ( $\operatorname{adj} M=1.80$ ) than for the control group ( $\operatorname{adj} M=2.44)$ where $0=$ not bothered by ones' health and $5=$ bothered all the time. There was a main effect of time on health perceptions, $F(1,173)=17.21, p<.001$. See Table 15 for group differences in health perceptions. 
Table 15

ANCOVA of Health Perceptions by Group by Time

\begin{tabular}{llllll}
\hline Source & $d f$ & $F$ & $P$ & $\eta^{2}$ & power
\end{tabular}

Covariates

\begin{tabular}{|c|c|c|c|c|c|}
\hline Age & 1 & .02 & .88 & .00 & .05 \\
\hline Gender & 1 & 2.10 & .15 & .01 & .30 \\
\hline Group & 1 & 4.75 & $<.001$ & .08 & 1.0 \\
\hline $\mathrm{MSE}_{\mathrm{b}}$ & 173 & 2.19 & & & \\
\hline Time & 1 & 17.21 & $<.001$ & .09 & 1.0 \\
\hline Time X Age & 1 & 8.93 & $<.01$ & .05 & .84 \\
\hline Time X Gender & 1 & 8.34 & $<.01$ & .05 & .82 \\
\hline Time X Group & 1 & .21 & .65 & .00 & .07 \\
\hline $\mathrm{MSE}_{\mathrm{w}}$ & 173 & .42 & & & \\
\hline
\end{tabular}

Post hoc tests revealed a significant difference between pre and post adjusted means experimental group ( $\operatorname{adj} M=2.36$ ) and adjusted mean for the control group (adj $M=1.88$ ) summed across experimental and control groups, with combined group significantly "improving" from pre to post. Gender was a significant covariate for the difference in health perceptions from pre to post, $F(1,173)=8.36, p<.004$. See Table 16 for group differences in health perception means pre and post. 
Table 16

Health Perception Means Pre and Post Adjusted for Age and Gender

\begin{tabular}{llll}
\hline \multicolumn{1}{c}{ Group } & $n$ & Pre & Post \\
\hline Experimental & 77 & $2.36_{\mathrm{a}}$ & $1.54_{\mathrm{b}}$ \\
Control & 100 & $1.88_{\mathrm{c}}$ & $2.20_{\mathrm{d}}$ \\
\hline
\end{tabular}

Note: Column (row) with same subscripts do not differ significantly, Bonferroni test, $p<.05$.

In summary, health status of the experimental group significantly differed on three of the five variable measures. They reported significant differences in general health, pain and disability but did not show significant differences in self-efficacy and health perceptions. The experimental group's self reported general health improved, while the control group's self reported general health remained constant. While both the experimental group's and the control group's pain levels improved, the experimental group showed significantly more pain improvement than the control. In the experimental group, the older participants showed the most gains in pain improvement. The disability scores of the experimental group improved significantly while the control group disability scores did not. Experimental and Control Group Differences for Health Behaviors

In order to determine if there were significant changes in health behaviors post education program intervention, an ANCOVA was conducted on the data for physician visit frequency, amount of time spent stretching/strengthening and amount of time spent performing aerobic exercise using age and gender as covariates. For significant $F$ tests, Bonferroni post hoc tests were carried out on the appropriate means to test for pair wise 
differences using $p<.05$. In this section, the results of each health behavior variable are discussed.

Physician visit frequency. Physician visit frequency outcome is measured by reporting both the number of physician visits to any physician as well as the number of physician visits specifically for arthritis symptomology. The data outcomes for both categories, physician visits and arthritis physician visits follows.

Physician visits. There was a significant main effect of group on the adjusted means for frequency of doctor visits summed over pre and post, $F(1,151)=28.09$, $p<.001$. The adjusted mean physician visit frequency for the experimental group was significantly lower (adj $M=2.19$ ) than for the control group (adj $M=3.72$ ). The control group saw the physician 1.5 more visits on average than the experimental group. Gender was a significant covariate for the difference, $F(1.151)=7.26, p<.008$. Refer to Table 17 for ANCOVA data on physician visits.

Arthritis physician visits. Main effect of group on arthritis physician visits did not show a significant difference between the experimental group adjusted mean $(\operatorname{adj} M=1.37)$ and control group adjusted mean (adj $M=1.47)$ on the adjusted means for arthritis doctor visits summed over pre and post, $F(1,148)=.14, p=.71$.

Exercise. Outcomes in exercise were measured using data on time in minutes spent performing stretching and strengthening exercises as well as data on time in minutes spent performing aerobic exercise such as walking, bicycling, and swimming. The data results for both exercise categories of time in minutes spent performing stretching/strengthening and aerobic exercise follows. 
Table 17

ANCOVA of Physician Visits (Medical) by Group by Time

\begin{tabular}{lrrrrr}
\hline \multicolumn{1}{c}{ Source } & $d f$ & $F$ & $p$ & $\eta^{2}$ & power \\
\hline Covariates & & & & & \\
Age & 1 & .08 & .78 & .001 & .06 \\
$\quad 1$ & .01 & .91 & .001 & .05 \\
Gender & 1 & 28.09 & $<.001$ & .16 & 1.00 \\
Group & 151 & 5.41 & & & \\
$\quad$ MSE & 1 & .07 & .79 & .001 & .06 \\
Time & 1 & .59 & .44 & .004 & .12 \\
Time X Age & 1 & 7.26 & $<.01$ & .01 & .76 \\
Time X Gender & 1 & .35 & .55 & .002 & .09 \\
Time X Group & & & & & \\
$\quad$ MSE $_{\mathrm{w}}$ & 151 & .862 & & & \\
\hline
\end{tabular}

Time spent performing stretching/strengthening. There was a significant difference between the experimental and control groups on the adjusted means for the amount of time spent stretching/strengthening summed over pre and post, $F(1,172)=$ $21.87, p<.001$. The adjusted mean minutes spent stretching per week for the experimental group was significantly higher $(\operatorname{adj} M=42.48)$ than for the control group ( $\operatorname{adj} M=12.80$ ). There was a significant interaction of group by time on the adjusted mean minutes spent stretching/strengthening per week from pre to post, $F(1,172)=$ $19.15, p<.001$. See Table 18 
Table 18

ANCOVA of Stretching/Strengthening Exercise by Group by Time

\begin{tabular}{|c|c|c|c|c|c|}
\hline Source & $d f$ & $F$ & $p$ & $\eta^{2}$ & power \\
\hline \multicolumn{6}{|l|}{ Covariates } \\
\hline Age & 1 & .84 & .36 & .005 & .15 \\
\hline Gender & 1 & .09 & .76 & $<.001$ & .06 \\
\hline Group & 1 & 21.87 & $<.001$ & 0.11 & 1.00 \\
\hline $\mathrm{MSE}_{\mathrm{b}}$ & 172 & 3143.59 & & & \\
\hline Time & 1 & .07 & .79 & $<.001$ & .06 \\
\hline Time X Age & 1 & .18 & .67 & $<.001$ & .07 \\
\hline Time X Gender & 1 & 2.16 & .14 & 0.01 & .31 \\
\hline Time X Group & 1 & 19.15 & $<.001$ & 0.10 & 1.00 \\
\hline $\mathrm{MSE}_{\mathrm{w}}$ & 172 & 640.07 & & & \\
\hline
\end{tabular}

Post hoc tests revealed that for the experimental group, the mean minutes spent stretching per week significantly increased from pre (adj $M=34.46)$ to post (adj $M=50.50$ ). For the control group, the mean minutes spent stretching per week significantly decreased from pre ( $\operatorname{adj} M=17.31)$ to post (adj $M=8.28)$. There was a significant difference between the experimental and control groups with regard to minutes spent performing stretching/strengthening exercises per week at pre and at post, with the experimental group stretching/strengthening exercises more at each time. See Table 19. 
Table 19

Stretching/Strengthening Means Pre and Post Adjusted for Age and Gender

\begin{tabular}{llll}
\hline \multicolumn{1}{c}{ Group } & $n$ & Pre & Post \\
\hline Experimental & 76 & $34.46_{\mathrm{a}}$ & $50.49_{\mathrm{b}}$ \\
Control & 100 & $17.31_{\mathrm{c}}$ & $8.28_{\mathrm{d}}$ \\
\hline
\end{tabular}

Note: Column (row) with same subscripts do not differ significantly, Bonferroni test, $p<.05$.

Time spent performing aerobic exercise. Considering the main effect of group on aerobic activity, there was a significant difference between the experimental and control groups on the adjusted mean for aerobic activity summed over pre and post, $F(1,170)=$ $4.60, p<.03$. The adjusted mean minutes spent doing aerobic activity per week for the experimental group was significantly higher $(\operatorname{adj} M=31.18)$ than for the control group (adj $M=18.56$ ). There was a significant interaction effect of group by time on the adjusted mean minutes spent doing aerobics per week from pre to post $F(1,170)=$ $30.65, p=<.001$. Refer to Table 20 .

Post hoc tests revealed that at pre test, the experimental group and the control group were not significantly different with respect to minutes per week spent doing aerobic activity $[\operatorname{adj} M(\exp )=24.86, \operatorname{adj} M($ control $)=28.11]$, but at posttest, there was a significant difference between the two groups, with the experimental group spending significantly more time doing aerobic exercise ( $\operatorname{adj} M=37.50)$ compared to the control group ( $\operatorname{adj} M=9.00$ ). For the experimental group, the mean minutes per week spent doing aerobic exercise significantly increased from pre to post, whereas for the control 
group, the mean minutes per week spent doing aerobics significantly decreased from pre to post. Refer to Table 21 .

Table 20

ANCOVA of Aerobic Exercise by Group by Time

\begin{tabular}{|c|c|c|c|c|c|}
\hline Source & $d f$ & $F$ & $p$ & $\eta^{2}$ & power \\
\hline \multicolumn{6}{|l|}{ Covariates } \\
\hline Age & 1 & 4.65 & .03 & .03 & .57 \\
\hline Gender & 1 & 0.99 & .32 & .01 & .17 \\
\hline Group & 1 & 4.59 & .03 & .03 & .57 \\
\hline $\mathrm{MSE}_{\mathrm{b}}$ & 170 & 2679.83 & & & \\
\hline Time & 1 & 1.62 & .20 & .01 & .25 \\
\hline Time X Age & 1 & 0.74 & .39 & .00 & .14 \\
\hline Time X Gender & 1 & 2.71 & .10 & .02 & .37 \\
\hline Time X Group & 1 & 30.65 & $<.001$ & .15 & 1.00 \\
\hline $\mathrm{MSE}_{\mathrm{w}}$ & 170 & 635.21 & & & \\
\hline
\end{tabular}

There were significant differences found between the experimental group and the control group on health behavior outcome variables of frequency of physician visits, and time spent performing stretching/strengthening exercise and time spent performing aerobic exercise. No significant differences were found between the experimental group and the control group the health behavior variables of frequency of physician visits for arthritis. 
Table 21

Aerobic Exercise Means Pre and Post Adjusted for Age and Gender

\begin{tabular}{cccc}
\hline Group & $n$ & Pre & Post \\
\hline Experimental & 74 & $24.86_{\mathrm{a}}$ & $37.50_{\mathrm{b}}$ \\
Control & 100 & $28.11_{\mathrm{c}}$ & $9.00_{\mathrm{d}}$
\end{tabular}

Note: Column (row) with same subscripts do not differ significantly, Bonferroni test, $p<.05$.

Summary Pre and Post Health Status and Health Behaviors

In order to answer the Specific research question 1, whether the Spanish Arthritis Self Management Education Program for Hispanic older adults with arthritis significantly improved the participant's health status and health behaviors as compared to a control group not receiving the education, health status and health behavior outcome data were analyzed using ANCOVAs. The results showed there was a significant difference, that is improvement in the experimental group compared to the control group in three of the five health status outcome variables - general health, pain, and disability, and three of the four health behavior variables - frequency of physician visits, time spent performing both stretching/strengthening exercise, and time spent performing aerobic exercise. There was not a significant difference in health status variables of self-efficacy and health perceptions. There was not a significant difference between the groups in health behavior variables in frequency of physician visits for arthritis.

In response to specific research question 1, the participants in the Spanish Arthritis Self Management Education Program improved in the health status variables of general health, pain, disability and improved in the health behaviors of frequency of 
physician visits, and time spent performing stretching/strengthening exercise and time spent performing aerobic exercise, however, they did not improve in health status variables of self efficacy and health perceptions, and health behavior variables of frequency of physician visits for arthritis. Refer to Table 24 for summary of group differences in health status and health behaviors pre and post participation in Spanish Arthritis Self Management Education Program.

Health Status and Health Behaviors of Participants Pre, Post and One-Year Post Education

So far the differences in health status and health behaviors for the experimental and control group pre and post education intervention have been discussed, but the critical issue for adult education is whether health status and health behaviors can be changed and become established for long term health benefits. To answer specific research question 2, the results of the repeated measures analysis are presented to determine the long-term one-year impact on health behaviors and health status of the participants of the Spanish Arthritis Self Management Education Program. GreenhouseGeisser was used to adjust for sphericity when necessary. Health Status Pre, Post, and One-Year Post

In order to determine the changes in health status one year following the education program, data were collected and analyzed at the start of the program (pre), at the conclusion of the program (post), and one year following the program on general health, pain, disability, self-efficacy, and health perceptions. The results of each health status outcome variable are discussed in this section. Table 22 summarizes the data results for health status by individual outcome variable. 
General health. When looking at health pre, post and year post education program intervention there was no significant main effect of general health. There were no significant differences found between the pre, post, and year post self reported general health.

Pain. The average pre pain score $(M=5.19)$ was significantly higher that the average post pain score $(M=4.31)$, but not significantly different from the year post $(M=4.58)$ pain score. There was no significant difference found between the post and year post scores.

Disability. There was a significant main effect of disability $F(2,109)=7.34$, $p<.002$. The average pre physical disability score $(M=.60)$ was significantly higher than both the average post $(M=.49)$ and year post $(M=.44)$ scores. There were no significant differences found between the average post and the average year post physical disability scores.

Self-efficacy. There was no significant main effect of self-efficacy. There were no differences found between the pre, post, and year post scores of self-efficacy for the experimental group.

Health perceptions. There was a significant main effect of health perception $F(2,130)=6.92, p=.001$. The average pre health perception score $(M=1.94)$ was significantly higher than both the average post $(M=1.49)$ and year post $(M=1.52)$ health perception scores. There was no significant difference found between the average post, and average year post health perception scores for the experimental group. 
Table 22

Health Status Pre, Post, and One-Year for Experimental Education Group

Time of Testing

\begin{tabular}{lcccccccc}
\cline { 3 - 7 } Health Status Variable & $n$ & Pre & Post & Year & $F$ & $p$ & $\eta^{2}$ & power \\
\hline General Health & 67 & $3.51_{\mathrm{a}}$ & $3.33_{\mathrm{a}}$ & $3.43_{\mathrm{a}}$ & 2.18 & .118 & .03 & .44 \\
Pain & 67 & $5.19_{\mathrm{a}}$ & $4.31_{\mathrm{b}}$ & $4.58_{\mathrm{b}}$ & 6.04 & .003 & .084 & .88 \\
Disability & 67 & $.60_{\mathrm{a}}$ & $0.49_{\mathrm{b}}$ & $.44_{\mathrm{b}}$ & 7.34 & .002 & .100 & .89 \\
Self Efficacy & 67 & $6.35_{\mathrm{a}}$ & $6.75_{\mathrm{a}}$ & $6.73_{\mathrm{a}}$ & 2.10 & .127 & .031 & .42 \\
Health Perceptions & 66 & $1.94_{\mathrm{a}}$ & $1.48_{\mathrm{b}}$ & $1.52_{\mathrm{b}}$ & 6.92 & .001 & .096 & .92
\end{tabular}

Note: Means with different subscripts are significantly different using Bonferroni test, $p<.05$.

There were no significant differences for the participants in the Spanish Arthritis Self Management Education Program before, immediately after completion, and one year following health status variables of self reported general health and self-efficacy. There were significant differences in the participants' health status pre and post participation in the education program for pain, disability, and health perceptions, but the changes were not significant from post to year post. When data collected one year following participation in the education is compared to baseline, pre questionnaire data, there were no significant differences in pain, disability, and health perceptions. The participants improved after the program, in health status variables of pain, disability, and health perceptions, but after one year the significant health status improvements were not sustained. 
In order to determine the changes in health behavior one year following the education program, data were collected and analyzed pre, post, and one year following participation in the Spanish Arthritis Self Management Education Program on health behavior outcome variables of frequency of physician visits both for medical and arthritis symptomology, and time spent performing exercise both stretching/strengthening, time spent performing aerobic exercise. The results for each health behavior outcome variable are discussed in this section. Table 23 summarizes the data results for health behavior for each individual outcome variable.

Physician visits. There was no significant main effect of physician visits. There were no differences found between the pre, post, and year post measurements of physician visit frequency.

Arthritis physician visits. There was no significant main effect of physician visits for arthritis. There were no differences found between the pre, post, and year post measurements.

Exercise stretching/strengthening. There was a significant main effect of time spent performing stretching /strengthening exercise $F(2,126)=8.91, p<.001$. The pre average time spent performing stretching/strengthening exercise $(M=39.61)$ was significantly lower than the post average time spent performing stretching/strengthening exercise $(M=56.48)$. This post mean time spent performing stretching/strengthening exercise was significantly higher than the mean year post time spent performing stretching/strengthening exercise $(M=28.36)$, but there was no significant difference found between the pre, and the year post mean time spent stretching/strengthening scores. 
Aerobic exercise. There was a significant main effect of time spent performing aerobic exercise $F(2,111)=3.43, p=.04$. The average time in minutes spent performing aerobics pre $(M=27.62)$ was significantly lower than the average post time in minutes spent performing aerobics $(M=39.52)$ but not significantly different than the average year post score $(M=25.24)$. There was also no significant difference found between the average pre and the average year post time spent performing aerobic exercise.

Table 23

Health Behavior Pre, Post and Year Post in Experimental Group

\section{Time of Testing}

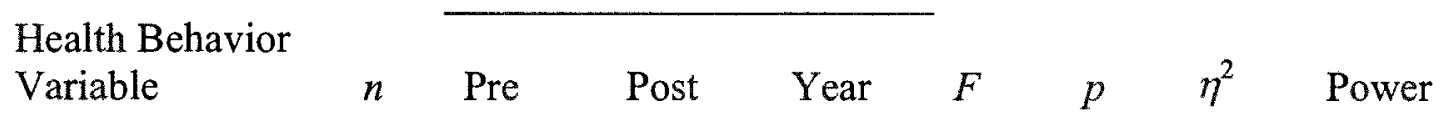

\begin{tabular}{lllllllll}
\hline Physician Visits & 46 & $1.96_{\mathrm{a}}$ & $2.07_{\mathrm{a}}$ & $2.20_{\mathrm{a}}$ & 1.01 & .34 & .02 & .22
\end{tabular}

Arthritis

$\begin{array}{lllllllll}\text { Physician Visits } & 67 & 1.09 \mathrm{a} & 1.30_{\mathrm{a}} & 1.12_{\mathrm{a}} & 1.03 & .34 & .024 & .20\end{array}$

Stretching \&

$\begin{array}{lllllllll}\text { Strengthening } & 67 & 39.61_{\mathrm{a}} & 56.48_{\mathrm{b}} & 28.36_{\mathrm{a}} & 8.91 & .00 & .124 & .97\end{array}$

$\begin{array}{lllllllll}\text { Aerobic Exercise } & 67 & 27.62_{\mathrm{a}} & 39.52_{\mathrm{b}} & 25.24_{\mathrm{a}} & 3.43 & .04 & .052 & .60\end{array}$

Note: Means with different subscripts are significantly different using Bonferroni test, $p<.05$.

In summary, there were no significant differences for the participants in the Spanish Arthritis Self Management Education Program before, immediately after completion, and one year following in the reported health behavior variables of frequency of physician visits and frequency of arthritis physician visits. There were significant 
differences in the participants' health behaviors pre and post participation in the education program for time spent performing stretching/strengthening exercise, and time spent performing aerobic exercise, but the differences were not significant from post to year post. When data collected one year following participation in the education was compared to baseline, pre questionnaire data, there were no significant differences for time spent performing stretching/strengthening exercise, and aerobic exercise. The participants improved immediately after the program, in health behaviors of time spent performing stretching/strengthening exercise, and time spent performing aerobic exercise but after one year the significant health behavior improvements were not sustained and returned to baseline levels.

Summary Health Status and Health Behaviors of Participants One-Year Post Education

To answer specific research question 2 , the results of the repeated measures analysis were presented to determine the long-term one-year impact on health status and health behaviors of the participants of the Spanish Arthritis Self Management Education Program.

The participants in the Spanish Arthritis Self Management Education Program, reported no significant differences pre, post, and one year following completion of the education program in the health status variables of general health and self efficacy and the health behaviors of frequency of physician visits and frequency of arthritis physician visits. The participants reported significant differences pre and post education participation in the health status variables of pain, disability, and health perceptions and in the health behaviors of time spent performing stretching/strengthening and time spent performing aerobic exercise. However, there were no significant differences 
immediately following the education compared to data collected one year later in the same health status variables of pain, disability, and health perceptions and health behavior variables of time spent performing stretching/strengthening and time spent performing aerobic exercise. Although the health status (pain, disability, and health perceptions) and health behaviors (time spent performing stretching/strengthening and aerobics) returned to baselines values, it is important to note that none of the measures decreased below pre questionnaire or baseline scores.

\section{Research Questions Answered}

The analysis of the health status and health behavior changes in the participants of the Spanish Arthritis Self Management Education Program as compared to a control group and the analysis of the pre, post, and one year post health status and health behavior changes of the participants provide the framework for the answers to the basic research question, and the specific research questions 1 and 2 . The basic research question is answered only after discussing the results for the specific research questions 1 and 2.

Specific Research Question 1

To answer specific research question 1, "Were there any changes in health status and in health behaviors in the experimental group as compared to a control group based on gender and age before and immediately following completion of the Spanish Arthritis Self Management Education Program?", health status and health behavior data were analyzed. There were positive health status improvements in three of the five variables measured, general health, pain, and disability pre and post for experimental group as 
compared to the control group. There were no differences in self-efficacy and health perceptions pre and post for the experimental group as compared to the control group.

Hypothesis $\left(H_{l}\right)$. There were significant positive changes in health status and in health behaviors in the experimental group as compared to a control group controlling for gender and age before and immediately following completion of the Spanish Arthritis Self Management Education Program.

This hypothesis is accepted for the health status variables of general health, pain, and disability, but the hypothesis is rejected for the health status variables for selfefficacy, and health perceptions. The results support the acceptance of the hypothesis for improvement in the health status variables of general health, pain, and disability. The self-efficacy and health perceptions both groups improved, but there was not a significant group difference, so the hypothesis for improvements in self-efficacy and health perceptions was rejected.

The results support the acceptance of the hypothesis for improvement in the health behavior of the experimental group as seen in the improved time spent stretching/strengthening and improved time spent performing aerobic exercise as well as the reduced frequency of physician visits for the experimental group. No change was seen in the frequency of arthritis physician visits.

There was a significant improvement in the health status and health behavior of Hispanic older adults with arthritis following the completion of the Spanish Arthritis Self Management Education Program therefore the hypothesis is accepted. Although all health status and health behaviors did not significantly improve, the majority, three of the five health status variables and three of the four health behaviors improved. Improvements for 
six of the nine health outcome variables were found pre to post education program. This supports the hypothesis of significant improvement in the health status and health behaviors of Hispanic older adults with arthritis following completion of the Spanish Arthritis Self Management Education Program. See Table 24 for a summary of the pre and post health status and health behavior differences of the experimental and control group.

Specific Research Question 2

To answer the specific research question 2 , "Were there any changes in health status and health behaviors of the experimental group at the conclusion of the program and one year following completion of the Spanish Arthritis Self Management Education Program?" data was collected on health status and health behaviors for the participants of the Spanish Arthritis Self Management Education Program, and a repeated measures analysis of variance was performed to analyze any changes. These results determined the long-term one-year impact on health behaviors and health status of the participants of the Spanish Arthritis Self Management Education program.

Hypothesis $\left(\mathrm{H}_{2}\right)$. There were significant improvements in the participants' health status and health behaviors immediately following completion of the program and one year following completion of the Spanish Arthritis Self Management Program.

This hypothesis is rejected. The participants did not reflect changes pre, post, or year post participation in the Spanish Arthritis Self Management Education Program for the health status variables of self reported general health and self efficacy and did not reflect changes in the health behaviors variables of frequency of physician visits 
Table 24

Changes in Health Status and Health Behavior from Pre to Post Test of the Control and Experimental Groups

\begin{tabular}{llcl}
\hline Source & Control & Experimental & Explanation \\
\hline *General Health & No change & Improved & \\
*Pain & Improved & Improved & Experimental improved \\
& & & significantly more. \\
*Disability & No change & Improved & \\
Self Efficacy & Improved & Improved & Both groups improved but \\
& & & no significant group \\
& & & difference. \\
Health & Improved & Bmproved & Both groups improved but \\
Perceptions & & no significant group
\end{tabular}

\section{Health Behavior}

*Physician Visits Increased Decreased

Arthritis Visits No change No change

*Stretching/ Decreased Increased

Strengthening

*Aerobic Exercise Decreased Increased

Note: ${ }^{*}$ denotes variable where significant changes $(p<.05)$ were observed. 
or frequency of physician visits for arthritis. The participants did show improvement immediately following the course for the health status variables of pain, disability, and health perception and for the health behaviors variables of time spent performing stretching/strengthening exercise and time spent performing aerobic exercise, but these gains made in health status and health behavior were not sustained for one year following the education. The health status and health behaviors variables that improved following participation in the Spanish Arthritis Self Management Education Program, returned back to baseline values after one year and no significant differences were found one year following completion of the education when compared to pre education questionnaire or baseline values. Although the health status (pain, disability, and health perceptions) and health behaviors (time spent performing stretching/strengthening and aerobics) returned to baselines values, it is important to note that none of the measures decreased below pre education questionnaire or baseline scores.

\section{Basic Research Question}

The answer to the basic research question of this study, "Was there an improvement in the health status and the health behaviors of Hispanic older adults with arthritis following the participation in the Spanish Arthritis Self Management Education Program?" develops from the results of specific research questions 1 and 2.

Basic hypothesis $\left(H_{b}\right)$. There was a significant improvement in the health status and health behavior of Hispanic older adults with arthritis following the completion of the Spanish Arthritis Self Management Education Program.

This hypothesis cannot be fully accepted. Although there was an improvement in the majority of the health status variables and the health behavior variables of Hispanic 
older adults with arthritis following the participation in the Spanish Arthritis Self Management Education Program, not all showed improvement. Improvements in health status and health behaviors were shown immediately following the course. However, when the long term health improvements were analyzed, no health status or health behavior variable significantly improved from pre baseline status to one year following the program. Therefore, there were no long-term health improvements found after participation in the Spanish Arthritis Self Management Education Program and the hypothesis for long-term health benefits must be rejected.

In the following chapter, the implications of the results presented here will be explained and discussed for their impact in the field of health promotion, adult education, and personal health benefits. 


\section{CHAPTER V}

\section{DISCUSSION}

This study examined the effectiveness of the Spanish Arthritis Self Management Education Program for Hispanic older.adults in Miami-Dade County, Florida to produce desired changes in health status and health behaviors. The effectiveness of the Spanish Arthritis Self Management Education Program was determined using questionnaires to collect data on outcomes in health status and health behaviors as defined by self-reported general health, pain, disability, self-efficacy, health perceptions, physician visits, and time spent exercising. The health status and health behavior changes one year following the education program were evaluated to determine if the program had long term effectiveness in changing health status and behaviors for the older Hispanic adults with arthritis.

In this chapter, a brief overview of the study is given followed by a discussion of the results from Chapter 4. The conclusion and discussion is based on the answers to the Basic and Specific Research questions of this study. The significance of this study is then described within the framework of adult education and health promotion and national health goals.

\section{Overview of the Study}

Although not a leading cause of death, arthritis is the most common chronic condition affecting older people and is a major cause of limited activity (Arthritis Fact Sheet, 2000). In Florida alone, arthritis affects over three million people. This translates into approximately 20 percent of all Floridians being affected by arthritis. According to the Florida Behavioral Risk Factor Surveillance Systems Data (2000), the prevalence 
rate for Hispanics with arthritis is estimated at 25 percent. Minorities such as Hispanics have traditionally been reluctant to pursue self-help programs, and have been identified as an under-served population in terms of medical care and allocation of resources (Fiscella, Williams \& Moss, 1997). Although during the past 15 years, arthritis selfmanagement programs in English have demonstrated positive impact on health behaviors, health status, and health care utilization (Hirano, Laurent, \& Lorig, 1994), these programs have not reached the Spanish communities where arthritis is the leading cause of disability (Morbidity and Mortality Weekly Report: Prevalence and impact of arthritis by race and ethnicity-United States, 1989-1991, 1996).

Purpose

The purpose of this study was to examine the impact of one such health promotion education program, the Spanish Arthritis Self Management Education Program, in improving the health status and health behaviors of Hispanic older adults with arthritis in Miami-Dade County, Florida. The Spanish Arthritis Self-Management Education Program is a community health education program developed at Stanford University Arthritis Center (California Arthritis Partnership Program, 2000). It is composed of six weekly, two-hour education sessions on the self-management of arthritis symptoms. The intent of this program is to help Hispanic older adults with arthritis better self manage and problem solve, to empower them to deal with their current symptoms, and to prevent a lifetime of disability and dependence.

The effectiveness of the Spanish Arthritis Self Management Education Program was determined by evaluating changes in the health status and health behaviors of the participants, Hispanic older adults with arthritic symptoms. Health status was measured 
using carefully selected survey instruments that collected data on self reported general health, pain, disability, self-efficacy, and health perceptions. Health behaviors were measured by amount of exercise and frequency of physician visits. This research asked the question, "Was there an improvement in the health status and the health behaviors of Hispanic older adults with arthritis following the participation in the Spanish Arthritis Self Management Education Program?

\section{Subjects}

The subjects for this study were participants from the Spanish Arthritis SelfManagement Education Program. Hispanic older adults were defined as males or females 65 years of age or older with self-reported Hispanic heritage. With eight educational sessions for 10-12 participants, the total sample was comprised of 80 subjects in the experimental group and 101 in the control group.

\section{Methodology}

A pre and post control group experimental design was used to assess the differences pre and post participation in the Spanish Arthritis Self Management Education Program. Subjects when registering for the program, were randomly placed in an experimental group to start the Spanish Arthritis Self Management Education program immediately or were placed on a waiting list for the next offering of the program. The experimental group completed the pre questionnaire the first week of class and a post education program questionnaire was completed at the last class six weeks later. The subjects on the wait list formed the control group. The control group was given the same pre education questionnaire as the intervention group and was surveyed again six weeks later when they were taken off the wait list and put into an education program. 
Demographic data (gender, age, and type of arthritis) were collected for all participants. Analyses of covariance (ANCOVA) were used to determine the pre and post differences in health status and health behaviors for the experimental and control group using gender and age as covariates.

To determine long-term effects of participation in the Spanish Arthritis Self Management Education Program a repeated measures design was used. Data on health status and health behavior were collected for the experimental group pre, post, and one year following completion of the program. One-year data were not collected for the control group as it would be unethical to withhold medical health education for one-year duration. Repeated measures analyses of variance (ANOVA) and post hoc tests, alpha $=.05$, were done to determine differences in the pre, post, and one year outcomes on the questionnaire measures (Merriam \& Simpson, 1995).

Seven instruments were used to assess the participant's changes in general health, pain status, disability, self-efficacy, health perceptions and amount of exercise, and physician visits. The seven instruments were the following: Medical Outcomes Study Self-Rated Health Item (Ware, Nelson, Sherbourne, \& Stewart 1992), Visual Analogue Pain Scale (Sherbourne, 1992), Health Assessment Questionnaire (HAQ) Disability Scale (Fries, Spitz, Krammes, \& Holman, 1980), Arthritis Self-Efficacy Scale (Lorig, Shoors, \& Holman, 1989), and Health Feelings Scale (Gonzalez, Stewart, Ritter, \& Lorig, 1995), Physical Activities Scale (Gonzalez, Stewart, et al., 1995), and self reported physician visits. The Spanish versions of these instruments have met acceptable levels of reliability and validity as researched by Gonzalez, et al. (1995). These scales are widely used in 
arthritis, medical evaluation, and health services research to measure changes in physical function, health, and pain levels.

Results and Discussion of Research Questions

This study is driven by the basic research question, "Was there an improvement in the health status and the health behaviors of Hispanic older adults with arthritis following the participation in the Spanish Arthritis Self Management Education Program?". To fully answer this basic research question, the specific research questions 1 and 2 must be discussed.

Specific Research Question 1

The specific research question 1 is, "Were there any changes in health status and in health behaviors in the experimental group as compared to a control group controlling for gender and age before and immediately following completion of the Spanish Arthritis Self Management Education Program?" First, the pre or baseline group differences need to be addressed and then the specific research question 1 can be answered in the context of the health status and health behavior differences between the control and experimental group at pre and immediately following the Spanish Arthritis Self Management Education Program.

Health Comparisons Pre Education Questionnaire

In terms of health status, the control group reported more pain, more disability, lower self-efficacy, than the experimental group but reported no difference in health perceptions. In terms of health behaviors, the control group reported more physician visits, spent less time stretching/strengthening, but reported no differences in arthritis physician visits and time spent performing aerobics than the experimental group. It 
should be noted that these differences occurred even with randomization of the subjects in the research design.

The experimental group was, in essence, a healthier cohort than the control group. This baseline health difference between the control and experimental group is a limitation of this study. With healthier individuals, it is often more difficult to see large changes in one's health reflected in questionnaires. Often the instruments are not sensitive to subtle but important functional individual, changes in health. Despite this, when compared to the control group, the experimental group post education still reflected improvement in health status and health behaviors when pre-questionnaire differences were adjusted within the ANCOVA statistical analysis. This lends even more support to the evidence of the education program being successful in changing behaviors and changing health status of the participants post education.

However, it is difficult to know whether the healthier experimental group showed improvement because they were physically and mentally more robust when compared to the control group.

Both groups self reported their general health as fair to poor, but it is the control group that is more bothered by, worried about, or preoccupied with their health. Persons with arthritis are constantly reminded of their disease within the daily fluctuations of pain, swelling, and weakness and joint immobility. Because of this, it seems appropriate that the self reported health of both of the groups would range in the fair to poor levels. It also seems appropriate that the control group, an older, more disabled cohort would report being more preoccupied with their health than the younger, healthier experimental group cohort. 
Age comparisons. The control group in this study was older than the experimental group. Clinical measures clearly indicate the decline of health with advancing age. Older adults are more likely to have chronic conditions that limit their activities. Increasing life span is associated with an increased prevalence of disease and functional disability in the elderly population (Bottomley \& Lewis, 2003). Therefore, the control group by being older may have also presented with generalized poorer health and disability than the experimental group.

Arthritis diagnosis comparisons. Some of the difference between the control and experimental group at pre questionnaire may be due to the larger number of persons in the control group $30.7 \%(n=31)$ with a diagnosis of rheumatoid arthritis. As rheumatoid arthritis is often more debilitating functionally than other arthritic diagnoses, this may help explain some of the health differences in the control and experimental groups. Persons with rheumatoid arthritis are commonly diagnosed earlier usually in their 30's or 40 's while persons with other types of arthritis are more commonly diagnosed in their 60 's -70 's. Persons with rheumatoid arthritis usually present with more joint deformity and more physical disability than those persons with osteoarthritis (Falvo, 1999). This difference in arthritis diagnosis and older age, may help to explain further the increased disability, and poorer self reported and perceived health in the control group.

Another finding of concern, was the large number of subjects who did not know the type of arthritis for which they were diagnosed. This is extremely important information for arthritis self-management because different types of arthritis are managed differently. Without knowing one's arthritic diagnosis, it is truly possible to be treating the arthritic symptoms incorrectly and possibly even causing harm. This is an area 
should be emphasized in the Spanish Arthritis Self Management Education Program content. With such a large percentage in both experimental and control group not being aware of their individual arthritis diagnosis, we have the possibility of $30-40 \%$ of the individuals in the study who may be incorrectly managing symptoms because of lack of knowledge. This lack of knowledge could stem from the minimal access to medical care and limited number of physician visits of the Hispanic individuals. Somewhere in the delivery of the health care to these individuals, basic information is either not being processed or received leaving these individuals at risk for increased arthritic disability due to possible erroneous management.

Attrition rate. The low attrition rate ( $12 \%$ for one year) for this study was acceptable. It is difficult to obtain data after a year post intervention. Many Hispanic individuals are extremely reluctant to give out personal information in person much less over the telephone to individuals that they do not know (Lorig, Gonzalez, Ritter, \& Nacif de Brey, 1997). As discussed earlier, telephone contact was a better means of gathering information from Hispanic individuals then a written survey (Lorig, Gonzalez, Ritter, \& Nacif de Brey, 1997). This study concurs with prior research on the effectiveness of on site and telephone data acquisition. It was to the interviewers credit and uniform practiced speech that seemed to exude trust as well as the added advantage that we were calling under the auspices of the South Florida Arthritis Foundation that may have helped produce the minimal attrition rate for this study.

In summary, the baseline differences in the health status and health behaviors between the control and experimental group was a limitation in this study. These differences occurred despite the randomization of subjects in the experimental design. 
The experimental group was a healthier, more robust cohort than the control. They were younger, reported less pain, less disability, higher self-efficacy, and were less bothered by their arthritis symptoms. The experimental group saw their physicians less and spent more time performing stretching and strengthening exercises. These differences in baseline health could affect the final health changes and range of health changes for the groups.

Group Differences Pre and Post Spanish Arthritis Self Management Education Program Participation

Now since the baseline group differences have been discussed, the differences in the health status and health behaviors of the participants in the Spanish Arthritis Self Management Education Program as compared to the control group follows. Each health status and health behavior variable outcome is discussed to answer specific research question 1.

Health Status

There were significant differences found between the control group and the experimental group in the health status variables of general health, pain, and disability. There were no differences in the group for changes for self-efficacy. Both groups improved in health perceptions but there was no significant difference between the groups.

General health. Asking people to rate their own health as excellent, very good, good, fair, or poor provides a common indicator of health easily measured in surveys. It represents physical, emotional, and social aspects of health and well-being (Idler \& Benyamini, 1997). Good to excellent health correlates with lower risk for mortality 
(Idler \& Benyamini, 1997). Participants in the Spanish Arthritis Self Management Education Program, reported their health in the good to very good range after the education and showed improvement in self-reported general health as compared to the control group who reported their health in the fair to good range. The participants or experimental group reported they were in overall better health after participating in the program. The experimental group averaged responses of "Good" health while the control group averaged responses in "Fair" or "Poor" health. With only five categories of selfrating of general health (excellent, very good, good, fair, poor) an entire category different is not only statistically but clinically relevant as well. Better health correlates to lower risk for mortality. The participants in the Spanish Arthritis Self Management Education Program saw themselves as healthier after the program.

Pain. The control group reported more pain than the experimental group on the pre questionnaire. After participating in the education program, the experimental groups' pain significantly decreased, while the control groups' pain significantly increased. The control group had more pain pre and post than the experimental group. There was an interaction effect with age in the experimental group, with those who were older reporting a greater reduction in pain. This means the older individuals profited more in terms of pain relief from the program. It also concurs with arthritis pain being a progressive disease in that even after six weeks, the control group without the education intervention experienced and reported increased pain symptomology from their arthritis.

Although there was a significant difference in reported pain post education program, the difference may not be clinically relevant. With a visual analog pain scale range of $0-10,0=$ no pain, $10=$ worst pain you have ever had, it is difficult to determine 
that a mean difference of approximately .81 in the scale is clinically relevant. Is a pain level of 5 functionally different than a pain level of 6 ? In the outcome of pain, although statistically significant, the functional translation is not clinically apparent. One might argue that any reduction in pain improves function, but with so minimal a change even if significant, it is difficult to conclude any definitive clinical relevance.

Disability. There was a significant improvement in the physical functioning of the participants after participating in the Spanish Arthritis Self Management Education program as measured by the physical disability score. This score takes into account how well one performs many daily activities, amount of assistance needed, and ambulation activity. It is a reflection on one's physical ability to perform life tasks. The experimental group showed significant improvement in physical functioning by having a lower disability score. This is important because the most important aspect of arthritis self management is to learn how to pace oneself to stay active within the pain and joint Self-efficacy. Self-efficacy or the belief one has in their successful ability to perform activities was not significantly different post course in the control and experimental groups. This contradicts similar results of the Lorig Arthritis Self Management Program findings in the English speaking population (Lorig \& Mazonson, 1993). Lorig links self-efficacy changes as the driving force behind the success of the education programs. The MacArthur Aging Studies showed self-efficacy as a consistent predictors of sustained activity in old age (Glass, Seeman, Herzof, Kahn, \& Berkman, 1995). The Hispanics of South Florida did not show the same results as the Hispanic populations in California or the participants in the English version of the Arthritis Self Management Programs. 
However, this no change in self efficacy, or belief in one's one power and ability to make changes, may be explained by the expectation for the predominantly Cuban culture that assigns higher value on persons in power and authority, such as physicians as being best to determine their individual course of medical treatment (Smart \& Smart, 1992).

It is also consistent with the concept of the fatalistic Cuban Hispanic culture that is based on an external locus of control. Fate determines one's path. Control is outside of the individual (Grossman, 1997). Therefore, in the predominant fatalistic Hispanic culture in Miami, the concept of self-efficacy was of the not the same critical import as seen in other Anglo and Hispanic studies. Self-efficacy did not show significant differences between the control and experimental group after participation in the Spanish Arthritis Self Management Program.

Lorig's theory of changes in self- efficacy being the motivating and driving force behind health changes was not seen in this study. The participants did show changes in health, despite not showing changes in self-efficacy. It appears according to this study with of Hispanic older adults in South Florida, the theory of increased self efficacy as being a predictor of health changes is not substantiated by the results.

Health perceptions. There was a significant difference post education between the control and experimental groups on health perceptions, or how bothered they were by their arthritic symptomology. If I were fatalistic in outlook, my feelings about my health and my control over my health would not be of critical import. "My health is always God's hands, but now I am helping too!' was one written response on the health perception section of the questionnaire. This is a lucid example of the changed perception 
for the participant in reference to the external, fatalistic, powerless view often attributed to individuals of Hispanic heritage. However, after the course, participant's views on their health were less fatalistic and depressive. The course helped change their perception or outlook on how they cope with the disease of arthritis.

\section{Health Behaviors}

There were significant improvements in health behaviors in the experimental group as compared to the control group for time spent exercising both stretching/strengthening and aerobics. Participants visited their physicians less often than individuals in the control group did. They did not differ from the control group in frequency of physician visits for arthritis. Each health variable outcome is discussed separately in the following text.

Exercise. There was a significant difference pre and post education intervention between the control and experimental group in the amount of time in minutes per week spent performing stretching and strengthening exercise as well as the amount of time spent performing aerobic exercise. This is an important finding because one main aspect in the education of self management of arthritis is explaining and emphasizing the critical aspect of exercise in reducing and preventing pain, joint deformity and immobility. Inactivity breeds immobility, immobility breeds pain, pain breeds joint deformity, joint deformity breeds disability and more inactivity until the vicious and insidious disabling downward spiral begins and the individual's functional abilities slowly decrease towards dependence. Individuals who exercise will experience better health. In this study, the participants were more active than the controls in both types of exercise. This is important because, if there is one behavior change that will impact older adult's quality 
of life with arthritis, it is increasing the amount of physical activity performed daily (Arthritis Prevalence and activity limitations- United States, 1990, 1994).

Physician visits. There was a significant difference in the number of physician visits over the last four months between the control and experimental group. This finding concurs with Lorig's findings of decreased physician visits and consequent monetary savings to the overburdened Medicare medical reimbursement system (Lorig \& Mazonson, 1993). The adjusted mean frequency of the experimental group physician visits was 1.5 less than the adjusted mean frequency of the control group. If this visit reduction were translated into monetary values, at approximately $\$ 150$ per visit, it would add up to an average cost savings of approximately $\$ 225$ per participant.

Arthritis physician visits. There was not a significant difference in the frequency of visits to the physician for arthritis between the control and experimental group. Part of the education program covers when to see your physician for arthritis care. This result may be explained by assuming the individuals may have already been seeing their physicians regularly or that the Hispanic individual is already at the lower end of the number of physician visits per year as reported ( $M=1.2$ arthritis $\mathrm{MD})(M=2.32$ physician visits) as compared to studies done in the Anglo population reporting means of four physician visits (Lorig \& Mazonson, 1993). If they are already on the lower frequency of physician visits, it does not make sense to think the subjects should reduce physician visit frequency further. In reality, since Hispanics are already identified as having reduced access to and availability of health care, perhaps it is an increase and not a decrease in arthritis physician visit frequency that should be encouraged. 
In summary, three of the five health status variables (general health, pain, and disability significantly improved and three of the four health behavior variables improved (frequency of physician visits, time spent performing stretching/strengthening exercise and time spent performing aerobic exercise). Therefore, the majority of the health status and health behavior variables improved. In response to specific research question 1 , the participants as compared to a control group did show significant improvement after participating in the Spanish Arthritis Self Management Education Program. Specific Research Question 2Differences in Health Pre, Post and One-Year Post

Differences in health status and health behavior one-year post education are the basis for specific research question 2 . Specific research question 2 is, "Were there any changes in health status and health behaviors of the experimental group at the conclusion of the program and one year following completion of the Spanish Arthritis Self Management Education Program?"

Health status and health behaviors of the participants in the Spanish Arthritis Self Management Education Program, showed no significant differences from post to year post in general health, disability, pain, self efficacy, health perceptions, physician visits, arthritis physician visits, and time spent performing stretching exercise and aerobic exercise. However, none of the measures decreased below pre questionnaire scores. Each health status and health behavior variable outcome is discussed in the following sections. 


\section{Health Status}

The differences in the health status variables of general health, pain, disability, self-efficacy, and health perceptions pre, post, and one year following the Spanish Arthritis Self Management Education Program follows.

General health. Self reported general health was not significantly different pre, post, and one-year post education program in the experimental group. The participants' views of their overall health did not change significantly. However, since arthritis is a chronic disabling disease with progressive symptomology, it is important to note that the participants' views on their general health did not decrease over the span of one year.

Pain. Pain was decreased from pre to post education. However, the pain reduction seen immediately post education was not sustained for one year. There was no significant decrease in pain from pre to year post. Since arthritis is a chronic disabling disease with progressive symptomology, it is important to note that the participants' reported pain did not worsen over the span of one year. Pain maintenance thusly was achieved long term for the participants. It can be questioned however, that the small range of decreased pain for the participants, although a statistically significant finding is of limited clinical relevance.

Disability. Disability was decreased from pre to post education. This means after participating in the Spanish Arthritis Self Management Education Program, subjects reported improved functional abilities. The level of improved functional abilities was not sustained for one year, however it did not decrease past the initial baseline status. Once again, the fact that the participants' function did not decline significantly over the span of 
one year is encouraging within the framework of a disabling, progressive, chronic disease such as arthritis.

Self-efficacy. There were no differences found between the pre, post, and year post ratings for self-efficacy. This finding is in contrast to the Lorig studies which reported changes in self-efficacy after the Arthritis Self Management Education Program as lasting as long as four years without formal reinforcement (Lorig \& Holman, 1993). It is possible that the fatalistic, external locus of control aspects of the Miami Hispanic culture are not as easily adapted. The theory of increased self-efficacy predicting changes in health was not substantiated in this study.

Health perceptions. The pre health perceptions score was significantly higher than both post and year health perception score. This means that the individuals after the education were less bothered by their arthritic symptomology. However, the gains in health perception from post to year post were not sustained. Once again, it is important to note there were not decreases to baseline after one year. The course did help participants feel less bothered by their arthritic symptomology.

\section{Health Behaviors}

The differences in the variables of physician visits, arthritis physician visits, time spent performing stretching/strengthening, and time spent performing aerobic exercise pre, post, and one year following the Spanish Arthritis Self Management Education Program follows.

Physician visits and physician visits for arthritis. There were no significant differences found in frequency of physician visits or frequency of physician visits for arthritis pre, post, and year post. This is in conflict with Lorig studies that report a 
significant reduction in the frequency of physician visits post Arthritis Self Management Education Program for English speaking individuals (Lorig, 1999). Part of the education program covers when to see your physician for arthritis care. Again, as previously pointed out, Hispanic individuals may have already been seeing their physicians minimally. The Hispanic individual is already at the lower end of the number of physician visits per year as reported ( $M=1.2$ arthritis $\mathrm{MD})(M=2.32$ physician visits) as compared to studies done in the Anglo population reporting means of four physician visits (Lorig \& Mazonson, 1993). Hence, a decrease in frequency of physician visits would not be expected since the Hispanic participants frequency of physician visits is already low.

Stretching/strengthening and aerobic exercise. Time spent performing stretching and strengthening exercise increased significantly pre to post education. However, amount of time spent stretching and strengthening decreased over the year reverting to the baseline activity levels. The same results were found for time spent performing aerobic exercise activity.

These results of long-term exercise non-compliance are unfortunate because exercise is a major component of arthritis management. These findings again are not consistent with prior studies on the Anglo population (Lorig \& Holman, 1993) that report increased time spent exercising post program to be maintained for even up to four years without reinforcement.

Exercise in minority populations is often viewed as unnecessary. It is a low priority for persons more concerned with managing every day activities. In the Hispanic population, exercise and physical activity may carry a stigma of menial labor. It is 
possibly for these reasons, the Hispanic population in Miami did not value and continue with exercise as a self-management tool. Exercise compliance is difficult in any population. It is suggested that reinforcement after the course might prove successful in helping to achieve better exercise compliance and certainly could be the basis for future study.

\section{Basic Research Question}

Having examined all the data within the framework of the two specific research questions the basic research question can now be discussed. The basic research question, "Was there an improvement in the health status and the health behaviors of Hispanic older adults with arthritis following the participation in the Spanish Arthritis Self Management Education Program?" can be answered.

The answer to the basic research question is yes, with qualifications. There was significant improvement immediately post course in the majority of health status and health behavior variables, however the improvements were not sustained for one year. So the program presents with limited success. It is important to note however, that the participants' health, although not improved in the long term, did not deteriorate as typically expected in aging individuals with arthritis, a chronic, progressive debilitating disease. Therefore, health of the participants by merely maintaining baseline health levels and by not deteriorating could be considered an improvement in health.

Significance and Impact of theSpanish Arthritis Self Management Education Program

In this section, the significance of this study for Hispanic individuals, the impact of the Spanish Arthritis Self Management Education Program on adult education, and on health promotion are discussed. 
Hispanic older adult participants in the six-week Spanish Arthritis Self Management Education program showed significant improvement in health status and health behaviors as compared to a control group not receiving the education program. These positive changes in health status and health behaviors were not sustained for one year following. However, it is critically important to emphasize that although the changes in health status and health behaviors were not sustained over the span of one year, the changes did not decrease past the initial baseline values. Arthritis is a chronic, progressive, debilitating disease. Over the course of one year, normal expectations of the arthritic disease progression would typically result in some functional decline seen in progressive pain, weakness, and immobility and depressive symptomology. Participants in the Spanish Arthritis Self Management Education Program maintained and managed their arthritic symptomology and were able to stave off the debilitating effects of arthritic disease symptomology. In fact, they reported the same general health status. This can be considered a successful management of arthritis disease progression.

Education programs and program results must be tested with all cultures and not one education program shifted onto minority populations without taking into account cultural differences and styles. The Spanish Arthritis Self Management Education Program was designed for the Hispanic culture in California, but had not been critically evaluated as to its effectiveness with the Hispanic culture in Miami. Hispanic is a label that combines many different cultures from many different countries and backgrounds under one label because of a common spoken language. Continued research is needed for answers on how to best help individuals of different cultures and sub cultures within each 
ethnic group. Hispanic persons with arthritis deserve health education programs to improve their quality of life, help them gain control over their arthritic disease progression and live healthier lives.

\section{Adult Education Impact}

Education is key in health promotion and disease prevention. Applying andragogical principles to health education and showing that it produces functional measurable health outcomes is critical to success of adult education health programs. Happiness data is not sufficient. Frequency data is not sufficient. Adult education program offerings must be critically evaluated on how and if they are effective' in changing and impacting the health of participants to assure increased and continued support for effective health promotion and education. Programs offered should be evidence based and scrutinized on all levels. When effective, data and results can provide impetus for further programs and programmatic funding. This study critically evaluated the effectiveness of one adult education health promotion offering, the Spanish Arthritis Self Management Education Program.

\section{Health Promotion and Education}

Health promotion theory postulates that education programs can be an effective initiative in producing positive health changes. This study examined one such health promotion education initiative, the Spanish Arthritis Self Management Education Program in order to critically evaluate its effectiveness in producing desired health changes in the minority Hispanic population.

Health promotion and health education are intertwined with adult education. The smallest portion of medical budget goes towards health education and health promotion 
efforts where the largest impact in terms of quality of life as well as monetary savings could be felt. Health promotion is the key to a healthier population. But until the long term effectiveness of the grass root health promotion community education programs such as the Spanish Arthritis Self Management Education Program are demonstrated, medical monies will flood to hospitals and high tech end of life care and bypass the health promotion arena.

The goals of Healthy people 2010 reflect the importance of community grass roots health promotion and education program that work to impact every person by lowering medical costs, and supporting healthier lives. Education is only successful if it can be shown to be effective in changing behaviors and health status. The Spanish Arthritis Self Management Education Program outcomes reflected an overall successful implementation but with limited long term effects.

\section{Recommendations for Future Research}

Health promotion theory postulates that education programs can be an effective initiative in producing positive health changes. This study examined one such health promotion education initiative in order to critically evaluate its effectiveness in producing desired health changes in the minority Hispanic population. As a summation of this study the following recommendations are made grouped under the following headings: Hispanic Older Adult, Arthritis Foundation, and Adult Health Education. Recommendations for Research for the Hispanic Older Adults

Hispanic older adult participants in the Spanish Arthritis Self Management Education program did not demonstrate the same changes as Anglo older adult participants in the English version of the Arthritis Self Management Education Program. 
The differences may be culturally based and as such require further research to improve on the effectiveness of educational offerings to Hispanic populations. "Hispanic" is a label that encompasses many cultural subgroups, and in some cases the differences between these groups may outweigh the similarities. The fact of sharing a common language and history does not necessarily imply that health beliefs and behaviors are homogeneous across different national origins. More research needs to be done within the subgroups of the Hispanic population to identify the unique needs of the diverse Hispanic subcultures to evaluate their unique characteristics and needs as adult learners. Recommendations for Research for the Arthritis Foundation

Arthritis self-management education programs in English have demonstrated a positive impact on health behaviors, health status, and health care utilization (Hirano, Laurent, \& Lorig, 1994). These programs have proliferated and been successful in the English speaking population. The Arthritis Foundation needs to continue to seek evaluation of its program offerings in the Hispanic populations and to make modifications as necessary to provide Hispanic individuals with effective arthritis self management interventions. The community adult health education programs being offered, although providing positive community public relations, are not fulfilling the objectives of the program to positively impact health and need to be revised in order to provide for more long-term retention of information and motivation for continued health behavior change. The Arthritis Foundation is challenged to continue to evaluate its program offerings on all levels. 
Recommendations for Research in Adult Health Education

Further studies need to be done to seek ways to improve educational offerings to improve long term retention of short-term health status and health behaviors gains in the Hispanic population. In this study, one limitation was the lack of control over the implementation of the education program. The content and delivery for the program was taught in a two-day workshop to lay older Hispanic adults with arthritis who were interested in working as the group instructors. In this study, there was no assurance as to the quality of delivery, content, facilitation, and use of andragogical principles. Could the results of the education program be improved with ongoing evaluation of the teaching and delivery of the program? Certainly, this would be an area of concern and further research to determine how an effective program can become even more effective.

Timing of the program, packaging, marketing aspects of the program all need to be evaluated to seek out exactly where the most impact can be made. For example, a study investigating reinforcement strategies such as telephone calls, monthly refresher groups or even scheduling the education sessions over a longer period could be explored to look for better long-term impact of the education program. There continues to be a need for strong research focusing on improving the lasting effects of the positive outcomes established through health education programs for every population.

Further studies need to be done analyzing the content and delivery of the Spanish Arthritis Self Management Education Program. Was the content of the program suited for what the individuals most needed to know to be effective managers of their individual arthritic symptomology? Was the delivery the most effective and appropriate for the 
targeted older adult Hispanic population? What in the content or delivery would help shape long term retention and application of the material presented?

A large portion of the participants in this study did not know their individual arthritis diagnosis. This is problematic because arthritis management is dependent on specific diagnosis. Research needs to be done focusing on why Hispanic older adults are not aware of their medical diagnosis. Is it the medical system that is not informing these individuals or is it that Hispanics are more apt to rely on medical authorities for their care and do not feel it important to be active participants in their medical care? These are questions for further investigation.

This study demonstrated adult education programs can help improve the overall health of Hispanic older adults with a progressive chronic disease, arthritis. The participants' health after one-year post education program, although not significantly improved, did not deteriorate. This health maintenance of the participants with a chronic, progressive, disabling disease serves to help reach the goals and objectives of Healthy People 2010 of increasing the quality and years of healthy life and eliminating health disparities among minority populations (Healthy People 2010, 2002). The health maintenance of the participants demonstrated the importance of adult education programs in health promotion and progressive disease management. However, health maintenance of individuals with chronic disease alone is not enough. Research needs to be done on preventative measures focusing on behaviors that will actually prevent the ensuing pain, deformity, and disability of arthritis. If effective preventative measures could be successfully implemented, and individuals could prevent the pain, deformity, and disability of arthritis, then the goals and objectives of Healthy People 2010 of increasing 
the quality and years of healthy life and eliminating health disparities among minority populations (Healthy People 2010, 2002) could be reached. 


\section{REFERENCES}

Aday, L.A. (1994). Health status of vulnerable populations. Annual Reviews of Public Health, 15, 487-509.

Arthritis Foundation Home Page. Retrieved March 10, 2003, from http://www.arthritis.org.

Bandura, A. (1997). Self efficacy: The exercise of control. New York: W.H. Freeman.

Bassford, T.L. (1995). Health status of Hispanic elders. Clinical Geriatric Medicine, 11, $25-28$.

Bottomely, J., Lewis, C.B. (2003). Geriatric rehabilitation: A clinical approach. $\left(2^{\text {nd }} \mathrm{ed}\right)$. Upper Saddle River, NJ: Prentice Hall.

Brookfield, S. (1990). Understanding and facilitating adult learning. San Francisco, CA: Josey Bass.

Brownson, R.C., Baker, E.A., \& Novick, L.F. (1999). Community based prevention: Programs that work. Gaithersburg, MD: Aspen Publishers.

Bureau of the Census: National Health Interview Survey (1995), United States Public Health Service, Washington, DC: United States Department of Commerce.

California Arthritis Partnership Program (2000). Local Grant Programs Final Report, Arthritis Foundation, New York Chapter, People with Arthritis Can Exercise, HIP Health Plan of NY.

Centers for Disease Control and Prevention. (CDC) (October 1, 2003) Arthritis Fact Sheet.Retrieved August 23, 2000 from

http://www.cdc.gov/nchs/fastats/arthrits.htm

Centers for Disease Control and Prevention. (1994). Arthritis prevalence and activity limitations United States - 1990. MMWWR, 43(24), 433-438.

Centers for Disease Control and Prevention (CDC). (1999). Targeting arthritis: The nation's leading cause of disability. Atlanta, GA.

Centers for Disease Control and Prevention (CDC). (2001). Healthy People 2010. Atlanta GA.

Centers for Disease Control and Prevention (CDC). (1994). Arthritis prevalence and activity limitations - United States, 1990. Morbidity and Mortality Weekly Report 43(24), 433-438. 
Chanldola, T., \& Jenkinson, K. (2000). Validating self rated health in different ethnic groups. Ethnicity and Health, 5(2), 151-159.

Community Partnerships for Adult Learning, Retrieved October 12, 2003 from, http://www.c-pal.net/build/assess/index/html

Decker, J. (1982). Summary. Journal of Rheumatology, 9,802-806.

Developments in Aging:1996, Vol.1(Report of the Special Committee on Aging, US Senate, Retrieved August 17, 2003 from, Http://www.aoa.dhhs.gov/aoa/pages/profil $96 / \mathrm{html}$

Dixon, J.S., \& Bird, H.A. (1989) Reproducibility along a $10 \mathrm{~cm}$ vertical analog scale. Annals Rheumatic Disease, 10, 87-89.

Downie, W.W., Leathman, P.A., Rhind, U.M., Weiht,U., Brenco, J.A., \& Anderson, J.A. (1978). Studies with pain ranging scales. Annals Rheumatic Disease, 37, 378-381.

Driscoll, A. (2001, July 25). Many lands give Florida its Latin flavor. The Miami Herald, $17 \mathrm{~A}$.

Falvo, D. (1999). Medical and psychosocial aspects of chronic illness and disease $\left(^{\text {nd }}\right.$ ed.). Gathersburg, MD: Aspen Publishers.

Fiscella, K., Williams, D.R., \& Moss, N.E. (1997). Inequality in quality: Addressing socioeconomic, race, and ethnic disparities in health care. Journal of the American Medical Association, 283, 2579-2584.

Florida Behavioral Risk Factor Surveillance System Data (2000) Retrieved on May 18, 2002 from, http://www.doh.state.fl.us/family/arthritis/state/2002statearthrept.pdf

Fries, J.F. (1997). Can preventive gerontology be on the way? American Journal of Public Health, 87, 12.

Fries, J.F., Spitz, P., Krammes, K.G., \& Holman, H.R. (1980). Measurement of patient outcomes in arthritis. Arthritis and Rheumatism, 23(2). 137-143.

Glass, T.A., Seeman, T.E., Herzog, A.R., Kahn, R.L., \& Berkman, L.F. (1995). Change in productive activity in late adulthood: MacArthur studies of successful aging. Gerontology Social Science, 50B, S65-S76.

Gonzalez, V.M., Stewart, A., Ritter, P., \& Lorig, K. (1995). Translation and validation of arthritis outcome measures into Spanish. Arthritis and Rheumatism, 38, 14291446.

Green, L.W., \& Lewis, F.M. (1986). Measurement and evaluation in health education and health promotion. Palo Alto, CA: Mayfield. 
Grossman, D. (1997) Cuban Americans. In Grosman,D. (Ed.) Transcultural health care, (pp.189-215). New York: F.A.Davis.

Haber, D. (1999). Health promotion and aging: Implications for the health professions (2nd ed.). New York: Springer.

Healthy People 2010, Goals (n.d.) Retrieved on October 12, 2003, from http://www.healthypeople.gov/About/goals.htm

Healthy People 2010 Fact sheet, (Last updated 11/02) Office of Disease Prevention and Health Promotion US Department of Health and Human Services, Washington, DC. Retrieved August 19, 2003 from, http://www.healthypeople.gov/about/hpfact.htm

Healthy People 2010 Full text document. Last updated December 2001. Retrieved August 12,2003 from http://www.healthypeople.gov/Document/tableofcontents.htm\#parta

Helmick, C.G., Lawrence, R.C., Pollard, R.A., Lloyd, E., \& Heyse, S.P. (1995). National arthritis data workgroup: Arthritis and other conditions: Who is affected now, who will be affected later? Arthritis Care Research, 8, 203-211.

Hirano, P., Laurent, D., \& Lorig, K. (1994). Arthritis patient education studies. 19871991: A review of the literature. Patient Education Counsel, 24, 9-34.

Hooyman, N., \& Kiyak, H.A. (1999). Social gerontology: A multidisciplinary perspective $\left(5^{\text {th }}\right.$ ed. $)$. Boston, MA: Allyn and Bacon.

Horowitz, R.I. (1987). The experimental paradigm and observational studies of causeeffect relationships in clinical medicine. Journal of Chronic Disease, 40, 91-99.

Idler, E.L., \& Benyamini, Y. (1997). Self-reported health and mortality: A review of twenty-seven community studies. Journal of Health and Social Behavior, $38,21-37$.

Israel, B.A. (1995). Evaluation of health education programs: Current assessment and future directions. Health Education Quarterly, 22(3), 364-389.

Jette, A.M. (1995). Outcomes research: shifting the dominant research paradigm in physical therapy. Physical Therapy, 70, 865-970.

Kane, R.L. (1997). Health outcomes research. Gathersburg, MD: Apsen.

Knowles, M.S. (1980). The modern practice of adult education: From pedagogy to andragogy $\left(2^{\text {nd }}\right.$ ed.). New York: Cambridge Books. 
Lawrence, R.C., Helmick, C.G., Arnett, F.C., Turner, A., \& Wright, C. (1998). Estimates of the prevalence of arthritis and selected musculoskeletal disorders in the United States. Arthritis \& Rheumatism, 41(5), 778-799.

Levkoff, R. (2000). The matching model of recruitment. Journal of Mental Health and Aging, 6(1), 29-38.

Lorig, K., Chastain, R.L., Ung, E., Shoor, S., \& Holman, H.R. (1989). Development and evaluation of a scale to measure perceived self-efficacy in people with arthritis. Arthritis and Rheumatism, 32, 37-44.

Lorig, K., Gonzalez, V.M., \& Ritter, P. (1999). Community-based Spanish language arthritis education program. Medical Care, 37(9), 957-963.

Lorig, K., Gonzalez, V.M., Ritter, P., Nacif de Brey, V. (1997). Comparisons of three methods of data collection in an urban Spanish speaking population. Nursing Research, 46(4), 230-234.

Lorig, K., \& Holman, H. (1993). Arthritis self-management studies: A twelve year review. Health Education Quarterly, 20 (1), 17-28.

Lorig, K., Mazonson, P., \& Holman, H. (1993). Evidence suggesting that health education for self-management in patients with chronic arthritis has sustained health benefits while reducing health care costs. Arthritis and Rheumatism, 36(4), 91-95.

Lorig, K., Shoor, M., \& Holman, H. (1989). Development and evaluation of a scale to measure perceived self-efficacy in people with arthritis, Arthritis and Rheumatism $32(1), 37-44$.

Lorig, K., Sobel, D., Stewart, A., Brown, B.W., Bandura A., Ritter, P., et al. (1999). Evidence suggesting that a chronic disease self management program can improve health status while reducing hospitalization: A randomized trial. Medical Care, $37,5-14$.

Lorig, K., \& Ward, M. M. (1996). Patient education interventions in osteoarthritis and rheumatoid arthritis: A meta analytic comparison with nonsteroidal antiinflammatory drug treatment. Arthritis Care and Research, 9(4), 292-301.

Manek, N.J., \& Lane, N.E. (2000, March 15). Osteoarthritis: Current concepts in diagnosis and management. American Family Physician, 14-21.

Merriam, S.B., \& Caffarella, R.S. (1991) Learning in adulthood. San Francisco, CA: Jossey- Bass. 
Minaire, P. (1992). Disease, illness and health: Theoretical models of the disablement process. World Health Organization Bulletin, 70, 373-9.

Minor, M. (1993). Exercise maintenance of persons with arthritis after participation in a class experience. Health Education Quarterly, 20(1), 83-95.

Morbidity and Mortality Weekly Report. (1996). Prevalence and impact of arthritis by race and ethnicity - United States, 1989-1991. Atlanta Georgia, CDC.

Nacif de Brey, V., \& Gonzalez, V.M. (1997). Recruiting for arthritis studies in hard to reach populations: A comparison of methods used in an urban Spanish speaking community. Arthritis Care and Research, 10(1), 64-71.

Nagi, S.Z. (1991). Disability concepts revisited: implications for prevention. In A.M. Pope \& A.R. Tarlov (Eds.), Disability in America: Toward a national agenda for prevention (pp. 281-317). Washington, DC Division of Health Promotion and Disease Prevention, Institute of Medicine National Academy Press.

National Center for Health Care Statistics (NCHS). Retrieved on September 27, 2003 from, http://www.cdc.gov/nchs/releases/95facts/95facts.htm

National Center on Minority Health and Health Disparities (NCMHD). (2003) Retrieved on October 14, 2003 from, http://ncmhd.nih.gov/

O'Neil G., \& Shirey, L. (2000, March). Arthritis: A leading cause of disability in the United States, cause profile, challenges for the $21^{\text {st }}$ century: Chronic and disabling conditions. National Academy on Aging Society, 5, 34-47.

Peace, S. (1990). Researching social gerontology: Concepts, methods, and issues.

London: Sage Publications in association with the British Society of Gerontology.

Portney, L.G., \& Watkins, M. P. (2000). Foundations of clinical research: Applications to practice. $\left(2^{\text {nd }}\right.$ ed.). Upper Saddle River, NJ: Prentice Hall Health.

Rall,W. (1996).The effect of progressive resistive exercise training in arthritis. Arthritis and Rheumatism, 39, 415-426.

Ramey, D.R., Raynaould, J.P., \& Fries, J.R. (1992). The health assessment questionnaire 1992: Status and review. Arthritis Care Research, 5, 119-129.

Schauffler, H., \& Rodriguez, T. (1996). Exercising purchase power for preventative care. Archives of Internal Medicine, 155, 1789-1795.

Searle Arthritis Foundation Grant. (1998). New York Partnership, New York Chapter Arthritis Foundation. 
Sherbourne, C.D. (1992). Pain measure. In A.L Stewart, J.E. Ware, (Eds.), Measuring functioning and well being: The medical outcomes study approach (pp.125-134). Durham, NC: Duke University Press.

Smart, J., \& Smart, D. (1992). Cultural issues in rehabilitation of Hispanics, Journal of Rehabilitative Nursing, 58(2), 29-36.

Sox, H. (1994). Preventative health services in adults. New England Journal of Medicine. 330, 1589-1595.

Stanford, E.P., \& Schoenrock, S.A. (1992). Delivery of health promotion programs: Outreach to minority elders. Washington, DC: American Association of Retired Persons.

Targeting Arthritis: The nation's leading cause of disability: At-a-glance. (1998). Atlanta, GA: Technical Information and Editorial Services Branch, National Center for Chronic Disease Prevention and Health Promotion (NCCDPHP).

US Bureau of the Census: 1990 Census of Population Social and Economic Characteristics of the United States (1993). Washington, DC.

Verbrugge, L.M., \& Jette, A.M. (1994). The disablement process. Social Science Medicine, 38, 1-14.

Ware, J.E., Nelson, E.E., Sherbourne, C.D., \& Stewart, A.L. (1992). Preliminary tests of a six-item general health survey: a patient application. In A.L Stewart, J.E. Ware, (Eds.), Measuring functioning and well being: The medical outcomes study approach (pp.802-816).Durham, NC: Duke University Press.

Windsor, R. (1994). Evaluation of health promotion, health education and disease prevention programs. Mountain View, CA: Mayfield. 
APPENDICES 
Appendix 1 - IRB Letters of Approval 


\title{
(1) \\ Florida International University
}

Office of the Director

\section{MEMORANDUM}

\author{
To: \\ Dr. Helen Cornely \\ CC: \\ File \\ From: \\ Yvette Peterson, Coordinator Institutional Review Board \\ Date: \\ July 17,2002 \\ Proposal Title: Spanish Arthritis Education Program
}

Approval \# 062701-05

The Institutional Review Board of Florida International University has approved your study for the use of human subjects. Your annual report will be due June 2003. As a requirement of IRB approval you are required to:

1) Provide immediate written notification to the IRB of:

- Any additions to, or changes in the procedures involving human subjects,

- Every serious or unusual or unanticipated adverse event as well as problems with the rights or welfare of the human subjects. Confirmation of receipt of serious AE reports must be made with the IRB office.

2) Utilize copies of the date stamped consent document(s) for the recruitment of subjects and receive annual renewal of consent documents.

3) Receive annual review and re-approval.

Special Conditions: None

Please note your approval number is indicated above. For further information, you may call the IRB office at 305-348-2494 or visit the DSRT web site at www.dsrt.fiu.edu.

U University Park

11200 S.W. 8 Street - PC 539

Miami, FL, 33199

(305) 348-2494 - Fax: (305) 348-4117
Division of Sponsored Research and Training

TDD, via FRS 1-800-955-8771 $\square$ Center for Engineering and Applied Sciences 10555 West Flagler Street - EAS 2425 Miami, FL 33174

(305) 348-6439 - Fax: (305) 348-6389 


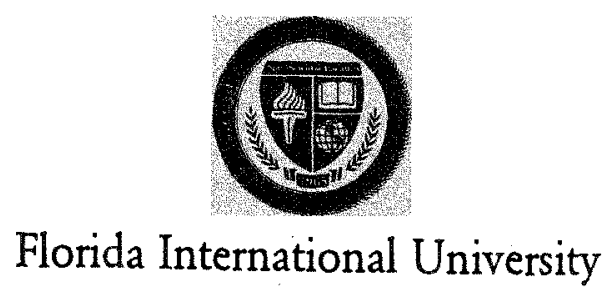

Office of the Director

\section{MEMORANDUM}

To:

Helen Cornely

CC:

File

From:

Yvette Peterson, Coordinator Institutional Review Board

Date:

October 25, 2001

Proposal Title: $\quad$ "Spanish Arthritis Education and Prevention Program" Approval \# 062701-05

Your study was deemed Exempt by the Institutional Review Board at Florida International University on June 27,2001. There are no additional requirements in regards to the conduct of your study. You are, however, required to submit your consent document for approval annually. If there are any additional changes in the protocol after you commence your study that may increase the risks that the human subjects are exposed to, you are required to resubmit your proposal to a Representative of the IRB for review.

Please call the IRB office at 348-2494 with questions or concerns or visit the DSRT web-site at www.dsrt.fiu.edu.

$\square$ University Park

11200 S.W. 8 Street - PC 539

Miami, FL 33199

(305) 348-2494 - Fax: (305) 348-4117
Division of Sponsored Research and Training

$\square$ Center for Engineering and Applied Sciences 10555 West Flagler Street - EAS 2425 Miami, FL 33174

(305) 348-6439 - Fax: (305) 348-6389

TDD, via FRS 1-800-955-8771

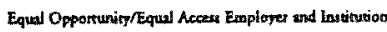


Appendix 2 - Sample Training Program Agenda 
Sample Agenda

\begin{tabular}{|c|c|c|}
\hline \multicolumn{3}{|l|}{ DAYONE } \\
\hline Activity \# & Aotivity & Time \\
\hline$\#$ & Introduction & $0: 00$ aim. \\
\hline$\# 2$ & $\begin{array}{l}\text { Overviow and History of the } \\
\text { Arthritle Solf-Help Course }\end{array}$ & O.40 a.m. \\
\hline$\# 3$ & Speclal Sonoltiltieo & $10,10 \mathrm{a.m.}$ \\
\hline \#4 & $\begin{array}{l}\text { Introduction to Arthritls and } \\
\text { Fibromyalgia } \\
\text { Break }\end{array}$ & $\begin{array}{l}10.20 \mathrm{am} . \\
10.50 \mathrm{am} .\end{array}$ \\
\hline$\# 5$ & $\begin{array}{l}\text { Exerclee for Fun and Fltines - } \\
\text { Where to Etart }\end{array}$ & $11: 00 \mathrm{a.m}$. \\
\hline$\$ 6$ & $\begin{array}{l}\text { Overvew of Self-Help Princlpleel } \\
\text { Introduction to the } \\
\text { Partilpative Nature of Thle } \\
\text { Cours }\end{array}$ & $11: 20 \mathrm{a.m}$ \\
\hline$\# 7$ & Introduction to Goal Setting & $11: 30$ i.m. \\
\hline$\# 8$ & Contracting & 12:00 p.m. \\
\hline & Lunch & $12: 30$ p.m. \\
\hline$\# 8$ & Gesslon One Review & 1:30 p.m. \\
\hline \#10 & Adult Education & 1:40 p.m. \\
\hline$\# 11$ & Flexlblltyy/6trengthening & \\
\hline & Exercies: & $2: 40$ p.m. \\
\hline & Brealk & 3:25 p.m. \\
\hline$\# 12$ & How to Monitor Exerelse & $3: 35$ p.m. \\
\hline$\# 13$ & $\begin{array}{l}\text { Introduction to Pain } \\
\text { Management }\end{array}$ & 3:55 p.m. \\
\hline$\# 14$ & Bain Managerient - Olatraction & 4:15 p.m. \\
\hline$\# 15$ & Jacobson Muecle Relaxution & $4.35 \mathrm{pm}$ \\
\hline$\$ 16$ & Seselon Two Review & $4.55 \mathrm{p} . \mathrm{m}$. \\
\hline$\# 17$ & $\begin{array}{l}\text { Day One Closing } \\
\text { Adjourn }\end{array}$ & $\begin{array}{l}\text { 5.06 p.m. } \\
\text { 5:15 p.m. }\end{array}$ \\
\hline
\end{tabular}




\begin{tabular}{|c|c|c|}
\hline \multicolumn{3}{|l|}{ DAY TWO } \\
\hline Activity \# & Aotlvity & Time \\
\hline$\# 18$ & Questions and Answers & $9: 00 \mathrm{a} . \mathrm{m}$. \\
\hline$\# 19$ & Fatlgue/Energy Conservation & $9: 10 \mathrm{a} . \mathrm{m}$. \\
\hline$\# 20$ & $\begin{array}{l}\text { Relaxation Through Gulded } \\
\text { Imagery. }\end{array}$ & $9: 30 \mathrm{a.m}$. \\
\hline$\# 21$. & $\begin{array}{l}\text { Dealing with Anger, Fear and } \\
\text { Frugtration }\end{array}$ & $9: 40 \mathrm{a} . \mathrm{m}$ \\
\hline$\# 22$ & Session Three Review & $10: 15 \mathrm{a} . \mathrm{m}$. \\
\hline$\# 23$ & $\begin{array}{l}\text { Healthy Eating } \\
\text { Break }\end{array}$ & $\begin{array}{l}10: 23 \text { a.m. } \\
10: 46 \text { a.m. }\end{array}$ \\
\hline$\# 24$ & $\begin{array}{l}\text { Preventing and Slowing } \\
\text { Osteoporosis }\end{array}$ & 11:00 a.m. \\
\hline$\# 25$ & Dealing with Depression & $11: 10$ a.m. \\
\hline$\# 26$ & $\begin{array}{l}\text { Identifying Negative Thoughts } \\
\text { and Attltudes: Self-Talk }\end{array}$ & $11: 25 \mathrm{a} . \mathrm{m}$. \\
\hline$\# 27$ & $\begin{array}{l}\text { Serslon Four Rovlow } \\
\text { Lunch }\end{array}$ & $\begin{array}{l}11: 50 \text { p.m. } \\
12: 00 \text { p.m. }\end{array}$ \\
\hline $\begin{array}{l}\# 28 \\
\# 29\end{array}$ & $\begin{array}{l}\text { Handling Problem Behavior } \\
\text { Communlcation Skills }\end{array}$ & $\begin{array}{l}\text { 1:00 p.m. } \\
\text { 2:00 p.m. }\end{array}$ \\
\hline$\# 30$ & $\begin{array}{l}\text { Working More Effectively with } \\
\text { Your Doctor/Health Care } \\
\text { Professlonal } \\
\text { Breaik }\end{array}$ & $\begin{array}{l}2: 20 \text { p.m. } \\
2: 40 \text { p.m. }\end{array}$ \\
\hline \#31 & $\begin{array}{l}\text { Problem-Solving Principles and } \\
\text { Practice. }\end{array}$ & 2:55 p.m. \\
\hline \#32 & $\begin{array}{l}\text { Problom-Solving as a Modeling } \\
\text { Technique }\end{array}$ & $3: 20$ p.m. \\
\hline$\$ 33$ & Sosolon Five Review & $3: 35$ p.m. \\
\hline$\# 34$ & $\begin{array}{l}\text { Day Two Clooing } \\
\text { Adjourm }\end{array}$ & $\begin{array}{l}\text { 3:45 p.m. } \\
4: 00 \text { p.m. }\end{array}$ \\
\hline
\end{tabular}




\begin{tabular}{|c|c|c|}
\hline \multicolumn{3}{|l|}{ DAY THREE } \\
\hline Aotillty \# & Aotlvity & Time \\
\hline \#35 & Qusetione and Answers & $\theta: 00 a_{1} m_{1}$ \\
\hline$\# 36$ & Feedback and Problem Solving & $8: 10$ a.m. \\
\hline$\# 37$ & Feedback on Exarclese & $9: 50 \mathrm{a} . \mathrm{m}$. \\
\hline$\$ 38$ & Medication Usage & $10,20 \mathrm{a} \cdot \mathrm{m}$. \\
\hline \#39 & $\begin{array}{l}\text { Evaluating Nontradtional } \\
\text { Treatment }\end{array}$ & $10: 40 \mathrm{am}$ \\
\hline & Break & $10,65 \mathrm{a} . \mathrm{m}$. \\
\hline$\# 40$ & Geoslon Skx Revilew & $11: 10$ a.m. \\
\hline$\# 41$ & Practice Teaching & $\begin{array}{l}11: 20 \text { a.m. } \\
12.35 \mathrm{o.m} .\end{array}$ \\
\hline$\# 42$ & Logistles for Condueting ASHC & 1:35 p.m. \\
\hline$\# 43$ & $\begin{array}{l}\text { What You're Afraid Mlght } \\
\text { Happen }\end{array}$ & 2.35 p.m. \\
\hline$\# 44$ & Closing & 3:05 p.m. \\
\hline & Adjourn & $3: 20 \mathrm{p} . \mathrm{m}$. \\
\hline
\end{tabular}


Appendix 3 - Pre- Classe Data Collection Instrument. Note same instrument used pre, post, and one year post. 
NOMBRE (NAME):

TELÉFONO (TELEPHONE): DÍA (DAY) NOCHE (EVENING)

DIRECCIÓN (ADDRESS)

CIUDAD (CITY) ESTADO (STATE) CÓDIGO POSTAL

CORREO ELECTRÓNICO (E-MAIL ADDRESS) (ZIP CODE)

EDAD (AGE) _ SEXO (SEX): DHOMBRE (MALE) DMUJER (FEMALE)

¿Qué tipo de artritis tiene Ud.? Marque todas las que le apliquen.

What type of arthritis do you have? Mark all that apply.

Osteoartritis degenerative

Dermatomiositis

Gota

Fibrositis/Fibromialgia

Sarcoidosis

ㅁ. No se que tipo de arthritis I don"t know what type of arthritis

\author{
$\square$ Osteoporosis \\ $\square$ Espondilitis Anquilosante \\ Ankylosing Spondylitis \\ $\square$ Artritis reumatoide \\ Rheumatoid arthritis \\ Lupus \\ Sclerodoma \\ Scleroderma
}

\section{SALUD GENERAL (GENERAL HEALTH)}

Generalmente, Ud. diria que su salud es (Por favor, marque solamente una respuesta.) Generally, Would you say your health is (Please mark only one answer)

$1 \square$ Excelente (Excellent)

$2 \square$ Muy Buena (Very good)

1,0 Buena (Good)

$$
\begin{aligned}
& 4 \text { a Regular } \\
& s \text { Mala (Poor) }
\end{aligned}
$$

\section{DOLOR (PAIN)}

Por favor marque en la escala de abajo el número que mejor describa la intensidad de su dolo: de artritis durante la última semana:

Please indicate on the scale below what number best describes the intensity of you arthritis pain during the last week: 


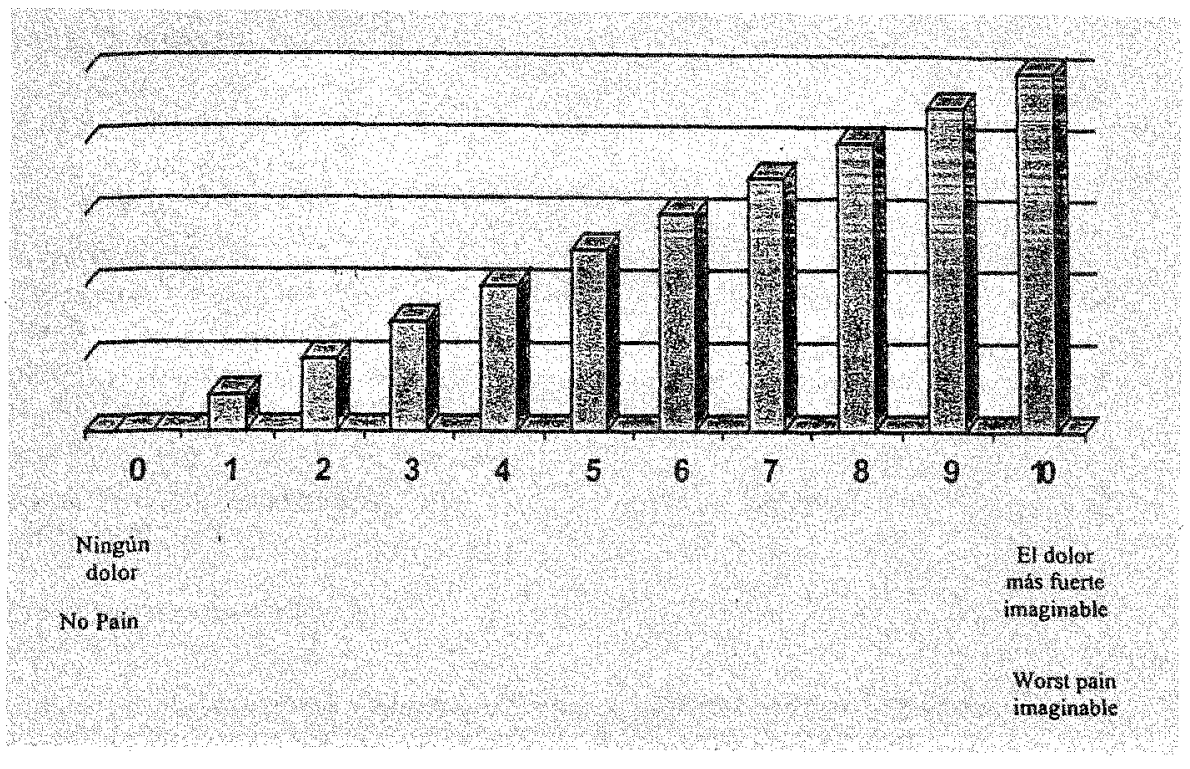

\section{HABILIDADES FÍSICAS (PHYSICAL ABILITIES)}

Lea las siguientes preguntas sobre sus habilidades fisicas, por favor marque la respuesta que mejor describa sus habilidades usuales (comunes) durante la semana pasada.

Read the following questions concerning your physical abilities. Please mark the answer that best describes your usual abilities during the past week.

¿Actualmente puede Ud: (Are you able to):

\begin{tabular}{|c|c|c|c|}
\hline $\begin{array}{c}\text { Sin } \\
\text { ninguna } \\
\text { dificultad } \\
\text { (Without } \\
\text { difficulty) }\end{array}$ & $\begin{array}{c}\text { Con } \\
\text { alguna } \\
\text { dificultad } \\
\text { (With } \\
\text { some } \\
\text { difficulty) }\end{array}$ & $\begin{array}{c}\text { Con } \\
\text { mucha } \\
\text { dificultad } \\
\text { (With } \\
\text { much } \\
\text { difficulty) }\end{array}$ & $\begin{array}{c}\text { No puedo } \\
\text { hacerlo } \\
\text { (Unable } \\
\text { to } \\
\text { perform) }\end{array}$ \\
\hline
\end{tabular}

Vestirse y arreglarse (Getting Dressed)

Vestirse, incluyendo amarrarse los zapatos y abrocharse (abotonarse)?

Get Dressed, including tying shoelaces and buttoning shirt?

Lavarse la cabeza?

Wash your hair? 


\section{Levantarse (Getting up)}

Levantarse de una silla que no tiene brazos?

Get up from a chair without armrests?

Acostarse y levantarse de la cama?

Lie down and get up from bed?

Comer (Eating)

Cortar su comida con cuchillo y tenedor?

Cut your food with a fork and knife?

Levantar hasta su boca una taza o vaso lleno?

Bring a full glass or cup to your mouth?

Caminar (Walking)

Caminar al aire libre en terreno plano?

Walking on level surfaces?

Subir cinco escalones (gradas)?

Go up five steps?

Por favor marque cualquier ayuda o aparato que Ud. usa regularmente para estas actividades:

Please mark any assistive devices used regularly for the completion of these activities

Bastón
Strait cane
$\square$ Aparato para caminar (andador)
Walker
$\square$ Muletas
Crutches
$\square$ Silla de ruedas
Wheelchair

$\square$ Aparatos o instrumentos para vestirse Devices for dressing

$\square$ Utensilios hechos especialmente para Ud. Custom made utensils

$\square$ Silla hecha especialmente para Ud. Custom made chair

$\square$ Otro (especifique) Other (specify)

Por favor marque las categorias para las cuales necesita regularmente ayuda de otra persona: Please mark the categories for which you need help from other people

$\square$ Vestirse y arreglarse (Getting dressed)

$\square$ Levantarse (Getting up) $\square$ Comer (Eating)

$\square$ Caminar (Walking)

Por favor, marque la respuesta que mejor describa sus habilidades usuales (comunes) durante la semana pasada. Please, mark the answer that best describes your usual abilities during the last week.

\section{Higiene (Hygiene)}

Bañarse y secarse todo el cuerpo?

Bathing and drying whole body?

Bañarse en la tina del baño? (bañadera o bañera)?

Bathing in tub

\begin{tabular}{|c|c|c|c|}
\hline $\begin{array}{c}\text { Sin } \\
\text { ninguna } \\
\text { dificultad } \\
\text { (Without } \\
\text { any } \\
\text { difficulty) }\end{array}$ & $\begin{array}{c}\text { Con } \\
\text { alguna } \\
\text { dificultad } \\
\text { (With } \\
\text { some } \\
\text { difficulty) }\end{array}$ & $\begin{array}{c}\text { Con } \\
\text { mucha } \\
\text { dificultad } \\
\text { (With } \\
\text { much } \\
\text { difficulty) }\end{array}$ & $\begin{array}{c}\text { (Unable } \\
\text { to } \\
\text { perform) }\end{array}$ \\
\hline
\end{tabular}


Sentarse y levantarse del inodoro (excusado)?

Sitting and getting up from toilet?

Alcanzar (Reaching)

Alcanzar y bajar algo que pese 5 libras, de una altura sobre su cabeza?

Reach and lower an object from overhead that weighs 5 pounds

Agacharse para recoger ropa del piso?

Squat to pick up clothes from the floor?

Agarrar (Grasping)

Abrir la puerta del auto (carro)?

Open the car door?

Abrir frascos que ya han sido abiertos?

Open containers that have been previously opened?

Abrir y cerrar las llaves del agua (los grifos)?

Open and close water faucets?

\section{Actividades (Activities)}

Hacer sus compras?

Doing the shopping?

Subir y bajar del auto (carro)?

Getting in and out of the car?

Hacer sus tareas domésticas (quehaceres) o trabajar en el jardín?

Able to do housework or gardening?

Por favor marque cualquier ayuda o aparato que Ud. usa regularmente para estas actividades:

Please indicate below whether help or an assistive device is needed for the following activities:

a Asiento elevado para el inodoro/excusado Elevated toilet seat

- Asiento para tina de baño (bañera) Tub/shower bench or chair

- Agarradera para la tina del baño (bañera) Grab bars for the rub/shower
- Abridor de frascos que han sido anteriormente abiertos Opener for containers that have been previously opened

- Aparatos con extensión para el baño Devices with an extension for use in the bathroom

aparatos con extensión para alcanzar Devices with an extension for reaching

O Otro (especifique)

Other (specify)

Por favor marque las categorias para las cuales necesita regulamente ayuda de otra persona: Please mark the categories for which you may need belp from another person:

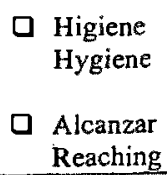

a Agarrar y abrir cosas Grasping and opening things

- Hacer compras (quehaceres) tareas domésticas Shopping/housework CONFIANZA AL HACER COSAS (CONFIDENCE IN DOING THINGS)

En las siguientes preguntas nos gustaria saber cómo le afecta el dolor de artritis y qué piensa Ud. de sus habilidades para controlar su artritis. En cada una de las siguientes escalas, por favor marque el número que major corresponda a su nivel de seguridad de que puede realizar en este momento las siguientes tareas.

In the following questions we would like to know how arthritis pain affects you and what you think your ability is to control your arthritis. In each of the following scales, please mark the number that corresponds to your level of confidence in that you can perform the following tasks at this moment.

1. ¿Qué tan seguro se siente Ud. de poder reducir bastante su dolor?

How sure are you that you can reduce your pain significantly? 


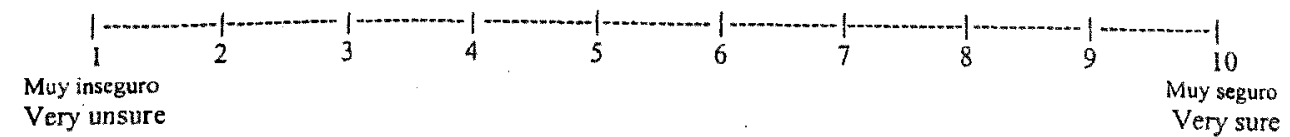

2. ¿Qué tan seguro se siente Ud. de poder evitar que el dolor de la artritis inferfiera con su sueño?

How sure are you that you can avoid arthritis pain from interfering with sleep?

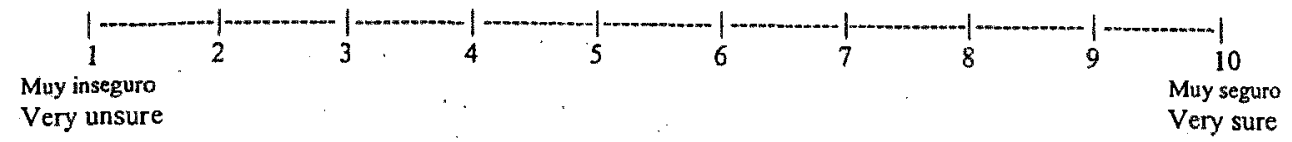

3. ¿Qué tan seguro se siente Ud. de poder evitar que el dolor de la artritis inferfiera con las cosas que quiere hacer?

How sure are you that you can avoid arthritis pain from interfering with things you would like to do?

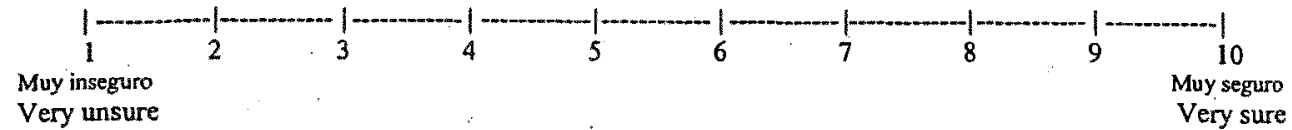

4. ¿Qué tan seguro se siente Ud. de poder regular su actividad para mantenerse activo sin empeorar (agravar) su artritis?

How sure are you that you can modify your activity to maintain active without aggravating arthritis symptoms?

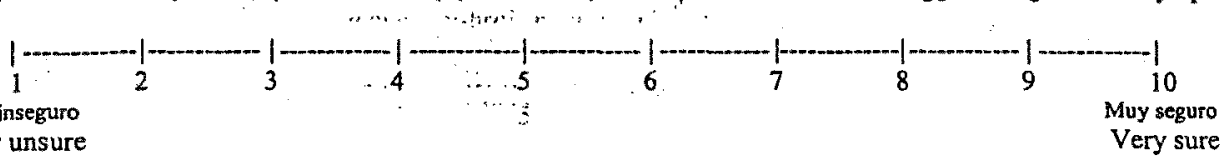

Muy inseguro
Very unsure

5. ¿Qué tan seguro se siente Ud. de poder evitar que la fatiga (el cansancio), debido a su artritis, inferfiera con las cosas que quiere hacer?

How sure are you that you can avoid fatigue due to arthritis interfere with things you would like to do?

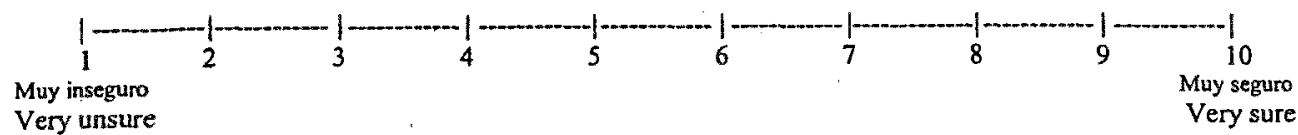

Very unsure

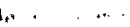

6. ¿Qué tan seguro se siente Ud. de poder ayudarse a si mismo a sentirse mejor si se siente triste? How sure are you that you can help yourself feel better if your feeling sad?

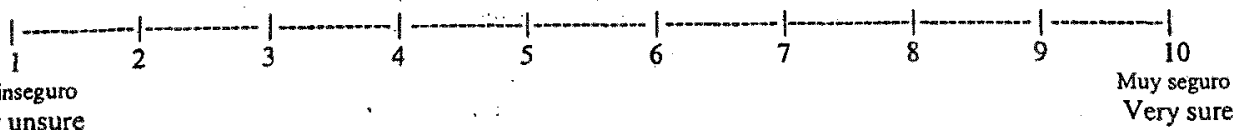

Very unsure

7. Comparándose con otras personas con artritis como la suya, ¿qué tan seguro se siente Ud. de poder sobrelleva el dolor de artritis durante sus actividades diarias?

Comparing yourself to others with arthritis like yours, how sure are you that you can overcome arthritis pain during daily activities?

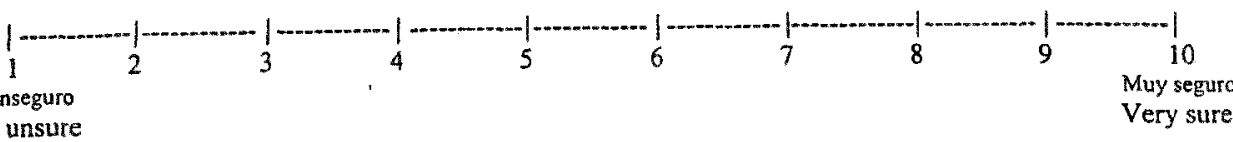

Very unsure

8. ¿Qué tan seguro se siente Ud. de poder sobrellevar la frustración debido a su artritis? 
How sure are you that you can overcome the frustration due to your arthritis?

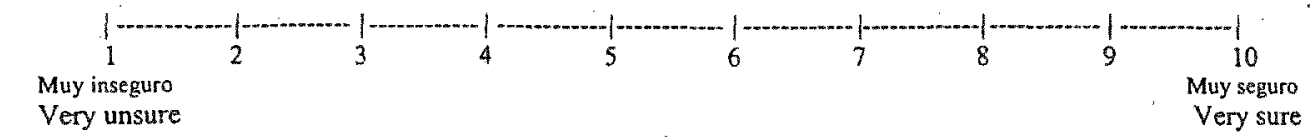

\section{CUIDADOS MEDICOS (MEDICAL CARE)}

1. ¿Cuántas veces ha visitado al médico durante los últỉnos 4 meses? (Si estuvo en el hospital, no incluya estas visitas.) How many times have you visited the doctor during the last 4 months? (If you were in the hospital do not include these visits)

2. ¿Cuántas de estas visitas al médico fueron debido a su artritis? How many of these doctor visits were due to your arthritis? Veces (times) Veces (times) ".

\section{ACTIVIDADES FISICAS (PHYSICAL ACTIVITIES)}

Durante la semana pasada (aún si no fue una semana normal) ¿cuánto tiempo en total usó (én toda la semana) en cada una de las siguientes actividades? Marque en los cuadros su respuesta.

During the last week, how, much time did you spend doing the following activities? Mark your answers in the boxes.

1. Hacer ejercicios estirar y fortalecer los músculos

$\begin{array}{ccc}\text { Ninguno } & \text { Menos de } & \mathbf{3 0 - 6 0} \\ \text { (None) } & 30 \text { minutos } & \text { minutos } \\ & \text { por } & \text { por } \\ & \text { semana } & \text { semana } \\ \text { (Less than } & (30-60 \\ & \text { 30 minutes } & \text { minutes } \\ \text { per week) } & \text { per week }\end{array}$

\begin{tabular}{|c|c|}
\hline $\begin{array}{c}\text { 1-3 horas } \\
\text { por } \\
\text { semana } \\
\text { ( } 1-3 \text { hours } \\
\text { per week) }\end{array}$ & $\begin{array}{c}\text { Más de } 3 \\
\text { horas por } \\
\text { semana } \\
\text { More } \\
\text { than } 3 \\
\text { hours per } \\
\text { week) }\end{array}$ \\
\hline
\end{tabular}

Exercising; stretching and strengthening muscles

2. Caminar como ejercicio

Walking as exercise

3. Nadar o hacer ejercicios en el agua

Swim or exercise in water

4. Andar en bicicleta (incluyendo bicicletas estacionarias)

Ride a bicycle (including stationary bicycles)

5. Usar máquinas para ejercicios (como escaleras, remar etc )

Use exercise equipment (stair climbers rowing machines eic.)

6. Hacer otro ejercicio aeróbico (especifique)

Perform any other aerobic exercise (specify) 
¿Cuánto tiempo durante la última semana... How much time during the last week...

1. ¿Se sintio desanimado(a) debido a sus problemas de salud?

Did you feel depressed or down due to you health problems?

2. ¿Se sintio temeroso(a) acerca de su salud en el futuro?

Did you feel scared or become preoccupied about you health in the future?

3. ¿Fue su estado de salud una preocupación en su vida?

Was your health statis a worry in your life?

4. ¿Se sintio frustrado(a) debido a sus problemas de salud?

Did you feel frustrated due to yoúr health problems?

Ninguna
vez
(Never)

0

0

Muy pocas
veces
(Very few
times)

Algunas

veces

Ocasio-

nalmente

(Occasion

es)

ally)

La

mayor

parte del

tiempo

(The

majority

of times)

4

5

1

2

3

Todo el

tiempo

(All the

time)

政

5 
VITA 


\section{VITA}

\section{HELEN Z. CORNELY}

Born, Ft. Collins, Colorado

\section{EDUCATION}

Doctoral Candidate in Adult Education and Human Resource Development

Florida International University, College of Education, Miami, FL, Fall 2003

Masters in Psychology with Gerontology Specialty

Nova University, Ft. Lauderdale, FL, 1979- 1981

Bachelors of Science in Physical Therapy

University of Pennsylvania, Philadelphia, PA 1972-1976

\section{CURRENT EMPLOYMENT}

Florida International University

College of Health and Urban Affairs, School of Health, Miami, FL

Chair, Department of Physical Therapy

Associate Professor, Department of Physical Therapy

Adjunct Faculty, Southeast Florida Center on Aging

Assistant Professor, Department of Physical Therapy

2002- present

1999 - present

1998 - present

Visiting Professor, Department of Physical Therapy

1994- 1999

Adjunct Lecturer, Department of Physical Therapy

1983-1991

\section{SELECTED PUBLICATIONS}

Cornely H, Tai Chi for health and fall prevention. Physical Therapy Advances, Oct 2002.

Cornely H. Interdisciplinary health promotion for low income older adults: one program. Gerinotes, 7 (4). February 2001.

Cornely H, Elfenbein P, Macias-Moriaty L. Interdisciplinary health promotion education for low income older adults. Journal of Physical Therapy Education. Summer 2001; 2(15), 37- 41 .

Cornely H. Back to basics: ambulatory assistive device prescription criteria. Physical Therapy Products. March/April 1999.

Risk Factor Assessment is Key in Preventing Falls: Interview of Cornely H. by Patricia Giannola, Physical Therapy Products. January/February 2000.

Cornely H. Demystifying the CSM submission process. Gerinotes. 6(3) April 1999. 
Cornely H. Smooth seas do not make skillful sailors. Gerinotes. 6(6) Nov 1999.

Cornely H. Demystifying the CSM submission process. Gerinotes. May 2000, Reprinted by request and popular feedback.

Cornely H, Haskins A, Rose-St. Prix C, DeMelo A. Assessing the effectiveness of minority classification in physical therapy school admissions selection. Journal of Physical Therapy Education. Fall 1998; 2(12).

Cornely H. Functional outcome difference using a rollator walker versus a two-wheeled rolling walker. Physical Therapy Case Reports. March 1998;1(2):104-106.

Cornely H. Life jacket adaptation. Physical Therapy Case Reports. March 1998; $1(2): 123-124$.

Cornely H. Tips for a sucessful nursing home visit. Gerinotes. March 1998;5(2) $17-21$.

Cornely H. Crossing the line: a case in geriatric advocacy. Gerinotes. 1998;5(4)13-15.

Cornely H. Walker gliders. Physical Therapy Case Reports. 1998; 1(3)307-308

Cornely H, Guest Editor. Focused issue on functional performance. Gerinotes. August 1998, 5(4).

\section{SELECTED FUNDED RESEARCH}

HUD-Interdisciplinary Health Promotion Education

ETAOC Neighborhood Coalition and Center on Aging

CO- Principle Investigator, Cornely H. Summer 2000 to Fall 2000. $\$ 250,000$

Improving the Quality of Life of Ventilator Dependent Patients through Visitation.

Principle Investigator: Cornely H. Christopher Reeves Paralysis Foundation

Quality of Life Grant, June 2000. \$5625

Grant in Aid-Minorities in Science

State University System of Florida, FIU Office of Equal Opportunity.

Full salary Spring 2001 plus $\$ 5000$ to department for adjuncts.

Accelerated Rehabilitation Track, MS in Physical Therapy

Project Director: Awilda Haskins, Co- Project Director: Helen Cornely.

United States Department of Education. June 1998- 2002. \$235,000 